\title{
Análise da expressão gênica e de proteínas reguladoras do fósforo e da remodelação óssea: efeitos do transplante renal e do ácido zoledrônico
}

\author{
Tese apresentada à Faculdade de Medicina da \\ Universidade de São Paulo para obtenção do título \\ de Doutora em Ciências \\ Programa de Nefrologia \\ Orientadora: Prof ${ }^{a}$ Dra. Rosa Maria Affonso Moysés
}

São Paulo 


\section{Dados Internacionais de Catalogação na Publicação (CIP)}

Preparada pela Biblioteca da

Faculdade de Medicina da Universidade de São Paulo

Creprodução autorizada pelo autor

Araújo, Maria Júlia Correia Lima Nepomuceno

Análise da expressão gênica e de proteínas reguladoras do fósforo e da remodelação óssea : efeitos do transplante renal e do ácido zoledrônico / Maria Júlia Correia Lima Nepomuceno Araújo -- São Paulo, 2017.

Tese(doutorado)--Faculdade de Medicina da Universidade de São Paulo. Programa de Nefrologia.

Orientadora: Rosa Maria Affonso Moysés.

Descritores: 1.Insuficiência renal crônica 2.Transplante de rim 3.Doenças ósseas metabólicas 4.Difosfonatos 5.Biópsia 6.Expressão gênica 


\section{Dedicatória}

À minha pequena Maria Emilia, que antes mesmo de nascer já transmite força e incentivo pra mamãe.

Ao meu marido Thiago Santos, pelo amor e carinho em todos esses anos, pelo companheirismo em todas as empreitadas, e pela paciência e comprensão em todos os momentos de ausência.

Aos meus pais amados, Emilia e Hermano, que são meu exemplo de ética, justiça e persistência. Desde cedo me ensinaram a trilhar meu próprio caminho e correr atrás dos meus sonhos. Essa vitória é nossa! 


\section{Agradecimentos}

À minha orientadora e amiga Rosa Maria Affonso Moysés, exemplo de médica e pesquisadora que exerce as duas funções com maestria. Tem me aguentado desde que inventei de fazer aquele trabalhinho pra mandar pra ASN lá em 2012! Obrigada pela paciência, pela atenção, por trazer aquele estímulo extra nos momentos de desânimo e por sempre acreditar que esse trabalho seria possível.

Em especial, ao Prof. Dr. Elias David-Neto que me recebeu no grupo de Transplante Renal e com quem aprendi a ser mais questionadora e nunca desistir nas primeiras dificuldades. Apaixonado pela pesquisa, é um grande motivador e entusiasta para o crescimento de todos que o cercam.

À Prof ${ }^{\text {a }}$ Dr ${ }^{\mathrm{a}}$. Vanda Jorgetti, que me acolheu na família do osso, pelo apoio e disponibilidade, pelas broncas, pelo incentivo, e pelo exemplo de simplicidade e grandeza. É uma verdadeira mãezona, tem um coração onde sempre cabe mais um.

À Rosilene Mota Elias, pelos ensinamentos estatísticos, pela paciência com as dúvidas de última hora, pelas valiosas dicas e por sempre me transmitir a certeza de que tudo vai dar certo.

À toda a equipe do LIM 16, pela grande ajuda em diversas etapas desta tese, e pela paciência em me ensinar todas as vezes que foram necessárias. Em especial à Ivone Braga, Luciene dos Reis, Wagner Dominguez, Luzia Furukawa e Fabiana Graciolli, vocês foram fundamentais para a conclusão deste trabalho.

Às minhas amigas queridas da residência de Nefrologia do HCFMUSP (Vivian, Ligia, Camila, Bernadete, Sara, Cintia, Irene, Raquel Melo, Raquel Maia, Loyana e Janaina), pela amizade, pelos momentos de diversão e descontração, por dividir as angústias, e por contribuirem para a vivência em São Paulo ser muito mais leve e prazerosa, vocês fazem parte da família que ganhei aqui!

Aos amigos do ambulatório de distúrbios do metabolismo mineral e ósseo, pela parceria, ajuda e incentivo. As terças-feiras não teriam sido as mesmas sem vocês! 
Aos amigos e colegas da Disciplina de Nefrologia do HCFMUSP, por todo o companheirismo nessa caminhada, a gente sofre, mas morre de saudades! Aprendi demais com todos vocês. Em especial à Igor Denizarde Bacelar Marques, pela contribuição essencial para a execução deste trabalho.

Ao Programa de Pós-Graduação da Disciplina de Nefrologia da Faculdade de Medicina da Universidade de São Paulo pela oportunidade e suporte acadêmico. Sou muito grata por poder fazer parte desse grupo.

À Disciplina de Nefrologia, representada por seus titulares Prof. Dr. Roberto Zatz e Prof ${ }^{a}$. Dra. Irene Noronha, pela oportunidade de realizar a residência médica em Nefrologia em um centro de excelência.

Aos pacientes que colaboraram para o estudo, sem os quais não teríamos alcançado nosso objetivo.

Ao $\mathrm{CNPq}$ (Conselho Nacional de Desenvolvimento Científico e Tecnológico) pelo suporte financeiro de auxílio à pesquisa.

Aos meus colegas de trabalho do Hsopital das Clínicas, INEDI e Nove de Julho, médicos, enfermeiros e técnicos de enfermagem, por fazerem meu dia mais leve e produtivo.

À toda minha família, avós, tios, primos, agregados, sempre meu porto seguro mesmo de longe. Difícil estar ausente em tantos momentos, mas em pensamento eu estou sempre junto de vocês!

À todos os meus amigos, não consigo citar todos, da infância, da adolescência, do colégio, da faculdade, da residência, do trabalho, da vida...longe ou perto, vocês são fundamentais na minha vida e fazem parte de quem eu sou! 
Esta tese está de acordo com as seguintes normas, em vigor no momento desta publicação:

Referências: adaptado de International Committee of Medical Journals Editors (Vancouver).

Universidade de São Paulo. Faculdade de Medicina. Divisão de Biblioteca e Documentação. Guia de apresentação de dissertações, teses e monografias. Elaborado por Anneliese Carneiro da Cunha, Maria Julia de A. L. Freddi, Maria F. Crestana, Marinalva de Souza Aragão, Suely Campos Cardoso, Valéria Vilhena. 3a ed. São Paulo: Divisão de Biblioteca e Documentação; 2011.

Abreviaturas dos títulos dos periódicos de acordo com List of Journals Indexed in Index Medicus. 


\section{Sumário}

Lista de abreviaturas

Lista de tabelas

Lista de figuras

Resumo

Summary

1 INTRODUÇÃ

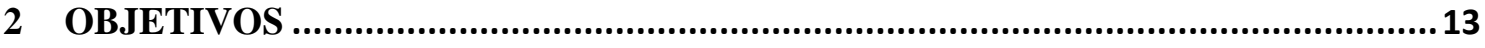

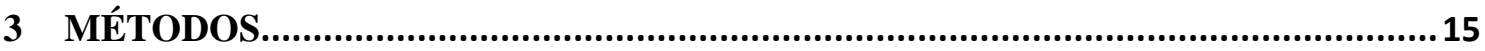

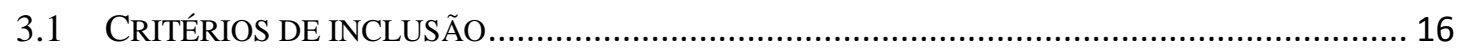

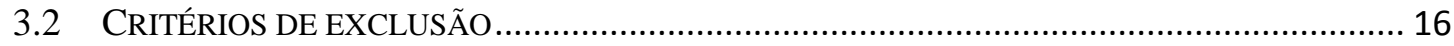

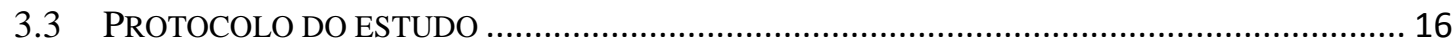

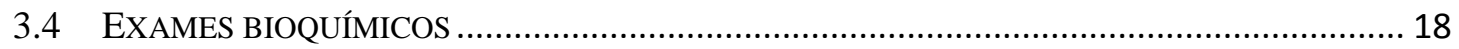

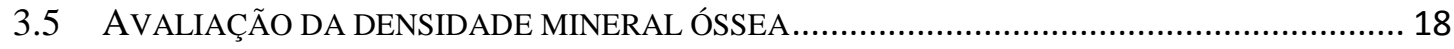

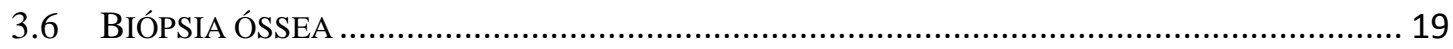

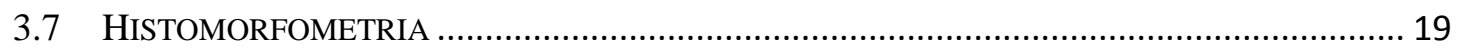

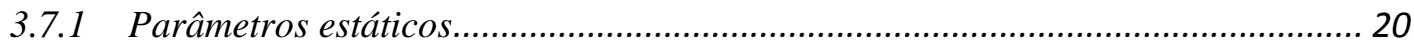

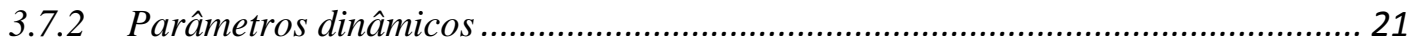

3.7.3 Sistema TMV (remodelação, mineralização e volume)......................................... 21

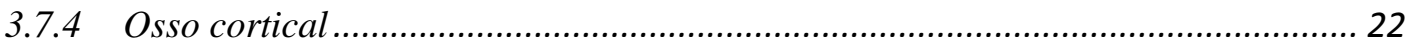

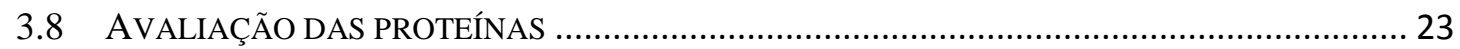

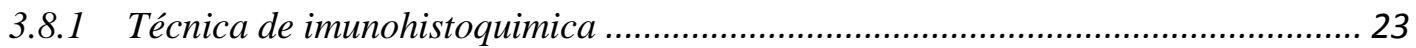

3.8.2 Técnica de quantificação de conteúdo proteico - multiplex .................................. 24

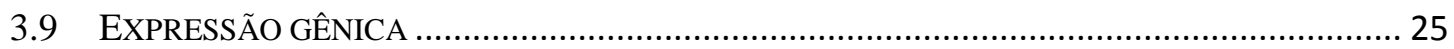

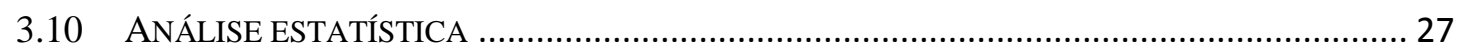

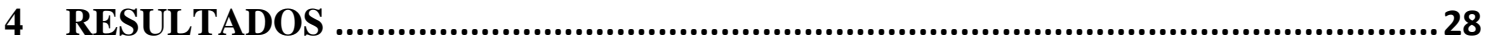

4.1 CARACTERÍSTICAS CLÍNICAS E LABORATORIAIS BASAIS ................................................. 30

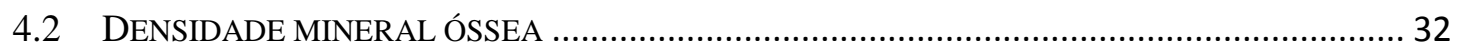

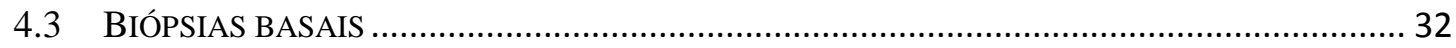

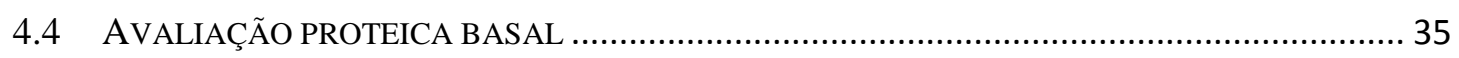

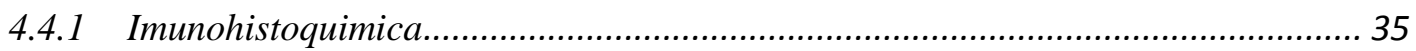

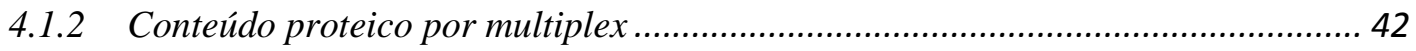

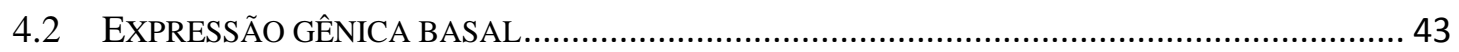

4.3 CORRELAÇÕES BASAIS DA IMUNOHISTOQUIMICA E MULTIPLEX..................................... 44

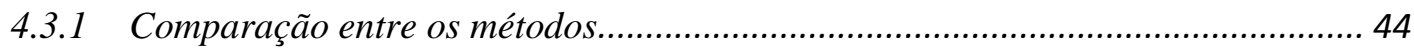

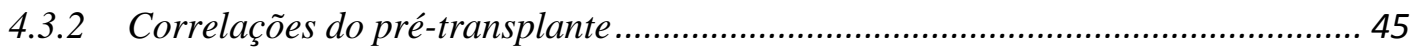

4.4 CARACTERÍSTICAS LABORATORIAIS, IMUNOSSUPRESSÃO E DMO APÓS 1 ANO ............. 46

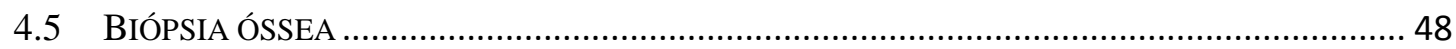

4.6 EXPRESSÃO PROTEICA PELA IMUNOHISTOQUIMICA E CONTEÚDO PROTEICO PELO

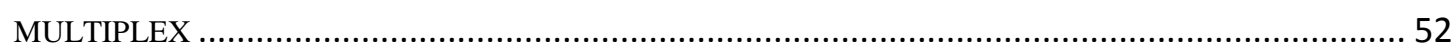

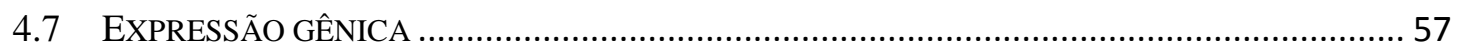


4.8 RESUMO DO COMPORTAMENTO DAS PROTEÍNAS ÓSSEAS ANTES E APÓS O TRANSPLANTE

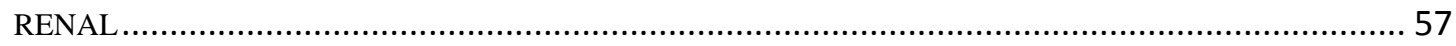

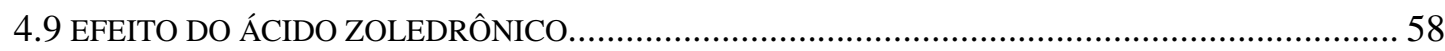

4.9.1 Parâmetros laboratoriais, imunossupressão e DXA............................................ 58

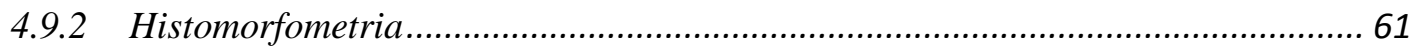

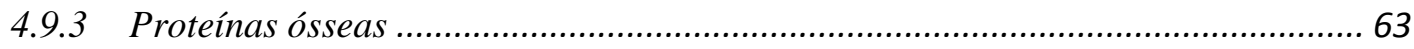

5 DISCUSSÃO

6 CONCLUSÃO

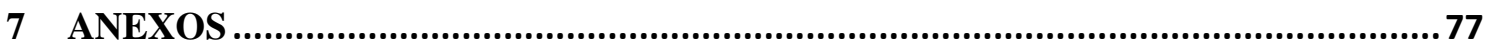

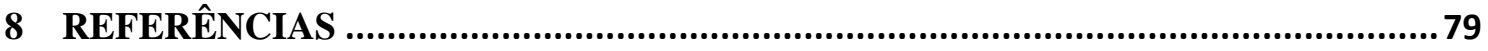

APÊNDICES 


\section{Lista de Abreviaturas}

$\begin{array}{ll}\text { ASBMR } & \text { American Society for Bone and Mineral Research } \\ \text { BFR/BS } & \text { Taxa de formação óssea (do inglês, bone formation rate) } \\ \text { BV/TV } & \text { Volume trabecular (do inglês, bone volume / tissue volume) } \\ \text { Ct.Po } & \text { Porosidade cortical (do inglês, cortical porosity) } \\ \text { Ct.Th } & \text { Espessura cortical (do inglês, cortical width) } \\ \text { DMO } & \text { Densidade Mineral Óssea } \\ \text { DP } & \text { Desvio-Padrão } \\ \text { DRC } & \text { Doença Renal Crônica }\end{array}$

DXA Absortometria de raio-x de dupla energia (do inglês, dual energy $x$-ray absortiometry)

DKK-1 Dickkopf-related protein 1

ELISA Enzyme-Linked Immunossorbent Assay

ES/BS Superfície de reabsorção (do inglês, eroded surface)

FMUSP Faculdade de Medicina da Universidade de São Paulo

$\mathrm{Fb} . \mathrm{V} / \mathrm{TV} \quad$ Fibrose medular (do inglês, fibrous volume)

FGF-23 Fator de crescimento do Fibroblasto 23

GAPDH Proteína gliceraldeído-3-fosfato desidrogenase

HC Hospital das Clínicas

KDIGO Kidney Disease: Improving Global Outcomes

IC Intervalo de confiança

LIM Laboratório de Investigação Médica

MAR Taxa de aposição mineral (do inglês, mineral aposition rate)

Mlt Tempo de mineralização (do inglês, mineralization lag time)

MS/BS Superfície mineralizante (do inglês, mineralized surface)

ND Não disponível

OV/BV Volume osteoide (do inglês, osteoid volume)

OS/BS Superfície osteoide (do inglês, osteoid surface)

O.Th Espessura osteoide (do inglês, osteoid thickness) 
Ob.S/BS Superfície osteoblástica (do inglês, osteoblast surface)

Oc.S/BS Superfície osteoclástica (do inglês, osteoclast surface)

OPG Osteoprotegerina

PTH Paratormônio

RANK Receptor ativador do fator nuclear Kappa-B

RANKL Ligante do receptor ativador do fator nuclear Kappa-B

Tb.N Número trabecular (do inglês, trabecular number)

Tb.Sp Separação trabecular (do inglês, trabecular separation)

Tb.Th Espessura trabecular (do inglês, trabecular thickness)

TCLE Termo de consentimento livre e esclarecido

TRAP5b Fosfatase ácida resistente ao tartarato 


\section{Lista de tabelas}

Tabela 1 - Tabela 1 - Sequência dos primers e tamanhos dos amplicons dos genes SOST, beta-catenina, OPG, RANKL, FGF-23 e GAPDH. .26

Tabela 2 - Características clínicas e parâmetros laboratoriais dos pacientes no prétransplante renal.

Tabela 3 - Avaliação da DMO por DXA no pré-transplante renal. .32

Tabela 4 - Parâmetros estáticos e dinâmicos da histomorfometria do pré-transplante renal. .34

Tabela 5 - Osteócitos marcados, osteócitos totais e expressão na imunohistoquimica nas biópsias do pré-transplante renal

Tabela 6 - Conteúdo proteico por multiplex nas biopsias do grupo controle e do prétransplante renal.

Tabela 7 - Comparação da expressão gênica das proteínas entre o grupo controle e o prétransplante renal.

Tabela 8 - Correlações entre o nível sérico, imunohistoquimica e multiplex das proteínas no pré-transplante renal .45

Tabela 9 - Parâmetros laboratoriais e DXA pré e 1 ano após o transplante renal. .48

Tabela 10 - Parâmetros estáticos e dinâmicos da histomorfometria pré e 1 ano após o transplante renal.

Tabela 11 - Expressão protéica óssea através de imunohistoquimica pré e 1 ano após o transplante renal. .56

Tabela 12 - Conteúdo proteico (multiplex) pré e 1 ano após o transplante renal. .56

Tabela 13 - Comparação da expressão gênica das proteínas entre o pré e 1 ano após o transplante renal.

Tabela 14 - Comportamento das proteínas ósseas pré e 1 ano após o transplante renal.58 
Tabela 15 - Avaliação do efeito do ácido zoledrônico e do transplante nos parâmetros

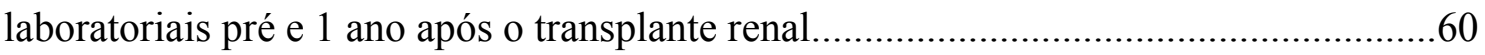

Tabela 16 - Avaliação do efeito do ácido zoledrônico e do transplante na histomorfometria pré e 1 ano após o transplante renal..............................................62 Tabela 17 - Avaliação do efeito do ácido zoledrônico e do transplante nas proteínas ósseas avaliadas por imunohistoquimica e multiplex pré e 1 ano após o transplante

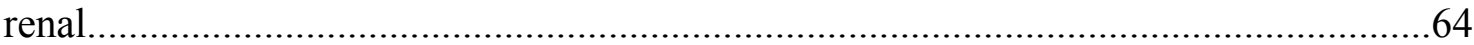




\section{Lista de figuras}

Figura 1 - Randomização dos pacientes .29

Figura 2 - Distribuição da classificação das biópsias ósseas do pré-transplante renal de acordo com o sistema TMV (remodelação, mineralização e volume) .33

Figura 3 - Padrão da expressão proteica da esclerostina no osso cortical na imunohistoquimica em biópsias do pré-transplante renal 36

Figura 4 - Padrão da expressão proteica da esclerostina no osso trabecular na imunohistoquimica em biópsias do pré-transplante renal

Figura 5 - Padrão da expressão proteica da beta-catenina no osso trabecular na imunohistoquimica em biópsias do pré-transplante renal .38

Figura 6 - Padrão da expressão proteica do RANKL no osso trabecular na imunohistoquimica em biópsias do pré-transplante renal.... 39

Figura 7 - Padrão da expressão proteica do OPG no osso trabecular na imunohistoquimica em biópsias do pré-transplante renal .40

Figura 8 - Padrão da expressão proteica do FGF-23 no osso trabecular na imunohistoquimica em biópsias do pré-transplante renal 41

Figura 9 - Distribuição da classificação das biópsias ósseas do pré e 1 ano após o transplante renal de acordo com o sistema TMV (remodelação, mineralização e volume)

Figura 10 - Expressão de esclerostina através da imunohistoquimica pré (A) e 1 ano (B) após transplante renal, 200x

Figura 11 - Expressão de beta-catenina total através da imunohistoquimica pré (A) e 1 ano (B) após transplante renal, aumento de 200x

Figura 12 - Expressão de RANKL através da imunohistoquimica pré (A) e 1 ano (B) após transplante renal, aumento de 200x 


\section{Resumo}

Araujo MJCLN. Análise da expressão gênica e de proteínas reguladoras do fósforo e da remodelação óssea: efeitos do transplante renal e do ácido zoledrônico [Tese]. São Paulo: Faculdade de Medicina, Universidade de São Paulo; 2017.

A maior parte dos distúrbios metabólicos da doença renal crônica (DRC) é revertida após um transplante renal bem-sucedido. Porém, alterações do metabolismo ósseo podem permanecer e estão associadas ao aumento de fraturas, calcificação vascular, perda de enxerto e mortalidade. A expressão óssea de proteínas osteocíticas está alterada na DRC e parece contribuir negativamente para a homeostase óssea. Há relatos de aumento da expressão óssea de FGF-23 e esclerostina em crianças que receberam transplante de órgãos sólidos em comparação com voluntários normais. Entretanto, análise da expressão destas proteínas em receptores adultos ainda não foi realizada. Avaliação de biopsia óssea em 31 pacientes uma semana antes e 1 ano após o transplante renal. Realizada histomorfometria óssea e avaliação das proteínas ósseas através de imunohistoquimica, multiplex e expressão gênica. Na avaliação das biópsias antes do transplante, houve concordância entre os achados de imunohistoquimica e multiplex para esclerostina e FGF-23. Um ano após o transplante renal bem-sucedido, observamos diminuição dos níveis séricos do PTH, TRAP5b, fosfatase alcalina óssea, FGF-23, OPG e esclerostina. Apesar da diminuição da esclerostina sérica, houve aumento de seu conteúdo ósseo pela imunohistoquimica, multiplex e expressão gênica. Também foi observado aumento do conteúdo proteico e da expressão gênica da beta-catenina fosforilada, confirmando a inibição da via Wnt. Esta inibição foi acompanhada do aumento do conteúdo ósseo de RANKL e diminuição da OPG. Em relação ao FGF-23, houve concordância entre níveis séricos e conteúdo proteico, confirmando sua menor síntese pelos osteócitos, e portanto, menor nível sérico, após o transplante renal. A recuperação da função renal após o transplante é acompanhada de mudanças nas proteínas séricas e ósseas. A esclerostina óssea aumentou, apesar da diminuição do nível sérico, acompanhada de mudanças em outras proteínas que confirmam a inibição da via Wnt. Esse achado pode ajudar a desvendar a fisiopatologia da doença óssea pós transplante e guiar a busca por novas terapias.

Descritores: Insuficiência renal crônica; Transplante de rim; Doenças ósseas metabólicas; Difosfonatos; Biópsia; Expressão gênica. 


\section{Summary}

Araujo MJCLN. Gene expression and bone remodeling proteins: kidney transplant and zoledronic acid effects [thesis]. São Paulo: "Faculdade de Medicina, Universidade de São Paulo"; 2017.

Most of the metabolic disorders of chronic kidney disease (CKD) improve after kidney transplantation, although bone metabolism might remain compromised, which is evidenced by high rates of bone loss, fractures and vascular calcification. Osteocytic bone protein expression is altered in CKD, and this seems to contribute negatively to bone health in these patients. It has been described that FGF-23 and sclerostin expression is increased in children after solid organ transplantation. However, little is known about bone-related proteins expression in adult recipients, which were analyzed prospectively in this study. Transiliac bone biopsies were obtained from 31 adult patients one week before and one year after transplantation. Bone fragments were used for histomorphometric analysis, as well as for bone proteins expression, measured by immunohistochemistry (IH) and multiplex. At baseline, we observed a significant correlation between IH expression and multiplex concentrations for sclerostin and FGF23. After a successful transplant, there was a decrease in PTH, TRAP5b, bone alkaline phosphatase, FGF-23, OPG and sclerostin. Although serum sclerostin decreased after the transplant, bone content of this protein increased through immunohistochemistry, multiplex and gene expression. We also observed an increase in the bone content and bone expression of phosphorylated beta-catenin, confirming the Wnt pathway inhibition, which was accompanied by RANKL increase and OPG decrease in the bone. A significant decrease in FGF-23 bone concentration was also seen, compatible with the serum decrease. Kidney function recovery after transplant is accompanied by significant changes in many bone proteins expression. Contradictory to the decrease in levels of serum sclerostin, its bone expression, actually, has increased, accompanied by the change of other proteins that confirm the Wnt pathway inhbition. This findings could help to unveil the patophysiology of post transplant bone disease and help to guide the search to new therapies.

Descriptors: Renal insufficiency chronic; Kidney transplantation; Bone diseases, Metabolic; Diphosphonates; Biopsy; Gene expression. 
1. INTRODUÇÃO 


\section{INTRODUÇÃO}

O transplante renal é uma das terapias substitutivas da função renal na doença renal crônica (DRC) e é considerado o tratamento de escolha para muitos pacientes, pois pode reverter muitas de suas alterações endócrinas, metabólicas e cardiovasculares, aumentando inclusive a expectativa de vida em relação ao tratamento dialítico ${ }^{1,2}$. Porém, os distúrbios do metabolismo mineral e ósseo nem sempre são totalmente corrigidos, e há relatos de alterações na remodelação, mineralização e volume ósseo anos após um transplante renal bem sucedido 3 .

A densidade mineral óssea (DMO) rapidamente decresce nos primeiros 6 a 18 meses pós-transplante, em sua maior parte devido às altas doses de corticoide. Após o primeiro ano, há uma desaceleração e até estabilização desta perda ${ }^{4,5}$. Entretanto, até $50 \%$ dos pacientes após 8 anos de transplante apresentam osteoporose com algum relato de fratura ${ }^{6}$. O risco relativo de fraturas nos pacientes transplantados é aproximadamente 4 vezes maior que em indivíduos saudáveis e é 30\% maior nos primeiros 3 anos pós transplante do que nos pacientes em diálise ${ }^{7-9}$. A taxa de fratura reportada nesses pacientes é entre 5 a $44 \%$, diminuindo em $1 \%$ a cada mês após o primeiro ano de transplante ${ }^{8,10,11}$.

As alterações do metabolismo ósseo pós-transplante são complexas e multifatoriais, influenciadas por fatores anteriores à cirurgia, como distúrbios da paratireoide, do metabolismo do cálcio, do fósforo, do magnésio, e da vitamina D, imobilidade, hipogonadismo, amiloidose, toxicidade por alumínio, dentre outras comorbidades e por fatores do pós-transplante como imunossupressão utilizada e duração da mesma, função do enxerto e distúrbios tubulares de reabsorção de cálcio e fósforo ${ }^{10,12}$. No tecido ósseo, podem ser caracterizadas tanto pela presença de doença óssea de baixa remodelação, como pela de alta ${ }^{7,13}$, sendo que esta última está associada à persistência do hiperparatiroidismo. Independente da taxa de remodelação 
óssea, diminuição do volume ósseo e anormalidades da mineralização são comumente encontradas nestes pacientes.

A maioria dos estudos iniciais com biópsia óssea em transplantados renais apontou predomínio de doença óssea de baixa remodelação, incluindo doença óssea adinâmica e osteomalácia, e as principais alterações são de diminuição da formação óssea e mineralização, com persistência da reabsorção óssea, o que favorece a perda de massa óssea ${ }^{14-16}$.

Estudo com 389 pacientes avaliou DMO após o transplante e evidenciou que a perda óssea foi mais prevalente no fêmur, e esta se associou positivamente ao sexo feminino, baixo índice de massa corpórea, idade, hiperparatiroidismo prévio e tempo pós transplante, sem nenhuma relação com a função do enxerto ${ }^{17}$. Em estudo realizado pelo nosso grupo com pacientes transplantados renais após 2 anos, apenas 5\% dos pacientes tinha biópsia óssea normal, quase todos ainda exibiam alteração na remodelação, mineralização e volume ósseos, com altos índices de persistência de hiperparatiroidismo e hipovitaminose D. ${ }^{3}$.

Estudos prospectivos mais recentes que incluíram pacientes com protocolos mais modernos de imunossupressão e minimização de corticoterapia têm encontrado perda de massa óssea de apenas 0,1 a 5,7\% na coluna lombar ${ }^{18}$, inclusive com incidência de fraturas menor do que as anteriormente relatadas na literatura. Transplantados renais de uma coorte canadense apresentaram incidência cumulativa de fratura em 10 anos de $1,7 \%$, menor do que os $3 \%$ que define uma população de risco. Neste estudo apenas as mulheres acima de 50 anos apresentaram risco aumentado de fratura ${ }^{19}$.

Por outro lado, uma parcela significativa dos pacientes apresenta persistência do hiperparatiroidismo, mesmo com diminuição dos níveis de paratormônio (PTH) nos primeiros 3 a 6 meses após o transplante. A incidência varia de acordo com a metodologia utilizada, podendo ser de 10 a $66 \%$ em pacientes transplantados renais ${ }^{20}$. Estudo prospectivo mais 
recente relatou mais de $80 \%$ de prevalência de hiperparatiroidismo persistente após 1 ano de transplante renal ${ }^{21}$, que além de ser fator de risco para fraturas ${ }^{22}$, tem sido cada vez mais associado com perda de enxerto e aumento de mortalidade ${ }^{23}$.

Assim como a doença mineral e óssea da DRC, a doença óssea pós-transplante tem fisiopatologia complexa e multifatorial, ainda não completamente esclarecida.

A imunossupressão pós-transplante tem grande impacto na patogênese da doença óssea. O papel dos corticoides já é bem estabelecido. Primariamente, o corticoide age sobre os osteoblastos e osteócitos ${ }^{24,25}$, causando supressão da formação óssea. Um dos principais mecanismos pelos quais os corticoides diminuem a produção de osteoblastos é pela oposição a via Wnt/Beta-catenina, inibida principalmente pelos antagonistas esclerostina e Dickkopfrelated protein 1 (DKK1), sintetizados pelos osteócitos. Estudos in vitro têm demonstrado aumento da expressão desses antagonistas durante o uso de corticoide; porém, estudos em humanos são escassos e mostram resultados contraditórios. A maioria demonstra aumento da esclerostina sérica, sem alteração ou com diminuição dos níveis de DKK1. Estipula-se que as discrepâncias sejam secundárias às diferenças na idade, doença de base, dose e duração do tratamento com corticoides. Os osteoclastos são a terceira linha de ação; provavelmente os corticoides diminuem a expressão da osteoprotegerina (OPG), e aumentam a expressão do fator estimulador de colônia dos macrófagos e o ligante do receptor ativador do fator nuclear KappaB (RANKL) nas células estromais e nos osteoblastos, resultando no aumento da osteoclastogênese e da meia-vida dos osteoclastos ${ }^{25}$.

Os dados sobre os inibidores de calcineurina são controversos. Li Sun e colaboradores demonstraram in vitro que a via da calcineurina promove diferenciação celular e formação óssea nos osteoblastos, e que a deleção ou inativação desta via inibe a diferenciação osteoblástica, levando a menor formação óssea. Estes achados podem explicar o mecanismo 
pelo qual os inibidores de calcineurina causam perda óssea ${ }^{26}$, já que a administração de ciclosporina em camundongos ocasionou perda substancial de massa óssea, particularmente no osso trabecular ${ }^{24}$. Entretanto, estudos in vitro também sugerem uma inibição da reabsorção óssea mediada pela ciclosporina ${ }^{24}$. Há menos estudos sobre o tacrolimus, mas também com resultados divergentes. Enquanto a perda óssea em ratos também foi um efeito encontrado, estudos com transplantados de fígado demonstrou uma DMO maior comparada a de pacientes usando ciclosporina, dois anos após o transplante ${ }^{24}$. Moreira e colaboradores investigaram os efeitos in vitro da imunossupressão nos osteoblastos, e detectaram que o tacrolimus, mesmo em doses mais elevadas que as usuais, não causou alteração, enquanto a ciclosporina, em maiores concentrações, diminuiu a proliferação e diferenciação dos osteoblastos e ainda aumentou morte por apoptose ${ }^{27}$. A associação dos inibidores da calcineurina com os corticoides pode potencializar a perda óssea em estudos in vitro ${ }^{26}$. Westenfeld e colaboradores demonstraram que a imunossupressão com sirolimus está associada com menores níveis séricos de marcadores de atividade e maturação de osteoclastos (TRAP5b - fosfatase ácida resistente ao tartarato - e RANKL) que nos pacientes que receberam tacrolimus. No estudo com cultura de células realizado pelo mesmo grupo, o sirolimus foi capaz de minimizar a reabsorção de hidroxiapatita pelos osteoclastos e reduziu em $90 \%$ o número de osteoclastos ativos ${ }^{28}$. Em relação aos demais imunossupressores, micofenolato mofetil e azatioprina parecem não ter efeito sobre o metabolismo ósseo ${ }^{24}$.

Portanto, além da divergência de resultados entre estudos in vitro com linhagens celulares e estudos clínicos, anteriormente relatada, há poucos estudos que tenham feito análise in vitro de células ósseas retiradas de pacientes. Estudo do nosso grupo foi o primeiro que avaliou linhagem osteoblástica in vitro, onde os osteoblastos exibiram proliferação maior que os controles; porém, tinham menor expressão de fosfatase alcalina, o que pode ter contribuído para a perda de massa óssea. Células de pacientes em uso de tacrolimus apresentaram taxa de 
proliferação maior que que os pacientes tratados com ciclosporina, sem relação com o volume trabecular $(\mathrm{BV} / \mathrm{TV})^{3}$.

Ainda não há consenso na literatura sobre qual a melhor forma de avaliação e tratamento da doença óssea após transplante. A monitorização dos parâmetros bioquímicos é útil para guiar o tratamento e o KDIGO (Kidney Disease: Improving Global Outcomes) recomenda dosagem semanal de cálcio e fósforo no período imediato pós-transplante até normalização dos níveis séricos. Depois, os níveis de cálcio, fósforo, PTH e vitamina D devem ser monitorados de acordo com as recomendações usuais do KDIGO para paciente com DRC em tratamento conservador observando a taxa de filtração glomerular ${ }^{29,30}$. A DXA (densitometria óssea por absorção de raios-X de dupla energia) não fornece boa informação sobre a qualidade do osso; entretanto, a sua realização tem sido recomendada para pacientes com taxa de filtração glomerular estimada maior que $30 \mathrm{ml} / \mathrm{min}$ nos primeiros 3 meses, principalmente se os pacientes estiverem em uso de corticoides ${ }^{30}$. A biópsia óssea permanece como o padrão ouro para avaliar as alterações ósseas, mas não deve ser feita rotineiramente, sendo reservada aos casos com fraturas graves e distúrbios inexplicáveis ou de difícil correção ${ }^{30}$. O uso dos bisfosfonatos pode melhorar a densidade mineral óssea e reduzir o risco de fratura óssea; porém, não parece ter efeitos sobre a sobrevida do paciente ou do enxerto ${ }^{31,32}$. Além disto, não há qualquer estudo que tenha utilizado fratura como desfecho para comprovar sua eficácia, e há o receio de que o bisfosfonato possa exacerbar a doença óssea adinâmica nesses pacientes. Portanto, ainda não há evidência que sustente o uso do bisfosfonato a longo prazo. Estudo prospectivo e randomizado avaliou o uso do pamidronato intravenoso até 6 meses após o transplante renal. As biópsias ósseas pré e pós foram realizadas apenas nos pacientes submetidos a transplante com doador vivo. O grupo intervenção teve a massa óssea preservada após 6 e 12 meses, verificadas por histomorfometria e DXA, quando comparados com os controles. Na biópsia de base, $50 \%$ dos pacientes apresentaram baixa remodelação, enquanto 
na biópsia após 6 meses todos os pacientes do grupo do bisfosfonato tinham doença óssea adinâmica, enquanto no grupo controles apenas os $50 \%$ de início ${ }^{33}$. Outro estudo randomizado e controlado avaliou o uso do ácido zoledrônico em 20 pacientes transplantados. Após 6 meses, o conteúdo de cálcio da coluna aumentou e a superfície osteóide aumentou em 39\% no grupo do ácido zoledrônico, mas não nos controles. A DMO do fêmur diminuiu no grupo placebo, mas não no ácido zoledrônico, e a DMO da coluna lombar aumentou em $31 \%$ no grupo do ácido zoledrônico comparada a uma queda de $38 \%$ no placebo. Marcadores sorológicos de reabsorção e formação óssea estavam diminuídos no grupo intervenção. Houve resolução similar da doença de alta remodelação nos dois grupos, como demonstrado pela diminuição da superfície óssea erosiva e número de osteoclastos e osteoblastos. Porém, não foi realizada a marcação óssea com tetraciclina, não podendo ser totalmente excluída a presença de baixa remodelação ou defeitos de mineralização ${ }^{12}$. Schwarz e colaboradores avaliaram o seguimento de três anos destes pacientes que receberam ácido zoledrônico ou placebo; ambos os grupos apresentaram melhora da mineralização óssea, avaliada por DXA, e não houve alteração significativa dos parâmetros de atividade osteoblástica. A OPG, marcador de inibição de reabsorção óssea, que estava elevada após 6 meses no grupo do ácido zoledrônico, retornou aos níveis basais durante esses 2 anos e meio, evidenciando que os efeitos de proteção óssea nos primeiros meses após a terapia não são mantidos após 3 anos de transplante ${ }^{34}$.

Outra opção para tratamento da osteoporose seria o denosumab, anticorpo monoclonal antagonista do RANKL, usado para prevenção de fraturas, principalmente em mulheres menopausadas. Este antireabsortivo aumentou a DMO em pacientes transplantados renais após 1 ano, mas teve maior incidência de infecção do trato urinário e hipocalcemia. Curiosamente, os pacientes do grupo controle deste estudo também apresentaram uma perda menor de DMO após o transplante do que o anteriormente relatado ${ }^{35}$. 
O KDIGO atualmente não recomenda retirada do corticoide e sugere que não seja utilizado como prática habitual pelo risco de aumento dos índices de rejeição. No entanto, há um sentido na tentativa de minimizar o uso de corticoide, tentando diminuir a perda óssea. $\mathrm{O}$ KDIGO recomenda tratamento com vitamina D ativa ou bisfosfonatos nos primeiros 12 meses após o transplante para aqueles pacientes com taxa de filtração glomerular estimada maior que 30m1/min e baixa DMO, e considerar biópsia óssea para orientar tratamento antes do uso dos bisfosfonatos devido ao alto índice de doença óssea adinâmica ${ }^{30}$.

A paratireoidectomia tem sido reservada para os casos de hiperparatiroidismo persistente mais grave com hipercalcemia severa ou refratária, fraturas, dores ósseas, calcificação vascular e calcifilaxia ${ }^{10}$. Vários estudos têm avaliado a eficácia de cinacalcete para o tratamento destes pacientes, principalmente os que apresentam hipercalcemia leve a moderada com bons resultados ${ }^{36}$. Porém, ainda não está estabelecido na literatura o melhor momento para o tratamento nem a terapia de escolha.

Recentemente, novos estudos têm utilizado outras técnicas e marcadores além da histomorfometria e exames como PTH e fosfatase alcalina, e que colocam o osteócito como célula chave para regulação de remodelação e mineralização. A doença óssea se inicia precocemente na DRC e está associada com alterações na morfologia e função de osteócitos ${ }^{37-}$ 40, que perfazem mais de $90 \%$ das células ósseas e estão mergulhados numa matriz mineralizada com canalículos interconectados ${ }^{41}$. Essas células orquestram o trabalho dos osteoblastos, que formam osso e dos osteoclastos, que fazem a reabsorção óssea, através da produção e secreção de fatores que permitem ao esqueleto se adaptar às diferentes mudanças hormonais e necessidades mecânicas ${ }^{42}$ Além disso, produzem e secretam fatores que afetam as outras linhagens por efeito parácrino e/ou autócrino e secretam hormônios que afetam outros tecidos por efeito endócrino ${ }^{43}$. 
O FGF-23 (Fator de crescimento de Fibroblastos 23) é produzido pelos osteócitos e é o principal regulador do metabolismo do fósforo. Ele, junto com o correceptor Klotho, liga-se ao receptor de FGF no túbulo proximal, levando a inibição da reabsorção renal de fósforo, sendo, portanto, um hormônio fosfatúrico ${ }^{44}$. FGF-23 age também na glândula paratireoide diminuindo a os níveis do $\mathrm{PTH}^{45}$. O FGF-23 não parece atuar diretamente nas atividades da linhagem osteoblasto/osteócito, mas provavelmente serve como um mensageiro para limitar o fornecimento de fósforo para mineralização ${ }^{46}$. Deleção do gene de FGF-23 origina camundongos com hiperfosfatemia, diminuição de DMO, formação óssea deficiente e acúmulo de osteóide não mineralizado ${ }^{44}$. Entretanto, os níveis de FGF-23 estão elevados na DRC e foram associados com doença e morte cardiovascular neste subgrupo de pacientes ${ }^{43}$. Os níveis de FGF-23 caem substancialmente após o transplante renal, principalmente durante o primeiro ano ${ }^{47,48}$, e há também o relato de que níveis mais elevados desta proteína no pré-transplante estão associados com perda do enxerto e mortalidade ${ }^{49}$. Porém, não há estudos que abordem o conteúdo ósseo dessa proteína após o transplante renal em pacientes adultos.

A família das proteínas Wnt compreende moléculas de sinalização que participam de múltiplos processos fisiológicos e que regulam diversas interações célula-célula durante a embriogênese. A via Wnt-beta-catenina, também denominada via canônica, é considerada o componente predominante da via Wnt e controla a diferenciação das células mesenquimais em várias linhagens ${ }^{50}$. A sua ativação leva a entrada do fator de transcrição beta-catenina no núcleo celular e ativação de transcrição gênica, enquanto sua inibição leva à fosforilação e consequente destruição da beta-catenina, sem transcrição gênica. No esqueleto, a via Wnt é uma via predominantemente anabólica ${ }^{51}$, promove diferenciação e maturação osteoblástica, e prolonga sobrevida de osteoblastos e osteócitos, linhagem celular responsável pela formação óssea. Além disto, estudos experimentais sugerem que a via Wnt também iniba indiretamente a osteoclastogênese, através do aumento da expressão de OPG e diminuição de RANKL em 
osteócitos e osteoblastos ${ }^{43}$. Portanto, há uma interação da via Wnt com a via RANK/RANKL/OPG. Esta segunda via foi descrita no início dos anos 2000 e identificou como osteócitos e osteoblastos ativam os osteoclastos, linhagem celular responsável pela reabsorção óssea ${ }^{52}$. Como dito anteriormente, a linhagem celular responsável pela formação óssea produz o RANKL, que irá se ligar ao RANK (receptor ativador do fator nuclear KappaB), presente nos precursores de osteoclastos. A interação do RANKL com o RANK favorece a diferenciação e sobrevida dos osteoclastos, aumentando, portanto, a reabsorção óssea. Por outro lado, como um mecanismo compensatório, osteócitos e osteoblastos também produzem a OPG, que se liga ao RANKL e compete com o RANK, inibindo a diferenciação osteoclástica. Portanto, é o balanço entre OPG e RANKL que irá determinar o número e atividade de osteoclastos e consequentemente, a reabsorção óssea. Assim, a ativação da via Wnt favorece não apenas a formação, como também inibe a reabsorção óssea ${ }^{53}$.

A via Wnt é regulada por muitos antagonistas, que podem se ligar diretamente aos ligantes e bloqueá-los ou se ligando a molécula LRP5/6, dentre esse segundo grupo estão o DKK1 e a esclerostina ${ }^{54}$. A repressão da via Wnt/beta-catenina é acompanhada da fosforilação da beta-catenina, tornando-a inativa ${ }^{55}$. O DKK1 é uma glicoproteína expressa pelos osteoblastos e osteócitos e promove internalização do complexo receptor da via Wnt, através da ligação a molécula LRP5/6 ${ }^{50}$.

Esclerostina é uma glicoproteína, decodificada pelo gene da esclerostina, produzida principalmente por osteócito maduros, se liga a molécula LRP5/6 diminuindo a disponibilidade do receptor da via Wnt aos ligantes, além disso também influencia nas concentrações de FGF23 e calcitriol ${ }^{50,56}$. Com a progressão da doença renal crônica, os níveis séricos de esclerostina aumentam, e chegam a níveis muito elevados no estágio final. Os níveis podem estar elevados devido a diminuição da eliminação renal ${ }^{54}$, mas há também a hipótese de que o aumento da produção contribua de forma mais importante para esse aumento ${ }^{57}$. Níveis séricos de 
esclerostina também estão associados com mortalidade em DRC, embora haja controvérsia a este respeito $^{46,58}$.

Poucos estudos avaliaram o nível sérico de esclerostina após o transplante renal. Tomei e colaboradores, em estudo com 19 pacientes transplantados em média por 2 anos, evidenciou níveis séricos de esclerostina semelhantes a pacientes com DRC pareados por idade e função renal ${ }^{59}$.

Análise post-hoc de Evenepoel e colaboradores avaliou os níveis circulantes de esclerostina em 50 pacientes transplantados renais, 50 controles DRC pareados por idade, sexo e taxa de filtração glomerular e 23 pacientes com hiperparatiroidismo severo com necessidade de paratireoidectomia para avaliar o impacto do hiperparatiroidismo persistente. Os níveis de esclerostina tiveram tendência a ser mais baixos nos pacientes transplantados renais em 12 meses quando comparados com seus controles de DRC, mas sem significância estatística. Os níveis séricos de esclerostina caíram em 61,2\% entre o pré e 3 meses após o transplante, porém houve aumento de $24,4 \%$ entre o terceiro mês e o primeiro ano, sendo esse aumento correlacionado com a diminuição do PTH. Foi observado aumento dos níveis séricos de esclerostina nos pacientes que foram submetidos a paratireoidectomia, acompanhando temporalmente a queda do $\mathrm{PTH}^{60}$. Portanto, a esclerostina sérica parece ter um comportamento bimodal após o transplante. Os níveis de esclerostina também foram avaliados prospectivamente em 42 pacientes submetidos a transplante renal, e nesta análise houve um declínio inicial para níveis normais ou abaixo do normal acompanhando a melhora da função renal e também influenciados pelo uso de corticóide. Subsequentemente, houve uma elevação gradativa durante o primeiro ano de transplante para níveis mais próximos do normal, não influenciada pela função renal, mas paralela à redução do PTH e normalização de outros parâmetros do metabolismo ósseo. Altos níveis pré-transplante e maior tempo de transplante foram os preditores independentes dos níveis séricos de esclerostina ${ }^{61}$. 
Assim como o nível sérico, a expressão óssea de esclerostina em pacientes portadores de DRC também vem sendo estudada nos últimos anos. Sabbagh e colaboradores demonstraram que uma das primeiras manifestações da doença óssea em DRC é a elevação da esclerostina, com consequente repressão da via Wnt, o que promove um aumento de RANKL e diminuição da OPG, culminando em ativação dos osteoclastos. Nos estágios mais avançados, o aumento de PTH suprime a esclerostina, mas outros antagonistas da via Wnt já estão ativados, perpetuando a supressão da via Wnt e ativação dos osteoclastos ${ }^{55}$. Outro estudo que avaliou o conteúdo ósseo em DRC, também encontrou aumento de esclerostina em estágios iniciais da DRC, enquanto FGF-23 e beta-catenina fosforilada tiveram expressão maior em estágios mais avançados ${ }^{62}$.

Entretanto, o único estudo realizado em pacientes transplantados foi realizado em população pediátrica. A expressão óssea de esclerostina foi avaliada por imunohistoquimica em crianças transplantadas ( 8 de rim e 14 de coração ou fígado). Os pacientes transplantados apresentaram expressão de esclerostina superior quando comparados a controles pediátricos DRC pré-dialíticos com função renal pareada. A expressão do FGF-23 também foi avaliada no estudo com pacientes pediátricos, e da mesma forma foi superior nos pacientes com transplante de órgão sólido quando comparados a controles pediátricos DRC pré-dialíticos com função renal pareada ${ }^{63}$. No entanto, este estudo não realizou uma avaliação longitudinal destes pacientes, ou seja, uma análise da expressão óssea destas proteínas antes e após o transplante para o mesmo paciente.

Não há descrição na literatura de expressão óssea de esclerostina ou outras proteínas reguladoras do metabolismo ósseo em pacientes adultos transplantados renais. Acredita-se que um melhor entendimento do papel destas proteínas na doença óssea pós-transplante poderia nos fornecer novas estratégias de tratamento em pacientes transplantados renais. 
2. OBJETIVOS 


\section{OBJETIVOS}

1. Primário:

Avaliar o efeito do transplante renal e do tratamento com ácido zoledrônico sobre a expressão gênica e proteica de hormônios reguladores do metabolismo de fósforo (FGF - 23) e de citocinas envolvidas na remodelação óssea (vias RANK/RANKL/OPG e Wnt/betacatenina).

2. Secundários:

Avaliar o efeito do transplante renal e do tratamento com ácido zoledrônico sobre a expressão de algumas proteínas ósseas através da imunohistoquimica.

Avaliar o efeito do transplante renal e do tratamento com ácido zoledrônico sobre o conteúdo ósseo destas proteínas através do multiplex.

Avaliar o efeito do transplante renal e do tratamento com ácido zoledrônico sobre expressão gênica destas proteínas no tecido ósseo através do PCR. 
3. MÉTodos 


\section{PACIENTES E MÉTODOS}

\subsection{Critérios de inclusão}

Pacientes candidatos a transplante renal com doador vivo no Serviço de Transplante Renal do Hospital das Clínicas (HC) da Faculdade de Medicina da Universidade de São Paulo (FMUSP), com condição clínica estável no peri-operatório e capacidade de manter seguimento regular após o transplante, após assinatura do termo de consentimento livre e esclarecido (TCLE). Os pacientes foram abordados antes do transplante, pela necessidade de agendamento prévio da biópsia óssea.

\subsection{Critérios de exclusão}

- Filtração glomerular $<30 \mathrm{ml} / \mathrm{min} / 1,73 \mathrm{~m}^{2}$ após uma semana de transplante.

- Pacientes menores de 18 anos.

- Pacientes com transplantes de outros órgãos simultaneamente.

- Pacientes que tiverem realizado paratireoidectomia ou com passado de doença óssea adinâmica (diagnosticada por biópsia óssea).

- PTH pré-transplante $<130 \mathrm{pg} / \mathrm{ml}$.

- Uso prévio de bisfosfonatos.

\subsection{Protocolo do estudo}

Este projeto é a complementação do protocolo do estudo CAPPesq $n^{\circ}$ 0776/11, registrado no Clinical Trials sob o número: NCT 01675089, aprovado pelo Comitê de Ética do HC - FMUSP. Os pacientes foram randomizados para um dos dois grupos. A randomização foi feita em blocos, através de um programa desenvolvido especificamente para este fim. Um grupo recebeu ácido zoledrônico em dose única de $5 \mathrm{mg}$ endovenosa e reposição de vitamina 
$\mathrm{D}_{3}$ com o objetivo de manter os níveis séricos de 25-hidroxivitamina $\mathrm{D}$ acima de $30 \mathrm{ng} / \mathrm{ml}$. O grupo placebo recebeu apenas vitamina $\mathrm{D}_{3}$ com os alvos anteriormente descritos. $\mathrm{O}$ ácido zoledrônico foi infundido diluído em solução salina ao longo de 15 minutos. Os pacientes foram previamente hidratados para evitar efeitos colaterais nefrotóxicos. Para pacientes do sexo feminino incluídas no estudo, foram oferecidos métodos anticoncepcionais e as devidas orientações, assim como já é feito rotineiramente para mulheres em idade fértil durante o primeiro ano de transplante no Serviço de Transplante Renal do HC - FMUSP.

Os pacientes foram submetidos a uma biópsia óssea de crista ilíaca com dupla marcação por tetraciclina na semana anterior ao transplante e após um ano de seguimento. Este procedimento é realizado rotineiramente pelos médicos do Departamento de Clinica Medica Nefrologia do HC - FMUSP, sob anestesia local. DMO medida por DXA foi realizada no momento do transplante e ao final dos 12 meses.

Parâmetros bioquímicos, incluindo cálcio e fósforo séricos, PTH, fosfatase alcalina, 25hidroxivitamina D, marcadores de formação e reabsorção óssea (fração óssea da fosfatase alcalina e TRAP5b, respectivamente), FGF-23, RANKL e OPG foram determinados a partir de amostras de sangue coletadas no momento do transplante e após os 12 meses. Dados clínicos, do transplante, medicações imunossupressoras e função renal também foram documentados, de acordo com a rotina de retornos ambulatoriais no período de pós-transplante.

Para efeito de comparação de alguns parâmetros que ainda não tem padrão de normalidade, foi utilizado fragmentos ósseos, do nosso banco de biópsias ${ }^{64}$, de um grupo de 12 pacientes com função renal normal, obtidos de uma cirurgia de reposição total do quadril realizada no Instituto de Ortopedia e Traumatologia do HC-FMUSP. As amostras foram transportadas em um meio adequado (MEM Dulbecco com 25nM tampão Hepes, penicilina $500 \mathrm{U} / \mathrm{mL}$, estreptomicina $500 \square \mathrm{g} / \mathrm{mL}$, anfotericina B $3 \mathrm{~g} / \mathrm{ml}$ ) e criopreservadas. Essas amostras foram pareadas por sexo e idade, e este grupo foi denominado de grupo controle. 


\subsection{Exames bioquímicos}

As análises de PTH (Valor de referência = 15 - 65 pg/ml) e 25-hidroxivitamina D (Valor de referência $=30-100 \mathrm{ng} / \mathrm{ml}$ ) foram feitas pelo método eletroquimioluminométrico. Fosfatase alcalina (Valor de referência $=35$ - 104 U/L) foi analisada pelo método cinético automatizado. Creatinina (Valor de referência $=0,7-1,2 \mathrm{mg} / \mathrm{dl}$ ) foi analisada pelo método colorimétrico cinético. Cálcio (Valor de referência = 8,6 - 10,2 mg/dl) e fósforo (Valor de referência = 2,7 4,5 mg/dl) séricos foram dosados pelo método colorimétrico automatizado. As análises da fração óssea da fosfatase alcalina (Valor de referência homens $=15$ - 41,3 U/L; mulheres = 11,6 - 29,6 U/L; Quidel Corporation, San Diego, Ca, EUA), TRAP5b (Valor de referência homens $=4,0 \pm 1,4 ; \mathrm{U} / \mathrm{L} ;$ mulheres = 2,9 \pm 1,4 U/L; Quidel Corporation, San Diego, Ca, EUA), esclerostina (Valor de referência = 0,2 - 0,6 ng/ml; Teco Medical Group, Sissach, Suíça), FGF - 23 intacto (Valor de referência = 8,2-54,3 pg/ml; Immutopics, Inc., San Clemente, Ca, EUA) e OPG (Valor de referência $=492 \pm 276$ pg/ml); Biovendor LM, Brno, República Checa) foram realizadas por ELISA (Enzyme-Linked Immunossorbent Assay). A análise do RANKL foi feita através do Milliplex®MAP Human Bone Metabolism Magnetic Bead Kit, baseado na tecnologia Luminex MAP® (Sem valor de referência; Merck Millipore, Darmstad, Alemanha).

\subsection{Avaliação da densidade mineral óssea}

A DMO foi avaliada por DXA, usando o densitômetro HOLOGIG Discovery (Hologic Inc, Bedford, MA, USA) no Laboratório de Metabolismo Ósseo da Disciplina de Reumatologia - LIM 17. As DMO foram expressas em $\mathrm{g} / \mathrm{cm}^{2}$ e analisadas na coluna lombar e quadril, sendo calculados os escores T e Z, para comparações com indivíduos jovens e pareados pela idade, respectivamente, da mesma raça e sexo. 


\subsection{Biópsia óssea}

Os pacientes foram submetidos a uma biópsia óssea de crista ilíaca com dupla marcação por tetraciclina uma semana antes do transplante e após um ano de seguimento. Este procedimento foi realizado no Hospital Dia do HC - FMUSP, sob anestesia local e sedação do paciente com midazolam, na dose de 5 a $15 \mathrm{mg}$, por via intramuscular. A tetraciclina foi administrada na dose de $20 \mathrm{mg} / \mathrm{Kg}$ de peso/dia, em duas tomadas, sendo a primeira nos $18^{\circ}$, $17^{\circ}$ e $16^{\circ}$ dias e a segunda, nos $5^{\circ}, 4^{\circ}$ e $3^{\circ}$ dias que antecederam a biópsia.

Após a realização da biópsia, o fragmento ósseo foi dividido em duas partes: a primeira, após inclusão em metil-metacrilato, sem descalcificação, foi utilizada para análise de histomorfometria e imunohistoquimica ${ }^{62}$; e a segunda foi congelada imediatamente em nitrogênio líquido e em seguida estocada em freezer a $-80^{\circ} \mathrm{C}$ em solução de Trizol ${ }^{\mathrm{TM}}$, para posterior processamento (homogeneização), dosagem proteica e avaliação de expressão gênica.

Para a homogeneização do fragmento ósseo foram utilizados tubos com esferas de metal de 2,8 mm (OMNI International, Kennesaw, USA), submetidos à agitação durante 3 ciclos de 60 segundos no Bead Ruptor (OMNI International, Kennesaw, USA). A proteína total e o RNA foram extraídos utilizando o reagente Trizol ${ }^{\mathrm{TM}}$ (Invitrogen, Carlsbad, USA) de acordo com as instruções do fabricante.

\subsection{Histomorfometria}

A histomorfometria foi realizada empregando-se o sistema de análise semi-automático e software OsteoMeasure ${ }^{\mathrm{TM}}$ (OsteoMetrics Inc., Decatur, GA, EUA). Os parâmetros histomorfométricos trabeculares estudados foram divididos em estáticos e dinâmicos, sendo os últimos analisados pela marcação com tetraciclina sob microscópio com luz ultravioleta. As denominações dos parâmetros, assim como suas abreviaturas, seguem os propostos pela

American Society for Bone and Mineral Research (ASBMR) ${ }^{65}$. Os valores de referência 
utilizados para os parâmetros estáticos foram os de controles normais locais ${ }^{64}$, enquanto que os dinâmicos seguiram os descritos na literatura ${ }^{66}$.

\subsubsection{Parâmetros estáticos}

- Volume trabecular - BV/TV (\%): é o volume ocupado pelo osso trabecular, mineralizado ou não, expresso como porcentagem do volume ocupado pela medula óssea e as trabéculas. Valor de referência: 21,8 \pm 7,2 (mulheres); $24 \pm 6,1$ (homens).

- Espessura trabecular - Tb.Th $(\mu \mathrm{m})$ : representa a média da espessura das trabéculas. Valor de referência: $126 \pm 28,8$ (mulheres); 127,9 $\pm 29,7$ (homens).

- Separação trabecular - Tb.Sp $(\mu \mathrm{m})$ : é a distância média entre as trabéculas. Valor de referência: 498,3 \pm 195,9 (mulheres); 420,6 \pm 124,1 (homens).

- Número de trabéculas - Tb.N (/mm ou $\left.\mathrm{mm}^{-1}\right)$ : representa o número de trabéculas ósseas por milímetro de tecido avaliado (é dado pela razão entre o volume trabecular e sua espessura). Valor de referência: $1,76 \pm 0,52$ (mulheres); 1,89 $\pm 0,42$ (homens).

- Volume osteóide - OV/BV (\%): é o volume ocupado por osso não-mineralizado (matriz osteóide), em relação ao volume trabecular (mineralizado e não-mineralizado). Valor de referência: 1,55 $\pm 1,9$ (mulheres); 2,9 $\pm 2,7$ (homens).

- Espessura osteóide - O.Th $(\mu \mathrm{m})$ : é a espessura da matriz osteóide expressa em micra. Valor de referência: 10,8 $\pm 3,2$ (mulheres); 11,7 $\pm 3,5$ (homens).

- Superfície osteóide - OS/BS (\%): é a porcentagem da superfície trabecular recoberta por matriz osteóide em relação à superfície do osso trabecular total. Valor de referência: 9,2 $\pm 8,4$ (mulheres); 16,1 $\pm 12,6$ (homens).

- Superfície osteoblástica - Ob.S/BS (\%): é a porcentagem da superfície trabecular recoberta por osteoblastos em relação a superfície trabecular total. Valor de referência: $1,2 \pm 3,2$ (mulheres); 1,2 $\pm 1,4$ (homens). 
- Superfície reabsorvida - ES/BS (\%): é a porcentagem da superfície trabecular que apresenta lacunas de reabsorção óssea, com a presença ou não de osteoclastos, em relação à superfície trabecular total. Valor de referência: 2,3 $\pm 2,4$ (mulheres); 1,75 $\pm 1,21$ (homens).

- Superfície osteoclástica - Oc.S/BS (\%): é a porcentagem da superfície trabecular recoberta por osteoclastos em relação à superfície trabecular total. Valor de referência: $0,03 \pm 0,06$ (mulheres); 0,03 $\pm 0,11$ (homens).

- Volume de fibrose - Fb.V/TV (\%): é a porcentagem da medula óssea ocupada por fibrose em relação à área avaliada. Valor de referência: 0 .

\subsubsection{Parâmetros dinâmicos}

- Superfície mineralizante - MS/BS (\%): é a porcentagem da superfície trabecular que apresenta dupla e simples marcações pela tetraciclina em relação à superfície trabecular total. Valor de referência: $12 \pm 5$ (mulheres); $18 \pm 8$ (homens).

- Taxa de aposição mineral - MAR ( $\mu \mathrm{m} /$ dia): a quantidade de mineral depositado no período entre as duas marcações pela tetraciclina. Valor de referência: $0,65 \pm 0,12$.

- Taxa de formação óssea - BFR/BS $\left(\mu \mathrm{m}^{3} / \mu \mathrm{m}^{2} /\right.$ dia): é o produto da taxa de aposição mineral (MAR) e a superfície mineralizante (MS/BS) em 365 dias ou um ano. Representa a taxa de osso mineralizado por dia ou um ano. Valor de referência: 0,07 $\pm 0,03$ (mulheres); 0,13 $\pm 0,07$ (homens).

- Intervalo de tempo para a mineralização - Mlt (dias): intervalo de tempo entre deposição e a mineralização da matriz osteóide. Valor de referência: 23,7 \pm 2,7 (mulheres); 21,3 \pm 2,3 (homens).

\subsubsection{Sistema TMV (remodelação, mineralização e volume)}

A análise histomorfométrica das biópsias pelo sistema TMV resultou no diagnóstico do 
tipo de remodelação - turnover - (alta, normal e baixa), da mineralização óssea - mineralization - (normal e anormal), bem como do volume - volume - (alto, normal ou baixo) ${ }^{67}$. A remodelação foi considerada baixa quando o BFR/BS estava menor que 1 desvio da média e alta quando estava 1 desvio acima da média. Consideramos mineralização normal, quando a O.Th encontrava-se dentro dos valores de referência associada a um intervalo de MLT menor que 50 dias; e mineralização anormal quando o O.Th era maior que o limite superior da normalidade do valor de referência e o MLT maior que 50 dias. Para a análise do volume ósseo, considerou-se como referência de normalidade uma amostra composta por 125 brasileiros saudáveis comparados por década e sexo ${ }^{64}$.

\subsubsection{Osso cortical}

O osso cortical foi avaliado no aumento de 50x empregando-se o sistema de análise semi-automático e software OsteoMeasure ${ }^{\mathrm{TM}}$ (OsteoMetrics Inc., Decatur, GA, EUA). Os parâmetros da cortical avaliados foram a espessura cortical (Ct.Th, $\mu \mathrm{m})$ e a porosidade cortical (Ct.Po, \%), definida como a porcentagem da área da porosidade cortical pela área da cortical. Ambos parâmetros seguiram as denominações e as abreviaturas de acordo com aqueles propostos pela American Society for Bone and Mineral Research (ASBMR) ${ }^{65}$. A Ct.Th foi considerada baixa, normal ou elevada quando os valores eram menores que 520, entre 520 e 1650, e acima de $1650 \mu \mathrm{m}$, respectivamente. Já a Ct.Po foi classificada em baixa, normal ou alta quando os valores eram menor que $1,9 \%$, entre 1,9 e $10 \%$, e maior que $10 \%$, respectivamente ${ }^{68}$. 


\subsection{Avaliação das proteínas}

Avaliação óssea das proteínas foi realizada através de duas metodologias: imunohistoquimica em tecido ósseo não descalcificado e conteúdo proteico através do multiplex.

\subsubsection{Técnica de imunohistoquimica}

A técnica para realização da imunohistoquimica das proteínas ósseas foi adaptada de um método previamente descrito ${ }^{69}$. Resumidamente, os cortes histológicos de $5 \mu \mathrm{m}$ foram submetidos à remoção do metacrilato com uma mistura de 50\% de xilol e 50\% de clorofórmio por 30 minutos. Em seguida as amostras foram reidratadas com álcool em concentrações decrescentes $(100 \%, 96 \%, 70 \%$ e $50 \%)$ por 20 segundos cada, submetidas a semidescalcificação com ácido acético a $1 \%$ por 10 minutos e lavadas duas vezes com água destilada.

Após desplastificação e semi-descalcificação, foi realizado bloqueio da peroxidase endógena com uma solução de peróxido de hidrogênio 3\% em álcool metílico por 30 minutos. Em seguida, foi feito o bloqueio inespecífico de Avidina/Biotina (Vector, Burlingame, CA) por 15 minutos cada e com solução a base de caseína por 15 minutos (DakoCytomation Protein Block, DAKO Corporation, Carpinteria, EUA). Na etapa seguinte, os cortes foram incubados com o anticorpo primário específico para cada proteína estudada: anti-FGF-23 produzido em camundongo (Clone 50-1, gentilmente cedido por Genzyme Corporation, EUA), diluição 1:200; anti-OPG produzido em cabra (N-20, sc-8468, Santa Cruz, Dallas, EUA ), diluição 1:80; anti-RANKL produzido em cabra (C-20, sc-7627, Santa Cruz, Dallas, EUA), diluição 1:80; anti-esclerostina humana produzido em camundongo (MAB1406, R\&D Inc., Minneapolis, EUA), diluição 1:100; anti-beta catenina produzido em coelho (ab6302, Abcam, Cambridge, Reino Unido), diluição 1:100; e anti-beta-catenina fosforilada (Phospho S37, ab47335, Abcam, 
Cambridge, Reino Unido), diluição 1:100. Todos anticorpos foram incubados em câmara úmida a $4^{\circ} \mathrm{C}$, por período determinado previamente.

O método de imunoperoxidase foi empregado utilizando-se o Complexo Avidina/Biotina (Vectastain ABC Kit, Vector, Burlingame, CA), de acordo com as instruções de uso do fabricante. O substrato cromogênico utilizado para visualização da reação foi 3 amino-9 ethyl-carbazol - AEC (Sigma Chemical Co, St. Louis, EUA) acompanhadas ao microscópio e, em seguida, interrompidas com fosfato tamponado (PBS). Os cortes foram contracorados com Hemalumbre de Mayer por cerca de 1 minuto e as lâminas montadas com glicergel (Merck, Hohenbrunn, Alemanha) e analisadas em microscópio óptico. Controles negativos simultâneos foram realizados em cada experimento, omitindo-se o anticorpo primário.

A expressão da esclerostina, FGF-23, OPG, beta-catenina total e fosforilada e RANKL foi analisada em microscópio Nikon Eclipse 50i aumento de 400x. Para quantificar a expressão dessas proteínas, avaliamos os osteócitos corados em relação aos osteócitos totais no tecido trabecular, sendo os valores expressos em porcentagem ${ }^{62,70}$.

\subsubsection{Técnica de quantificação de conteúdo proteico - multiplex}

Nos lisatos proteicos obtidos dos fragmentos de biópsias ósseas dos pacientes e de 12 amostras de indivíduos normais, foram determinados os níveis proteicos da Esclerostina, OPG, RANKL, DKK-1 e FGF-23, através de kits Milliplex® MAP (multi-analyte panels - Human Bone Magnetic Bead Panel - HBNMAG-51K, EMD Millipore Corporation, Darmstadt, Alemanha), baseado na tecnologia Luminex ${ }^{\mathrm{TM}}$ xMAP, de acordo com as instruções do fabricante.

O princípio dessa tecnologia utiliza microesferas impregnadas com dois diferentes tipos de corantes fluorescentes que permite a obtenção de diferentes tipos de combinação de cores. 
Essas microesferas são também conjugadas com anticorpos específicos. Uma vez adicionandose as amostras de interesse na reação, os anticorpos específicos "capturam" seus respectivos antígenos, permitindo, inclusive, que vários possam ser detectados ao mesmo tempo. Em seguida, anticorpos específicos conjugados com biotina são adicionados na reação. Esses irão também “capturar" seus respectivos antígenos de interesse, formando então um sistema de captura "sanduiche" (anticorpo-antígeno-anticorpo). Após essa etapa, adiciona-se estreptavidina conjugada com ficoeritrina (PE) que irá ligar-se ao anticorpo conjugado com a biotina. Uma vez formado esse imuno-complexo, a reação está pronta para ser lida num sistema de detecção (Luminex 200M, Luminex Inc., Austin, EUA) das microesferas, identificando o anticorpo-antígeno à ela associado e a magnitude do sinal obtido pela estreptavidina - PE, que é diretamente proporcional à quantidade dos antígenos de interesse detectados.

Como ainda não há um padrão de normalidade para a quantificação dessas proteínas no tecido ósseo usamos o grupo controle para comparação.

\subsection{Expressão gênica}

A concentração do RNA total foi determinada por meio da leitura em 260 nm, e o grau de pureza pelas relações 260/280 nm (contaminação com proteína) e 260/230 nm (contaminação com compostos fenólicos) no espectrofotômetro Nano Drop 1000 (Thermo Scientific). As amostras com pureza satisfatórias foram as que obtiveram razões 260/280 próximas de 2,0 e 260/230 entre 1,8 e 2,2. A partir do RNA total extraído, foram sintetizados o cDNA pelo método da transcriptase reversa (Improm-II Reverse Transcriptase, Promega Corporation, Madison, USA) utilizando o termociclador (DNA Engine, MJ Research, Massachusetts, USA), o qual posteriormente foi utilizado para quantificar a expressão gênica por meio do PCR quantitativo. 
A expressão gênica foi determinada por meio de PCR quantitativo a partir do cDNA utilizando o método de SYBR Green (Rotor Gene SYBR Green PCR kit, Qiagen, Hilden, Alemanha) e o termociclador Rotor-Gene Q, (Qiagen, Hilden, Alemanha). Os genes analisados foram SOST (ACC\# AF_331844.1), RANKL (ACC \# NM_003701.3), OPG (ACC\# U94332), beta-catenina (ACC\# X_87838.1), FGF-23 (ACC\# NM_020638.2) e o gene normalizador GAPDH (Proteína gliceraldeído-3-fosfato desidrogenase - ACC\# NM_002046.4) através dos seus respectivos primers (Tabela 1), os quais foram desenhados pelo programa da IDT (Integrated DNA Technologies). A análise dos resultados foi realizada de forma relativa, com a comparação entre dois grupos, controle e experimental. Para isso, o grupo controle foi constituído de amostras de 12 indivíduos saudáveis com função renal normal e também serviu como referência para as curvas dos ensaios. Os resultados da expressão gênica foram analisados pelo programa REST 2009 (Relative Expression Software Tool).

Tabela 1 - Sequência dos primers e tamanhos dos amplicons dos genes SOST, Beta-catenina, OPG, RANKL, FGF-23 e GAPDH.

\begin{tabular}{|c|c|c|}
\hline Gene & Sequência $5^{\prime}-3^{\prime}$ & $\begin{array}{l}\text { Tamanho do } \\
\text { amplicon }\end{array}$ \\
\hline SOST (sense) & GGGCAACTGTAGATGTGGTT & \multirow{2}{*}{84} \\
\hline SOST (antisense) & GTCCCGAAGGAGAATTGTGTAG & \\
\hline Beta-Catenina (sense) & CTTCACCTGACAGATCCAAGTC & \multirow[b]{2}{*}{98} \\
\hline $\begin{array}{c}\text { Beta-Catenina } \\
\text { (antisense) }\end{array}$ & ССТТССАТСССТТССТGTTTAG & \\
\hline OPG (sense) & GATGTCCAGATGGGTTCTTCTC & \multirow{2}{*}{95} \\
\hline OPG (antisense) & CTGAGTTAGCAGGAGACCAAAG & \\
\hline RANKL (sense) & CCCAAGTTCTCATACCCTGATG & \multirow{2}{*}{118} \\
\hline RANKL (antisense) & TTCCTCTCCAGACCGTAACT & \\
\hline FGF-23 (sense) & ACCACATGGTCAGGCTCTTG & \multirow{2}{*}{111} \\
\hline FGF-23 (antisense) & TCCAAGGGGATTGAGACCCA & \\
\hline GAPDH (sense) & CAAGAGCACAAGAGGAAGAGAG & \multirow{2}{*}{102} \\
\hline GAPDH (antisense) & CTACATGGCAACTGTGAGGAG & \\
\hline
\end{tabular}

SOST esclerostina; OPG osteoprotegerina; RANKL ligante do receptor ativador do fator nuclear Kappa-B; FGF-23 Fator de crescimento do Fibroblasto 23, GAPDH Proteína gliceraldeído-3-fosfato desidrogenase. 


\subsection{Análise estatística}

Os dados descritivos foram expressos como médias e desvios-padrão ou medianas e intervalo 25-75\%, para variáveis com distribuição paramétrica e não paramétrica, respectivamente. A distribuição normal foi avaliada pelo teste de D’Agostino-Pearson. Variáveis categóricas foram analisadas por qui-quadrado.

Para comparação das médias das variáveis contínuas de distribuição paramétrica intra e entre os grupos foi aplicado o teste t de Student, pareado e não pareado, respectivamente. Os testes de Wilcoxon e Mann-Whitney U foram usados para determinar a significância entre variáveis não paramétricas.

Foi utilizado o GLM, para avaliar o efeito do tratamento (ácido zoledrônico ou placebo) e do transplante renal (pré e pós), assim como a interação entre esses fatores.

Foi utilizado o coeficiente de correlação de Pearson ou de Spearman para avaliar a associação entre as variáveis contínuas de acordo com a distribuição paramétrica e não paramétrica, respectivamente.

Significância estatística foi assumida para resultados de $\mathrm{p}<0,05$.

A análise estatística foi realizada no software SPSS for Windows versão 17.0. 
4. Resultados 


\section{RESULTADOS}

Conforme demonstrado na Figura 1, durante o período de inclusão, foram realizados 64 transplantes em pacientes com doador vivo no HC - FMUSP. Destes, 34 eram elegíveis para o estudo e foram incluídos na randomização. Nenhum paciente recusou a participação. Dos 17 pacientes incluídos no grupo intervenção, um foi excluído por ter perdido o enxerto precocemente ( $<7$ dias), devido a uma trombose venosa, e uma paciente não realizou a biópsia de controle por dificuldade técnica. No grupo placebo uma paciente foi excluída por ter seu transplante suspenso.

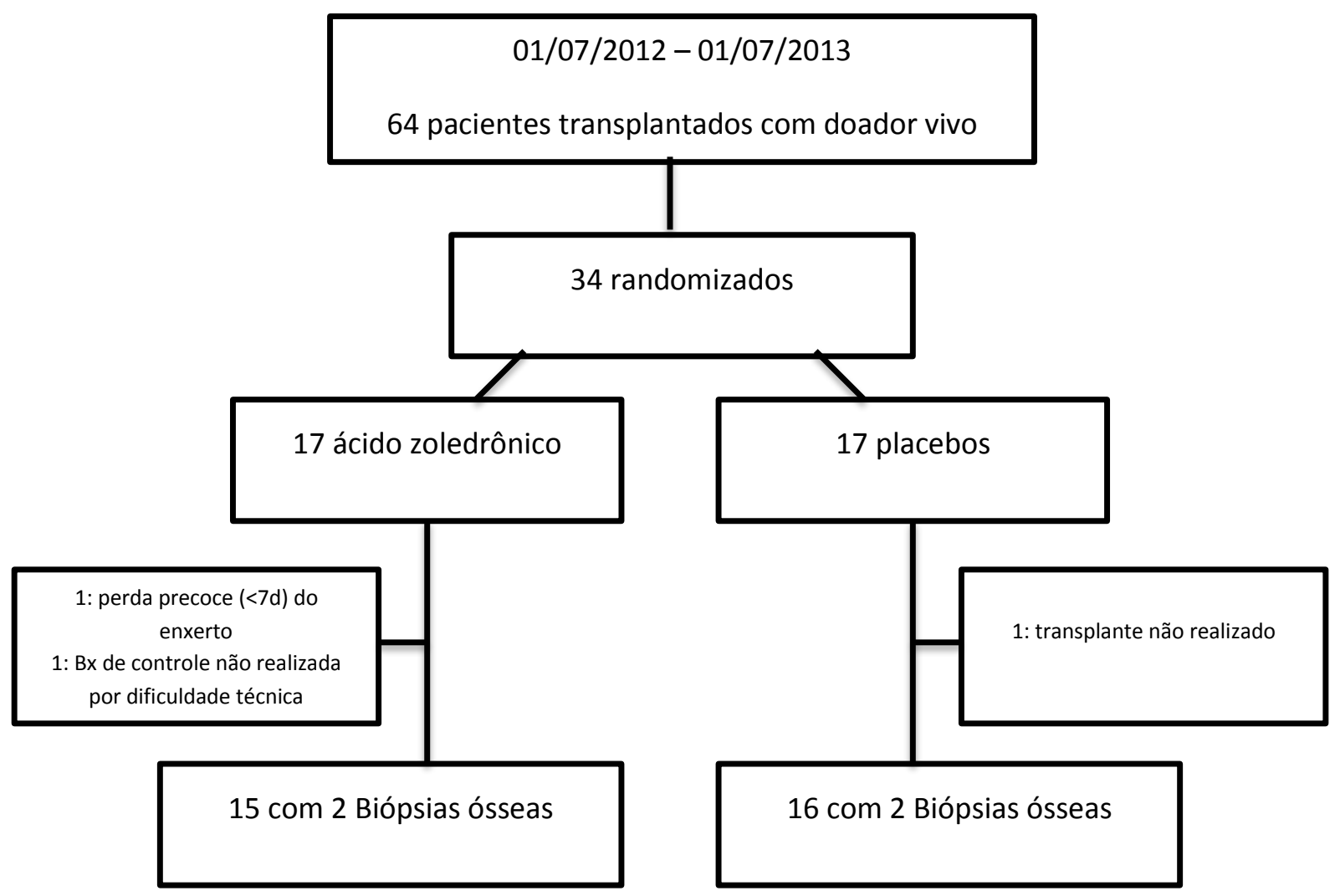

Figura 1 - Randomização dos pacientes. 


\subsection{Características clínicas e laboratoriais basais}

A maioria dos pacientes era jovem, com idade média de $42 \pm 11$ anos, e com um tempo em diálise de 27 (14 - 49) meses, sendo que 15 (48\%) estavam em diálise há menos de 2 anos. Vinte e sete (87\%) pacientes estavam em hemodiálise, $3(10 \%)$ em diálise peritoneal e uma paciente foi transplantada preemptivamente. A principal causa de DRC foi glomerulonefrite crônica, em 58\% dos pacientes. Dezenove (61\%) eram homens e 23 (74\%) da raça branca.

Com relação aos achados bioquímicos, hipocalcemia estava presente em 7 (23\%) dos pacientes, $3(10 \%)$ apresentavam hipercalcemia e quase todos os pacientes, 29 (93\%), tinham hiperfosfatemia. Três $(10 \%)$ pacientes apresentavam PTH baixo $(<130 \mathrm{pg} / \mathrm{ml}$, ou 2 vezes o limite superior do valor de referência, de acordo com as recomendações do KDIGO), estes pacientes apresentavam valores prévios de PTH ( $<3$ meses) acima de $130 \mathrm{pg} / \mathrm{ml}$, e por isso foram incluídos no estudo. Sete pacientes (23\%) apresentavam valores de PTH acima de 585 $\mathrm{pg} / \mathrm{ml}$ (ou 9 vezes o limite superior do valor de referência, de acordo com as recomendações do KDIGO). Porém, se considerarmos o valor de 300 pg/ml de PTH, 19 (61\%) estavam acima desse corte. Três pacientes (10\%) apresentavam deficiência de 25-vitamina $\mathrm{D}(<15 \mathrm{ng} / \mathrm{ml}), 19$ $(61 \%)$ insuficiência $(15-30 \mathrm{ng} / \mathrm{ml})$ e $9(28 \%)$ suficiência (> $30 \mathrm{ng} / \mathrm{ml})$. Esclerostina, fração óssea da fosfatase alcalina e TRAP5b estavam elevadas. Os parâmetros clínicos e laboratoriais estão detalhados na Tabela 2.

A maior parte dos pacientes, 23 (74\%), recebeu basiliximab como terapia de indução, os outros $8(16 \%)$ receberam ATG. Todos receberam a mesma imunossupressão de manutenção, composta por tacrolimus, micofenolato sódico e prednisona. 
Tabela 2 - Características clínicas e parâmetros laboratoriais dos pacientes no pré-transplante renal.

\begin{tabular}{|c|c|c|}
\hline Característica & Pré-transplante & Valores de referência \\
\hline Sexo masculino & $19(61)$ & \\
\hline \multicolumn{3}{|l|}{ Raça } \\
\hline Branco & $22(71)$ & \\
\hline Pardo & $6(19)$ & \\
\hline Negro & $3(10)$ & \\
\hline Idade (anos) & $39(30-51)$ & \\
\hline Tempo em diálise (meses) & $32(15-56)$ & \\
\hline \multicolumn{3}{|l|}{ Tipo de diálise } \\
\hline Hemodiálise & $27(87)$ & \\
\hline Diálise peritoneal & $3(10)$ & \\
\hline Sem diálise & $1(3)$ & \\
\hline $\begin{array}{l}\text { Causa da doença renal crônica } \\
\text { Glomerulonefrite } \\
\text { Nefroesclerose hipertensiva } \\
\text { Nefropatia diabética } \\
\text { Doença renal policística } \\
\text { Outras } \\
\text { Indeterminada }\end{array}$ & $\begin{array}{l}17(56) \\
4(13) \\
2(6) \\
1(3) \\
2(6) \\
5(16)\end{array}$ & \\
\hline Índice de massa corpórea $\left(\mathrm{kg} / \mathrm{m}^{2}\right)$ & $23,8(20,1-25,9)$ & \\
\hline Cálcio sérico (mg/dl) & $9,1(8,7-9,6)$ & $8,6-10,2$ \\
\hline Fósforo sérico (mg/dl) & $7,2(6,1-8,4)$ & $2,7-4,5$ \\
\hline Fosfatase alcalina (UI/L) & $155(85-192)$ & $35-104$ \\
\hline PTH (pg/ml) & $370(207-530)$ & $35-65$ \\
\hline 25-Hidroxivitamina D (ng/ml) & $26(18-34)$ & $30-100$ \\
\hline Esclerostina (ng/ml) & $1,12(0,63-1,83)$ & $0,2-0,6$ \\
\hline Fosfatase alcalina óssea (UI/L) & $90(34-127)$ & $\mathrm{H}: 15-41,3 ; \mathrm{M}: 11,6-29,6$ \\
\hline TRAP5b (UI/L) & $9,18(6,71-12,75)$ & $\mathrm{H}: 4,0 \pm 1,4 ; \mathrm{M}: 2,9 \pm 1,4$ \\
\hline RANKL (pg/ml) & $4,98(2,96-9,80)$ & - \\
\hline OPG (pg/ml) & $1797(1289-2424)$ & $492 \pm 276$ \\
\hline RANKL/OPG & $0,004(0,002-0,006)$ & - \\
\hline FGF-23 (pg/ml) & $899(221-2625)$ & $8,2-54,3$ \\
\hline
\end{tabular}


PTH paratormônio; $\mathrm{H}$ homem; $\mathrm{M}$ mulher; TRAP5b fosfatase ácida resistente ao tártaro; RANKL Ligante do receptor ativador do fator nuclear Kappa-B; OPG Osteoprotegerina; FGF23 Fator de crescimento do Fibroblasto 23.

Os dados estão expressos em forma de (n; \%) ou mediana e intervalo $25-75 \%$.

\subsection{Densidade mineral óssea}

A maioria dos pacientes tinha densidade mineral óssea avaliada por DXA dentro da faixa de normalidade ou de osteopenia. Osteoporose (escore $\mathrm{T} \leq 2,5$ ) na coluna lombar ou fêmur total foi encontrada em 8 (26\%) pacientes, sendo 1 nos dois, 5 na coluna lombar e 2 no fêmur total, conforme descrito na Tabela 3.

Tabela 3 - Avaliação da DMO por DXA no pré-transplante renal.

\begin{tabular}{cccc}
\hline $\begin{array}{c}\text { DMO } \\
\left(\mathrm{g} / \mathrm{cm}^{2}\right)\end{array}$ & $\begin{array}{c}\text { Normal } \\
(\mathrm{T}>-1 \mathrm{DP})\end{array}$ & $\begin{array}{c}\text { Osteopenia } \\
(-2,5<\mathrm{T}<-1 \mathrm{DP})\end{array}$ & $\begin{array}{c}\text { Osteoporose } \\
(\mathrm{T}<-2,5 \mathrm{DP})\end{array}$ \\
\hline
\end{tabular}

Homens

$\begin{array}{ccccc}\text { Coluna lombar } & 0,96 \pm 0,15 & 6 & 8 & 4 \\ \text { Fêmur total } & 0,89 \pm 0,11 & 8 & 10 & 0 \\ \text { Mulheres } & & & 5 & 2 \\ \text { Coluna lombar } & 0,87 \pm 0,12 & 5 & 5 & 3 \\ \text { Fêmur total } & 0,76 \pm 0,15 & 4 & 0\end{array}$

DMO densidade mineral óssea; DXA absortometria de raio-x de dupla energia; DP desvio padrão.

Os dados estão expressos em forma de média \pm desvio-padrão.

Os escores $\mathrm{T}$ basais estão expressos em desvios-padrão abaixo da média de um indivíduo saudável de 30 anos de idade, do mesmo sexo.

\subsection{Biópsias basais}

Os resultados de histomorfometria óssea encontram-se descritos na Tabela 4. Baixa remodelação estava presente em 10 pacientes (32\%) e alta remodelação em 20 pacientes (65\%). Baixo volume ósseo foi encontrado em 4 pacientes (13\%). Em 22 pacientes (71\%), o volume ósseo estava dentro da faixa de normalidade e em 5 (16\%), acima das médias para indivíduos 
da mesma idade e sexo, como descrito anteriormente. Com relação à mineralização, ela estava anormal em 20 pacientes (65\%). Uma paciente não conseguiu realizar a marcação por tetraciclina, e por isso não tem a classificação de remodelação e mineralização. A distribuição do sistema TMV está ilustrada na Figura 2.

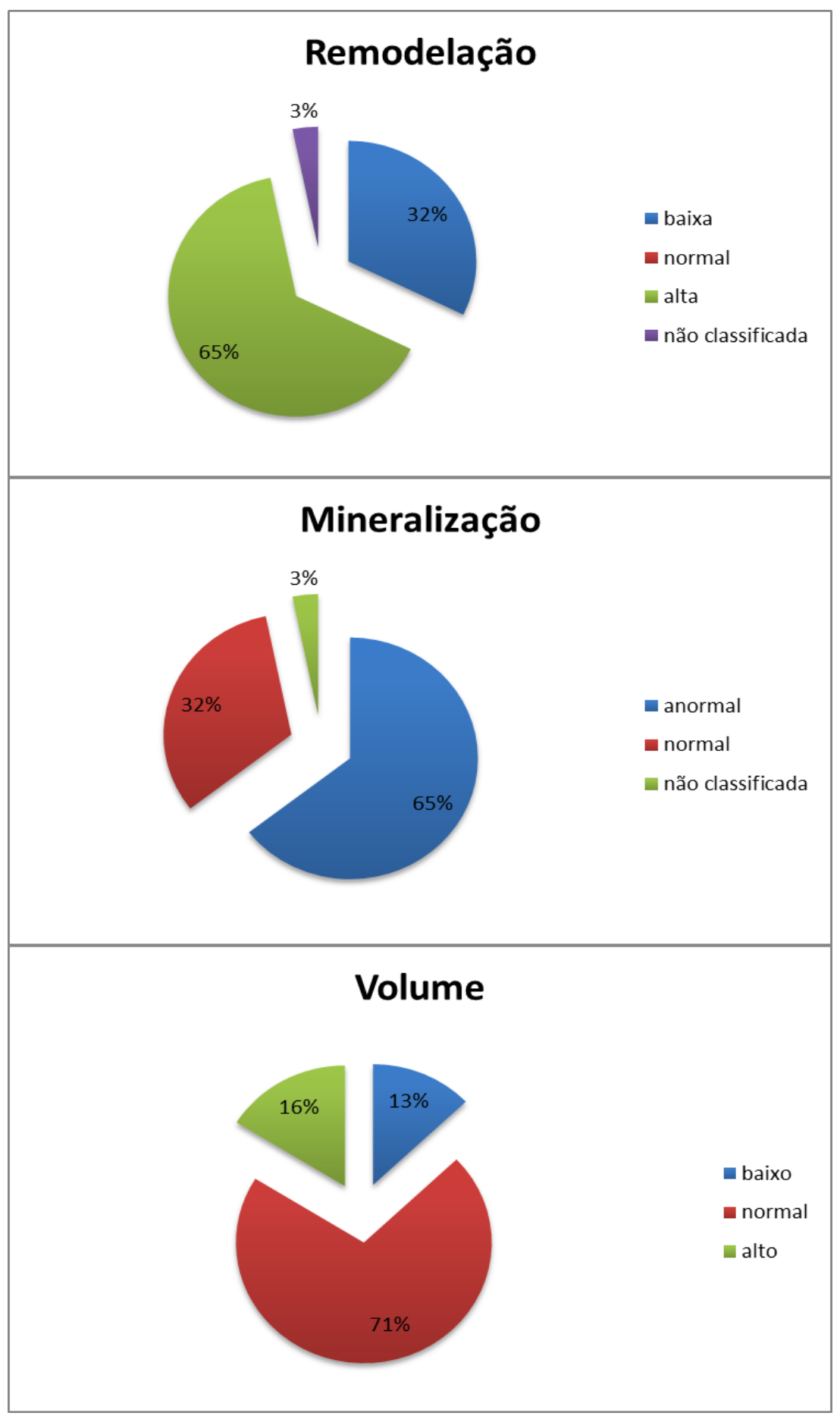

Figura 2 - Distribuição da classificação das biópsias ósseas do pré-transplante renal de acordo com o sistema TMV (remodelação, mineralização e volume) 
Tabela 4. - Parâmetros estáticos e dinâmicos da histomorfometria do pré-transplante renal.

\begin{tabular}{|c|c|c|c|}
\hline \multirow{2}{*}{ Parâmetro } & \multirow[t]{2}{*}{ Pré-transplante } & \multicolumn{2}{|c|}{ Valor de referência } \\
\hline & & Homem & Mulher \\
\hline \multicolumn{4}{|l|}{ Estáticos } \\
\hline BV/TV (\%) & $23,1(20,9-27,6)$ & $21,8 \pm 7,2$ & $24 \pm 6,1$ \\
\hline Tb.Sp $(\mu \mathrm{m})$ & $362(291-474)$ & $420,6 \pm 124,1$ & $498,3 \pm 195,9$ \\
\hline Tb.N (/mm) & $2,03(1,65-2,37)$ & $1,89 \pm 0,42$ & $1,76 \pm 0,52$ \\
\hline Tb.Th $(\mu \mathrm{m})$ & $121,2(110-138,8)$ & $127,9 \pm 29,7$ & $126 \pm 28,8$ \\
\hline OV/BV (\%) & $6,59(2,2-11,27)$ & $2,9 \pm 2,7$ & $1,55 \pm 1,9$ \\
\hline OS/BS (\%) & $40,3(20,3-49,5)$ & $9,2 \pm 8,4$ & $16,1 \pm 12,6$ \\
\hline O.Th $(\mu \mathrm{m})$ & $9,65(5,98-12,64)$ & $11,7 \pm 3,5$ & $10,8 \pm 3,2$ \\
\hline Ob.S/BS (\%) & $7,22(4,98-15,69)$ & $1,2 \pm 1,4$ & $1,2 \pm 3,2$ \\
\hline ES/BS (\%) & $10,8(7,5-15,6)$ & $1,75 \pm 1,21$ & $2,3 \pm 2,4$ \\
\hline Oc.S/BS (\%) & $1,33(0,56-2,89)$ & $0,03 \pm 0,11$ & $0,03 \pm 0,06$ \\
\hline $\mathrm{Fb} . \mathrm{V} / \mathrm{TV}(\%)$ & $0,22(0,01-1,60)$ & 0 & 0 \\
\hline Ct.Po (\%) & $7,1(5,6-8,8)$ & $1,9-10$ & $1,9-10$ \\
\hline Ct.Th $(\mu \mathrm{m})$ & $756(572-904)$ & $520-1.650$ & $520-1.650$ \\
\hline \multicolumn{4}{|l|}{ Dinâmicos } \\
\hline MS/BS (\%) & $6,4(3,9-9,9)$ & $18,3 \pm 7,5$ & $11,5 \pm 4,5$ \\
\hline $\operatorname{MAR}(\mu \mathrm{m} / \mathrm{dia})$ & $1,03(0,76-1,35)$ & $\begin{array}{c}1,4(1,03- \\
2,25)\end{array}$ & 0,931 \\
\hline $\begin{array}{c}\text { BFR/BS } \\
\left(\mu \mathrm{m}^{3} / \mu \mathrm{m}^{2} / \text { dia }\right)\end{array}$ & $\begin{array}{c}0,037(0,007- \\
0,102)\end{array}$ & $0,13 \pm 0,07$ & $0,07 \pm 0,03$ \\
\hline Mlt (dias) & $71,6(40-415,8)$ & $21,3 \pm 2,3$ & $23,7 \pm 2,7$ \\
\hline
\end{tabular}

$\mathrm{BV} / \mathrm{TV}$ volume trabecular; Tb.Sp separação trabecular; Tb.N número trabecular; Tb.Th espessura trabecular; OV/BV volume osteóide; OS/BS superfície osteóide; O.Th espessura osteóide; Ob.S/BS superfície osteoblástica; ES/BS superfície de reabsorção; Oc.S/BS superfície osteoclástica; $\mathrm{Fb} . \mathrm{V} / \mathrm{TV}$ fibrose medular; $\mathrm{Ct}$.Po porosidade cortical; $\mathrm{Ct}$.Th espessura cortical; MS/BS superfície mineralizante; MAR taxa de aposição mineral; BFR/BS taxa de formação óssea; Mlt tempo de mineralização.

Os dados estão expressos em forma de mediana e intervalo $25-75 \%$. 


\subsection{Avaliação proteica basal}

\subsubsection{Imunohistoquimica}

A esclerostina estava expressa em grande quantidade e difusamente pelo tecido ósseo, e mais intensamente na região cortical. Na região trabecular, estava mais presente nos osteócitos centrais e mais maduros. O FGF-23 também apresentou distribuição difusa, mas bem menos intensa que a esclerostina na região cortical, e mais presente nos osteócitos periféricos da região trabecular. A expressão da beta-catenina total e da fosforilada era fraca na região cortical, distribuindo-se na parte mais central das traves ósseas e de maneira menos intensa que o FGF-23. OPG e RANKL foram encontrados principalmente na periferia das traves e nos corpos celulares de osteócitos (Figuras 3-8). O número de osteócitos marcados para cada uma destas proteínas encontra-se descrito na Tabela 5. 


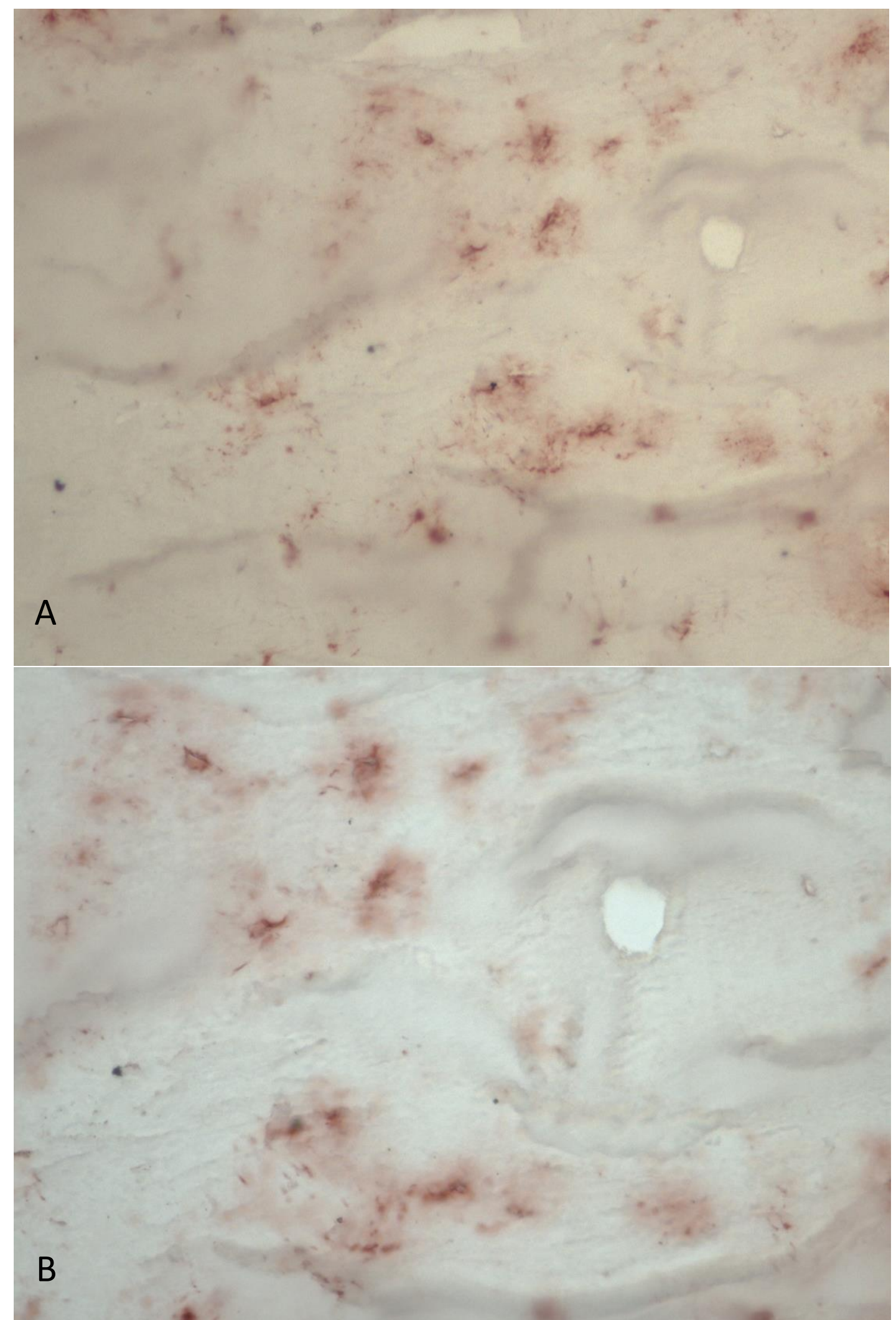

Figura 3 - Padrão da expressão proteica da esclerostina no osso cortical na imunohistoquimica em biópsias do pré-transplante renal.

A: Aumento de 200x; B: Aumento de 400x. 


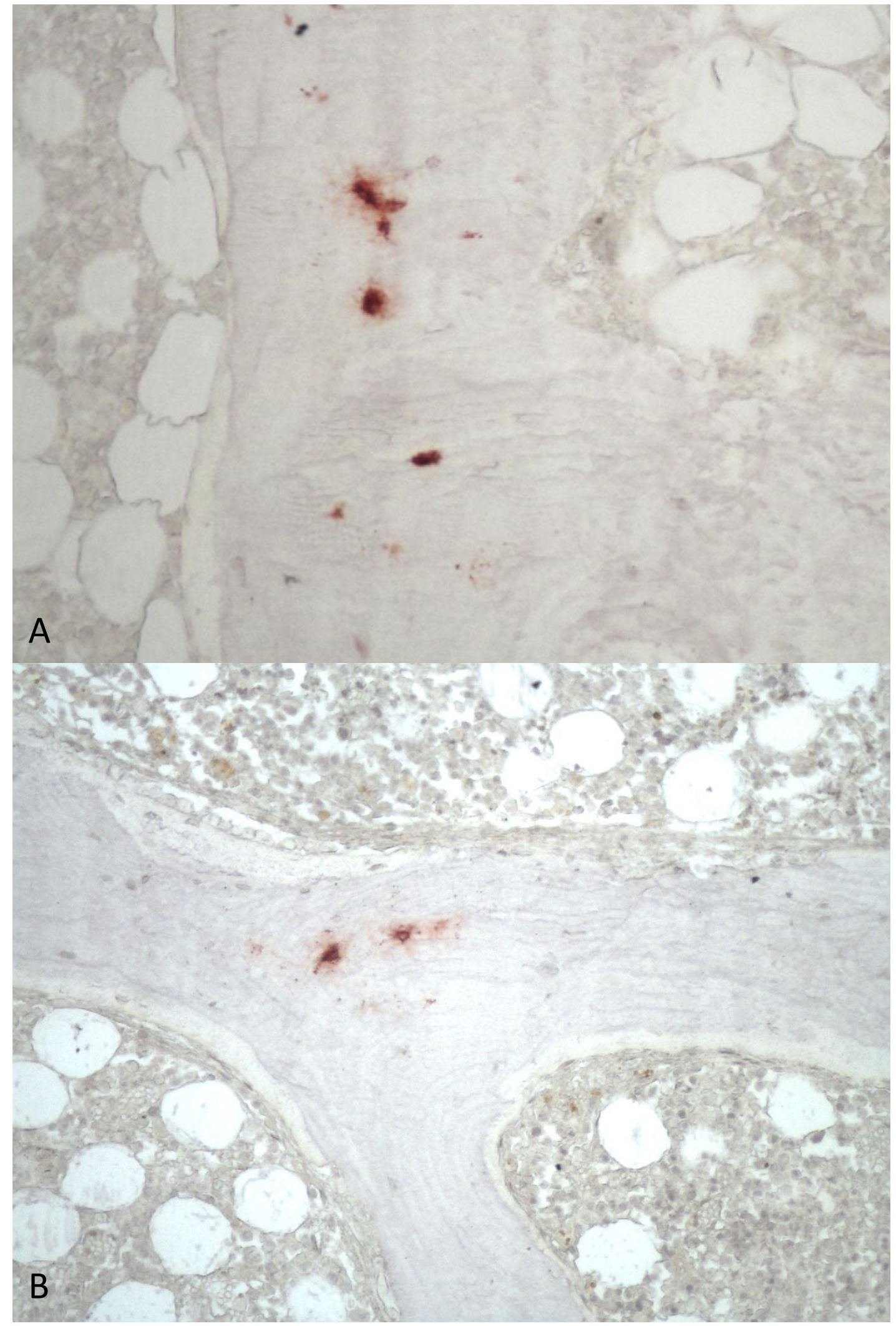

Figura 4 - Padrão da expressão proteica da esclerostina no osso trabecular na imunohistoquimica em biópsias do pré-transplante renal. A: Aumento de 200x; B: Aumento de 200x. 


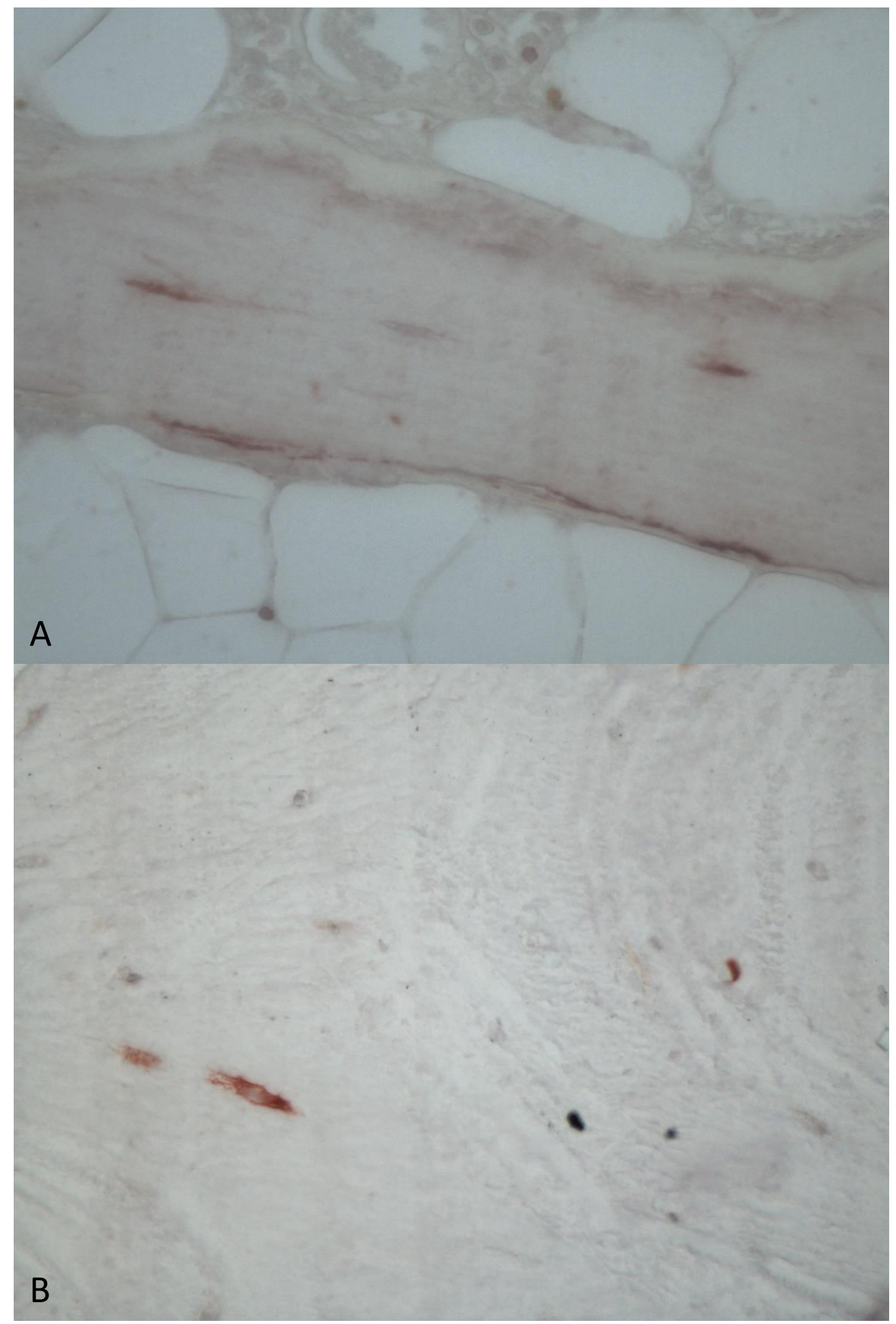

Figura 5 - Padrão da expressão proteica da beta-catenina no osso trabecular na imunohistoquimica em biópsias do pré-transplante renal. A: Aumento de 200x; B: Aumento de 400x. 


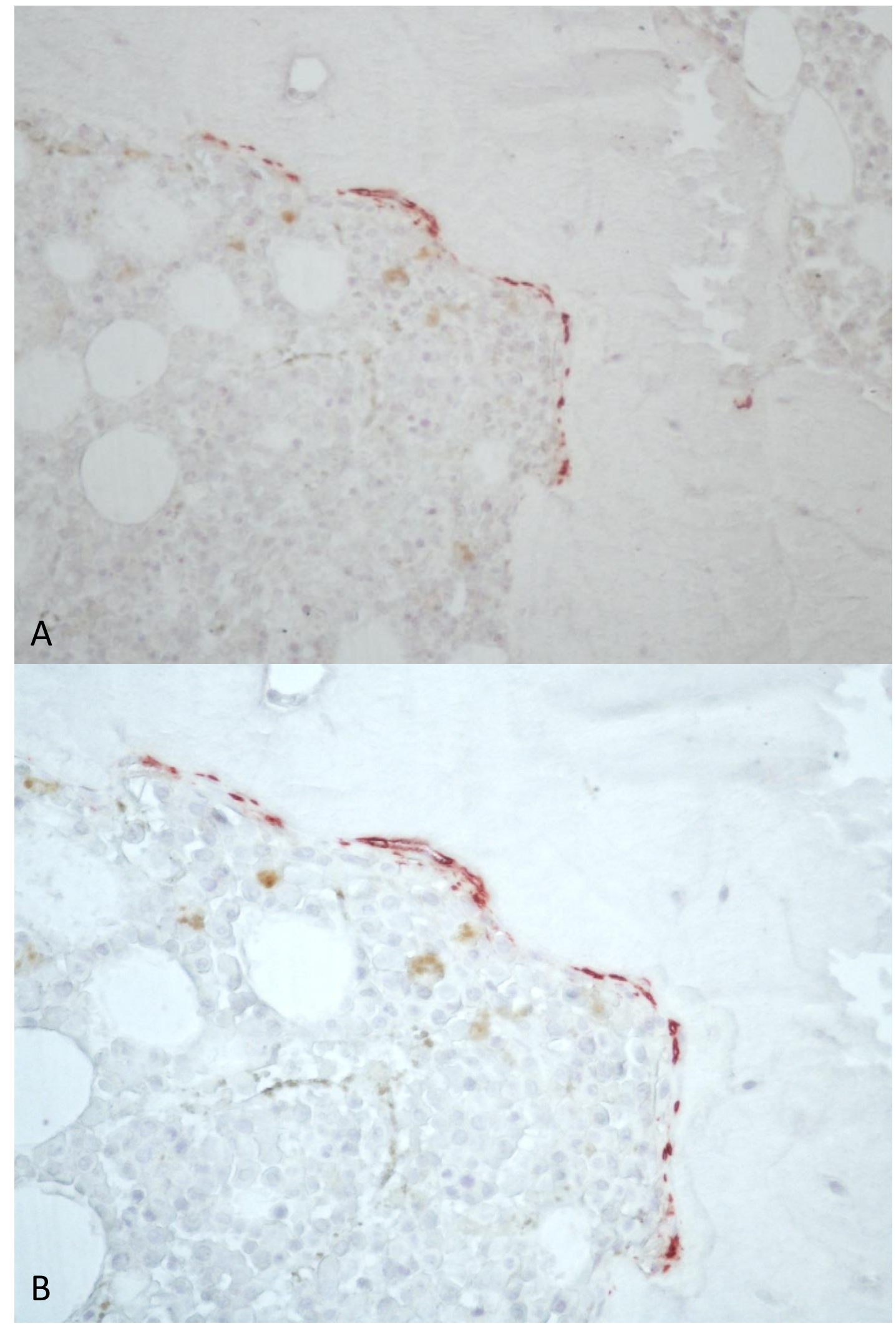

Figura 6 - Padrão da expressão proteica do RANKL no osso trabecular na imunohistoquimica em biópsias do pré-transplante renal.

A: Aumento de 200x; B: Aumento de 400x. 


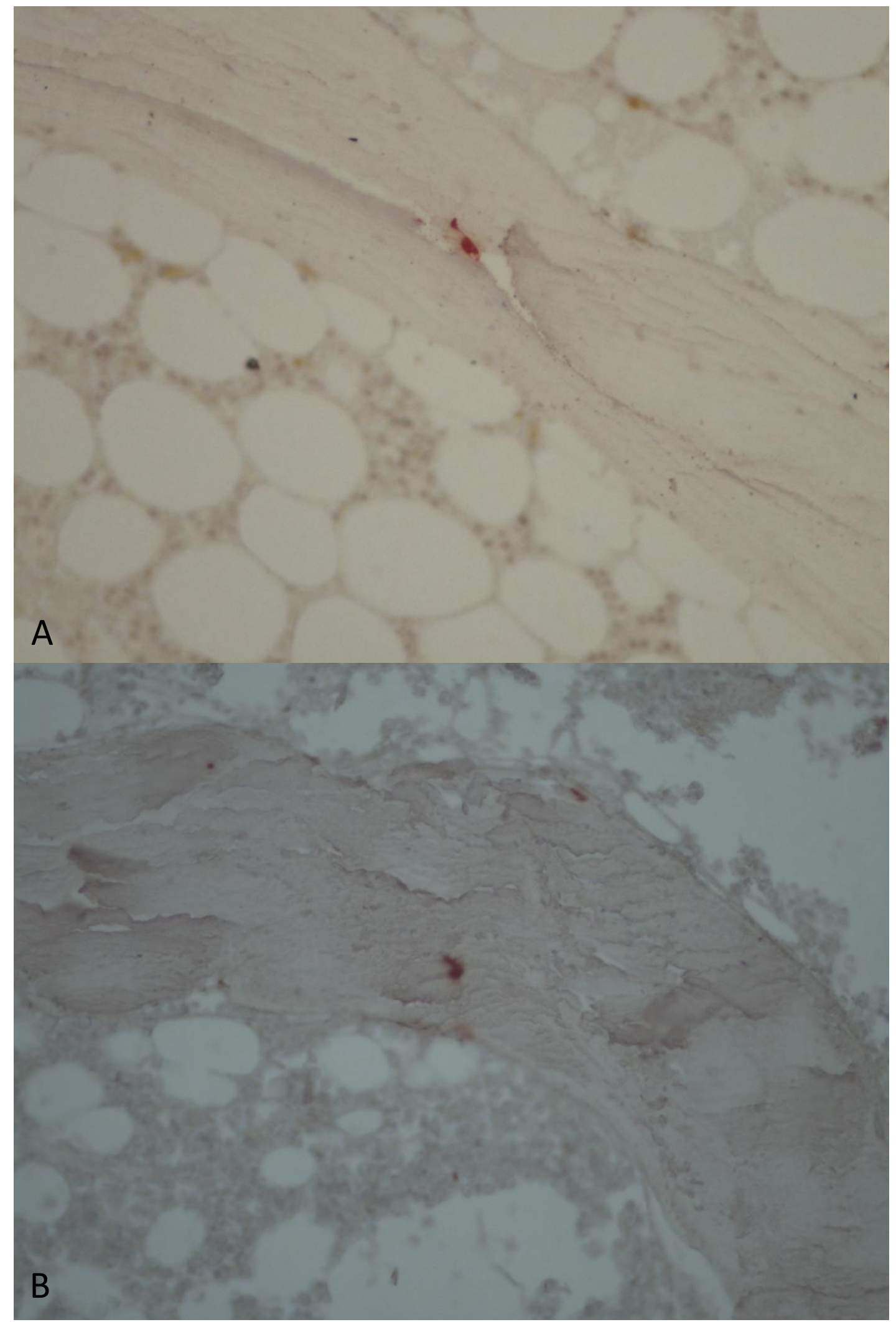

Figura 7 - Padrão da expressão proteica do OPG no osso trabecular na imunohistoquimica em biópsias do pré-transplante renal.

A: Aumento de 200x; B: Aumento de 400x. 


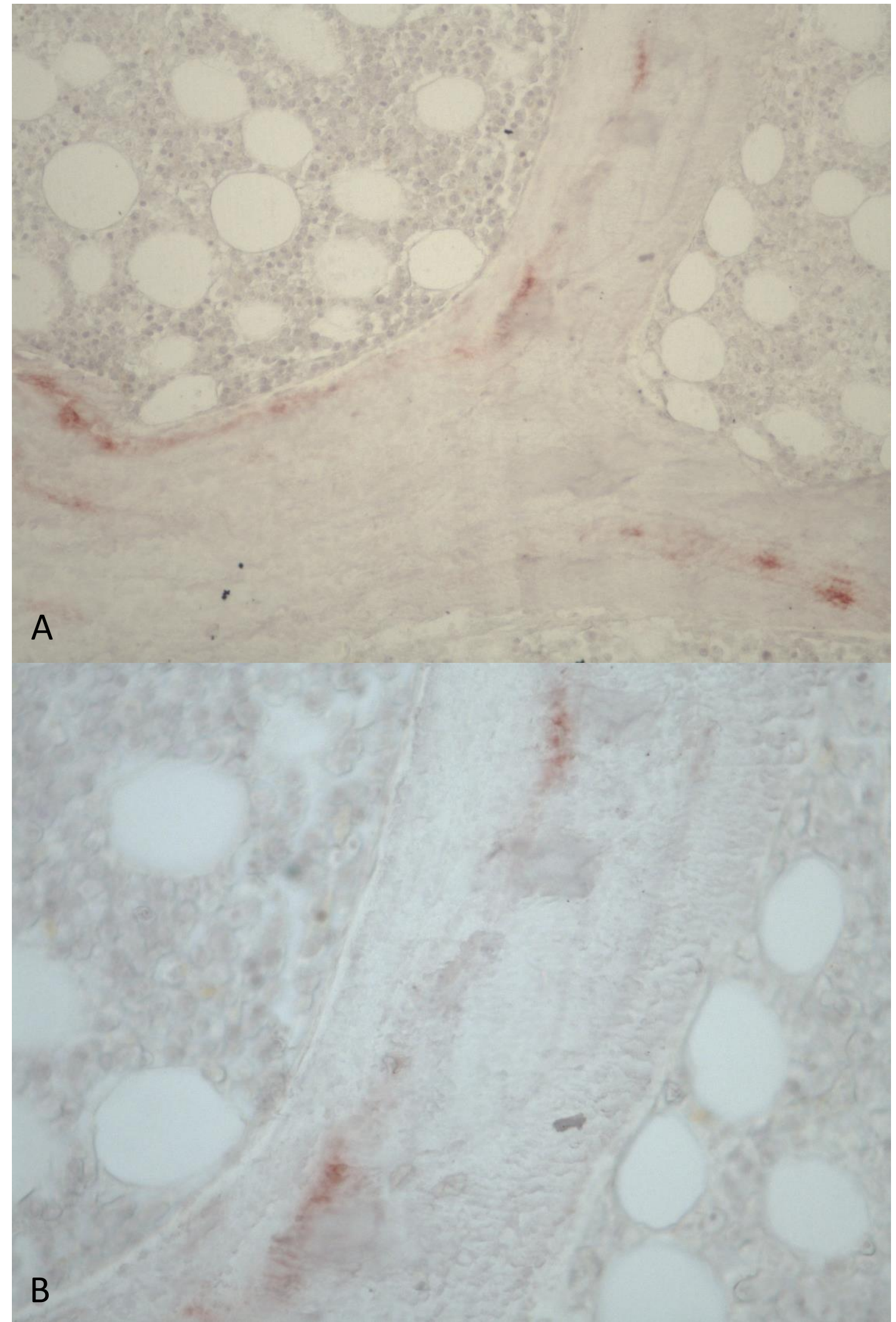

Figura 8 - Padrão da expressão proteica do FGF-23 no osso trabecular na imunohistoquimica em biópsias do pré-transplante renal.

A: Aumento de 200x; B: Aumento de 400x. 
Tabela 5 - Osteócitos marcados, osteócitos totais e expressão na imunohistoquimica nas biópsias do pré-transplante renal.

\begin{tabular}{cccc}
\hline Proteína & $\begin{array}{c}\text { Osteócitos } \\
\text { marcados }\end{array}$ & $\begin{array}{c}\text { Osteócitos } \\
\text { totais }\end{array}$ & $\begin{array}{c}\text { \% Osteócitos } \\
\text { marcados/totais }\end{array}$ \\
\hline $\begin{array}{c}\text { Esclerostina } \\
\text { Beta-catenina total }\end{array}$ & $27(11-56)$ & $656(285-862)$ & $5,6(1,8-14,2)$ \\
$\begin{array}{c}\text { Beta-catenina } \\
\text { fosforilada }\end{array}$ & $23(6-40)$ & $656(285-862)$ & $3,6(1,3-6,5)$ \\
RANKL & $4(1-12)$ & $656(285-862)$ & $0,76(0,21-1,42)$ \\
OPG & $6(4-8)$ & $656(285-862)$ & $1,33(0,64-1,89)$ \\
FGF-23 & $37(7-125)$ & $656(285-862)$ & $7,8(1,8-24)$
\end{tabular}

RANKL ligante do receptor ativador do fator nuclear Kappa-B; OPG osteoprotegerina; FGF23 Fator de crescimento do Fibroblasto 23.

Os dados estão expressos em forma de mediana e intervalo $25-75 \%$.

\subsubsection{Conteúdo proteico por multiplex}

O conteúdo proteico avaliado pela técnica de multiplex mostrou aumento da concentração óssea de esclerostina, de RANKL e de FGF-23 em relação ao grupo controle. A A relação RANKL/OPG também estava aumentada em relação aos controles. Não foram detectadas diferenças para DKK1 e OPG entre os dois grupos, conforme discriminado na Tabela 6. 
Tabela 6 - Conteúdo protéico por multiplex nas biópsias do grupo controle e do pré-transplante renal.

\begin{tabular}{cccc}
\hline $\begin{array}{c}\text { Proteína } \\
\mathbf{p g} / \mathbf{m g}\end{array}$ & $\begin{array}{c}\text { Grupo controle } \\
(\mathbf{n = 1 2})\end{array}$ & $\begin{array}{c}\text { Pré-transplante } \\
(\mathbf{n = 3 1})\end{array}$ & $\mathbf{p}$ \\
\hline Esclerostina & $215(95-483)$ & $544(382-945)$ & 0,0024 \\
DKK1 & $1,58(1,13-2,12)$ & $2,94(2,23-3,81)$ & 0,2103 \\
RANKL & $0,78(0,37-1,25)$ & $4,55(3,41-7,29)$ & $<0,0001$ \\
OPG & $0,40(0,19-0,75)$ & $0,62(0,44-0,76)$ & 0,3643 \\
RANKL/OPG* & $1,09(0,15-2,24)$ & $6,65(3,16-13,82)$ & $<0,0001$ \\
FGF-23 & $2,83(2,18-5,56)$ & $6,32(4,29-12,96)$ & $<0,0001$
\end{tabular}

DKK1 Dickkopf-related protein 1; RANKL Ligante do receptor ativador do fator nuclear Kappa-B; OPG Osteoprotegerina; FGF-23 Fator de crescimento do Fibroblasto 23.

* sem unidade

Os dados estão expressos em forma de mediana e intervalo $25-75 \%$.

\subsection{Expressão gênica basal}

Finalmente, também pudemos observar que a expressão gênica de esclerostina estava aumentada em pacientes com DRC quando comparados com os controles, assim como de OPG e RANKL. Em consonância com os níveis séricos e conteúdo ósseo, também encontramos aumento da expressão gênica do FGF-23, enquanto a transcrição gênica de beta-catenina estava diminuída, embora não significativamente, em relação aos controles (Tabela 7). 
Tabela 7 - Comparação da expressão gênica das proteínas entre o grupo controle e o prétransplante renal.

\begin{tabular}{|c|c|c|c|c|c|c|}
\hline Gene & Tipo & Expressão & Erro-padrão & IC 95\% & $\mathbf{p}$ & Resultado \\
\hline $\begin{array}{c}\text { GAPDH } \\
\text { pré/controle }\end{array}$ & Referência & 1,0 & & & & \\
\hline $\begin{array}{l}\text { Esclerostina } \\
\text { pré/controle }\end{array}$ & Alvo & 3,349 & $0,62-18,38$ & $0,13-84,45$ & 0,0001 & elevado \\
\hline $\begin{array}{l}\text { Beta-catenina } \\
\text { pré/controle }\end{array}$ & Alvo & 0,743 & $0,31-1,74$ & $0,07-3,25$ & 0,089 & - \\
\hline $\begin{array}{l}\text { RANKL } \\
\text { pré/controle }\end{array}$ & Alvo & 4,026 & $1,52-11,31$ & $0,62-39,39$ & 0,0001 & elevado \\
\hline $\begin{array}{c}\text { OPG } \\
\text { pré/controle }\end{array}$ & Alvo & 3,078 & $0,50-20,18$ & $0,11-89,78$ & 0,001 & elevado \\
\hline $\begin{array}{c}\text { FGF-23 } \\
\text { pré/controle }\end{array}$ & Alvo & 3,452 & $1,15-9,85$ & $0,41-42,22$ & 0,0001 & elevado \\
\hline
\end{tabular}

\subsection{Correlações basais da imunohistoquímica e multiplex}

\subsubsection{Comparação entre os métodos}

Conforme descrito na Tabela 8, observamos que os níveis séricos de esclerostina e a expressão óssea por imunohistoquimica se correlacionaram positivamente com o conteúdo proteico ósseo por multiplex. Não houve correlação entre o nível sérico de esclerostina e a expressão da mesma pela imunohistoquimica. A expressão óssea de OPG se correlacionou negativamente com o conteúdo proteico por multiplex e sem correlação com o nível sérico. Não houve correlação entre o nível sérico de RANKL e a expressão do mesmo pela imunohistoquimica ou o conteúdo proteico por multiplex. O nível sérico de FGF-23 teve boa correlação com a imunohistoquimica e o multiplex. Além disto, a expressão de FGF-23 por imunohistoquimica também se correlacionou com conteúdo proteico ósseo por multiplex. 
Tabela 8 - Correlações entre o nível sérico, imunohistoquímica e multiplex das proteínas no pré-transplante renal.

\begin{tabular}{|c|c|c|}
\hline Esclerostina & & \\
\hline & Imunohistoquimica & Multiplex \\
\hline Nível sérico & $\mathrm{r}=0,132 ; \mathrm{p}=0,487$ & $r=0,510 ; p=0,011$ \\
\hline Imunohistoquimica & - & $r=0,563 ; p=0,003$ \\
\hline \multicolumn{3}{|l|}{ RANKL } \\
\hline & Imunohistoquimica & Multiplex \\
\hline Nível sérico & $\mathrm{r}=-0,003 ; \mathrm{p}=0,988$ & $\mathrm{r}=-0,203 ; \mathrm{p}=0,352$ \\
\hline Imunohistoquimica & - & $r=0,059 ; p=0,790$ \\
\hline \multicolumn{3}{|l|}{ OPG } \\
\hline & Imunohistoquimica & Multiplex \\
\hline Nível sérico & $\mathrm{r}=0,112 ; \mathrm{p}=0,595$ & $\mathrm{r}=-0,221 ; \mathrm{p}=0,323$ \\
\hline Imunohistoquimica & - & $r=-0,431 ; p=0,040$ \\
\hline \multicolumn{3}{|l|}{ FGF-23 } \\
\hline & Imunohistoquimica & Multiplex \\
\hline Nível sérico & $r=0,579 ; p=0,002$ & $r=0,757 ; p=0,0001$ \\
\hline Imunohistoquimica & - & $r=0,742 ; p=0,0001$ \\
\hline
\end{tabular}

RANKL Ligante do receptor ativador do fator nuclear Kappa-B; OPG Osteoprotegerina; FGF23 Fator de crescimento do Fibroblasto 23.

\subsubsection{Correlações do pré-transplante}

A esclerostina sérica se correlacionou positivamente com o OPG sérico $(\mathrm{r}=0,417 ; \mathrm{p}=0,030)$ e negativamente com a TRAP5b $(\mathrm{r}=-0,546 ; \mathrm{p}=0,002)$. A esclerostina pela imunohistoquimica se corelacionou negativamente com OV/BV ( $\mathrm{r}=-0,408 ; \mathrm{p}=0,023)$, O.Th $(r=-0,417 ; p=0,02)$, Ob.S/BS $(r=-0,445 ; p=0,012)$, Oc.S/BS $(r=-0,453 ; p=0,01)$ e Fb.V/TV $(r=-$ 0,465; $\mathrm{p}=0,008)$. O conteúdo de esclerostina pelo multiplex se correlacionou negativamente com a fosfatase alcalina $(r=-0,500 ; p=0,011)$ e PTH séricos $(r=-0,640 ; p=0,001)$, com TRAP5b 
$(r=-0,609 ; p=0,001)$, com fosfatase alcalina óssea $(r=-0,578 ; p=0,002)$, com OV/BV $(r=-0,588$; $p=0,002)$, OS/BS (r=-0,561; p=0,004), F.Bv (r=-0,678; $p=0,001), \operatorname{MS} / B S(r=-0,768 ; p=0,001)$, BFR/BS ( $r=-0,761 ; p=0,001)$, OTh $(r=-0,565 ; p=0,003)$, Obs/BS $(r=-0,726 ; p=0,001)$, ES/BS $(\mathrm{r}=-0,615 ; \mathrm{p}=0,001)$ e Ocs.BS $(\mathrm{r}=-0,582 ; \mathrm{p}=0,002)$.

A beta-catenina fosforilada da imunohistoquimica se correlacionou positivamente com o OPG sérico $(\mathrm{r}=0,503 ; \mathrm{p}=0,010)$.

O OPG sérico se correlacionou positivamente com o FGF-23 sérico $(\mathrm{r}=0,549 ; \mathrm{p}=0,003)$. A OPG da imunohistoquimica se correlacionou positivamente com Tb.SP $(r=0,539 ; p=0,003)$, Tb.Th $(r=0,652 ; p=0,0001)$ e $O . T h(r=0,610 ; p=0,0001)$ e negativamente com fosfatase alcalina óssea ( $r=-0,662 ; p=0,0001)$, PTH ( $r=-0,561 ; p=0,002)$, TRAP5b ( $r=-0,548 ; p=0,002 ;)$ e Tb.N $(\mathrm{r}=-0,617 ; \mathrm{p}=0,0001), \mathrm{Fb} . \mathrm{V}(\mathrm{r}=-0,713 ; \mathrm{p}=0,0001 ;), \mathrm{OV} / \mathrm{BV}(\mathrm{r}=-0,672 ; \mathrm{p}=0,0001), \mathrm{OS} / \mathrm{BS}(\mathrm{r}=-$ 0,607; $\mathrm{p}=0,0001)$, ObS.Bs ( $\mathrm{r}=-0,736 ; \mathrm{p}=0,0001)$. Ocs.Bs $(\mathrm{r}=-0,672 ; \mathrm{p}=0,0001)$ e Ct.Po $(\mathrm{r}=-$ 0,643; $\mathrm{p}=0,0001)$. A OPG do multiplex se correlacionou positivamente com tempo de diálise $(r=0,566 ; p=0,003)$, PTH $(r=0,655 ; p=0,001)$, TRAp5b $(r=0,606 ; p=0,001)$ e BFR/BS $(r=0,511$; $\mathrm{p}=0,009)$.

O FGF-23 da imunohistoquimica se correlacionou negativamente com a fosfatase alcalina óssea $(r=-0,513 ; \mathrm{p}=0,004)$ e com OV/BV $(r=-0,572 ; \mathrm{p}=0,001)$.

A beta-catenina total da imunohistoquimica não apresentou nenhuma correlação significativa. RANK $-\mathrm{L}$ sérico, do multiplex e da imunohistoquimica também não apresentaram nenhuma correlação significativa.

\subsection{Características laboratoriais, imunossupressão e DMO após 1 ano}

Após 1 ano do transplante renal, a função renal dos pacientes estava satisfatória, com uma mediana de creatinina de $1,2 \mathrm{mg} / \mathrm{dl}$ e taxa de filtração glomerular estimada pelo MDRD de $62 \mathrm{ml} / \mathrm{min}$. Houve aumento do nível do cálcio sérico, com diminuição dos níveis de fósforo 
e fosfatase alcalina. Um paciente apresentou hipocalcemia, enquanto $2(6,5 \%)$ apresentaram hipercalcemia. Doze pacientes (38\%) apresentavam hipofosfatemia e $3(10 \%)$, hiperfosfatemia. Não houve variação significativa do nível de 25-hidroxivitamina D, mas apenas um paciente apresentava deficiência $(<15 \mathrm{ng} / \mathrm{ml})$, e $15(48 \%)$ apresentavam insuficiência $(15-30 \mathrm{ng} / \mathrm{ml})$. Os níveis de PTH caíram consideravelmente de 370 pg/ml para 74 pg/ml. Entretanto, se considerarmos como PTH alvo o valor superior de referência do ensaio da nossa instituição (65 pg/ml), 20 pacientes (64\%) tinham dosagens elevadas de PTH e seriam classificados como portadores de hiperparatiroidismo persistente após o transplante renal. Apenas um paciente tinha concomitantemente PTH e cálcio elevados. Também houve queda significativa nos valores de fosfatase alcalina óssea, TRAP5b, esclerostina, OPG e principalmente FGF-23. Mesmo com o declínio, 27 (87\%) estavam acima do valor de referência para OPG, 10 (32\%) para fosfatase alcalina óssea, 9 (29\%) para esclerostina, 7 (22\%) para TRAP5b, porém apenas 3 (10\%) para FGF-23. Houve aumento dos níveis de RANKL, e da relação RANKL/OPG, conforme demonstrado na tabela 9.

Houve aumento da DMO medida pela DXA tanto na coluna lombar como no fêmur total (tabela 9). Osteoporose ( $\mathrm{T}$ escore $\leq 2,5$ ) na coluna lombar ou fêmur total foi encontrada em $6(19 \%)$ pacientes, 2 a menos que no basal, 3 homens e 3 mulheres, sendo 5 na coluna lombar e 2 no fêmur total.

A dose média de corticóide utilizada em 1 ano pelos pacientes foi de 3.770,5 $\pm 162,3$ mg de prednisona. A maior parte dos pacientes continuou em uso do esquema tríplice iniciado (tacrolimus, micofenolato sódico e prednisona); dois pacientes foram convertidos de micofenolato sódico para azatioprina, aos 2 e 5 meses de transplante, ambos do grupo placebo; um paciente do grupo zolendrônico foi convertido de micofenolato sódico para everolimus aos 9 meses de transplante e um paciente do grupo placebo foi convertido de tacrolimus para ciclosporina após 2 meses de transplante. Apenas um paciente foi submetido à 
paratireoidectomia 11 meses após o transplante renal. Nenhum paciente fez uso de cinacalcete no primeiro ano de transplante.

Tabela 9 - Parâmetros laboratoriais e DXA pré e 1 ano após o transplante renal.

\begin{tabular}{|c|c|c|c|}
\hline Parâmetro & Pré-transplante & Pós-transplante & $p$ \\
\hline Creatinina (mg/dl) & & $1,20(0,95-1,49)$ & \\
\hline Cálcio (mg/dl) & $9,1(8,7-9,6)$ & $9,5(9,1-9,9)$ & 0,014 \\
\hline Fósforo (mg/dl) & $7,2(6,1-8,4)$ & $2,8(2,5-3,8)$ & $<0,0001$ \\
\hline Fosfatase alcalina (UI/L) & $155(85-192)$ & $94(64-105)$ & 0,001 \\
\hline PTH (pg/ml) & $370(207-530)$ & $76(56-102)$ & $<0,0001$ \\
\hline 25-hidroxivitamina D (ng/ml) & $26(18-34)$ & $29(18-36)$ & 0,202 \\
\hline Esclerostina (ng/ml) & $1,12(0,63-1,83)$ & $0,53(0,43-0,64)$ & $<0,0001$ \\
\hline Fosfatase alcalina óssea (UI/L) & $90(34-127)$ & $29(19-37)$ & $<0,0001$ \\
\hline TRAP5b (UI/L) & $9,18(6,71-12,75)$ & $2,69(1,78-5,3)$ & $<0,0001$ \\
\hline RANKL (pg/ml) & $4,98(2,96-9,80)$ & $8,45(5,90-12,64)$ & 0,004 \\
\hline OPG (pg/ml) & 1797 (1289-2424) & $1117(986-1476)$ & $<0,0001$ \\
\hline RANKL/OPG & $0,004(0,002-0,006)$ & $0,007(0,004-0,013)$ & 0,004 \\
\hline FGF-23 (pg/ml) & $899(221-2625)$ & $22(15-34)$ & $<0,0001$ \\
\hline DMO coluna lombar $\left(\mathrm{g} / \mathrm{cm}^{2}\right)$ & $0,92 \pm 0,14$ & $0,95 \pm 0,13$ & $<0,0001$ \\
\hline DMO femur total $\left(\mathrm{g} / \mathrm{cm}^{2}\right)$ & $0,84 \pm 0,15$ & $0,88 \pm 0,13$ & $<0,0001$ \\
\hline
\end{tabular}

DXA absortometria de raio-x de dupla energia; PTH paratormônio; TRAP5b fosfatase ácida resistente ao tártaro; RANKL Ligante do receptor ativador do fator nuclear Kappa-B; OPG osteoprotegerina; FGF-23 Fator de crescimento do Fibroblasto 23; DMO densidade mineral e óssea.

Os dados estão expressos em média \pm desvio-padrão, em caso de distribuição normal, ou mediana e intervalo $25-75 \%$.

\subsection{Biópsia óssea}

Após um ano de transplante renal, houve diminuição do número de trabéculas e aumento da separação das mesmas, mas sem mudança no volume ósseo. Houve diminuição do volume e superfície osteóide, assim como da superfície osteoblástica, acompanhadas da diminuição da superfície osteoclástica e da superfície de reabsorção, evidenciando a 
diminuição tanto da formação quanto da reabsorção óssea. Porém, não foi observada alteração da taxa de formação óssea. Houve aumento da espessura cortical, com diminuição da porosidade. Foi observada também uma diminuição muito evidente da fibrose medular após 1 ano de transplante renal. Houve diminuição da superfície mineralizante, mas sem alteração da taxa de aposição mineral ou no tempo de mineralização, conforme detalhado na Tabela 10.

Após 1 ano de transplante, aumentou a proporção de pacientes com baixa remodelação de $10(32 \%)$ para $20(65 \%)$, e diminuiu a de alta, de $20(65 \%)$ para apenas $1(3 \%)$; p < 0,0001. Não houve mudança nos padrões de distribuição de volume e mineralização. A distribuição do sistema TMV está ilustrada na Figura 9. 


\section{Remodelação}

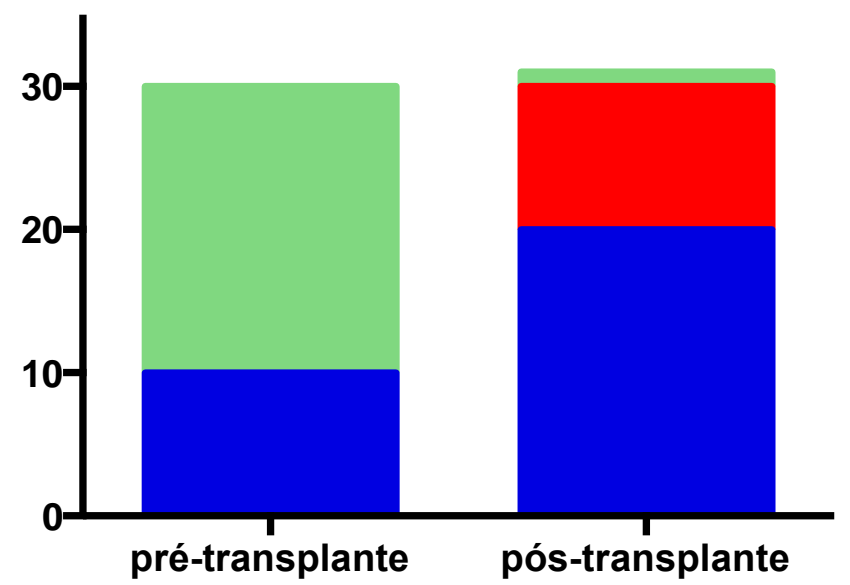

$P<0,0001$

Mineralização

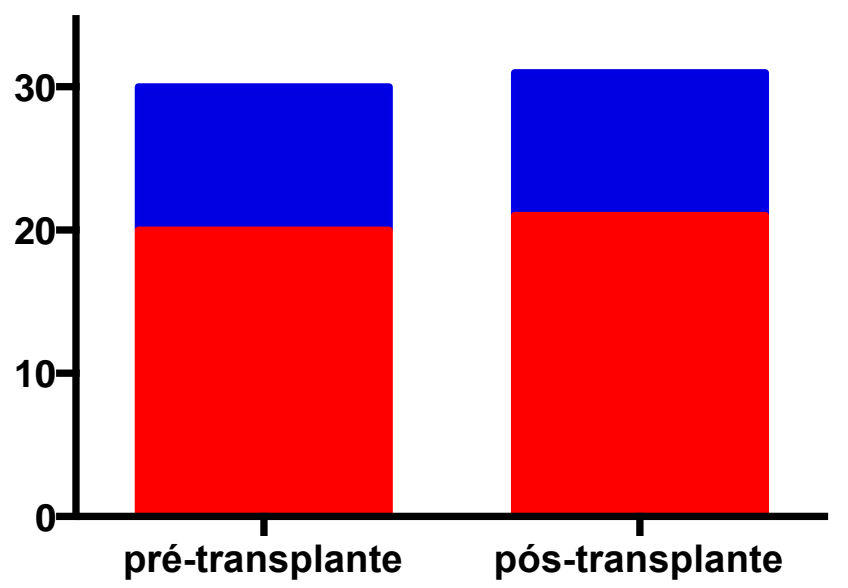

$P=1,0$

Volume
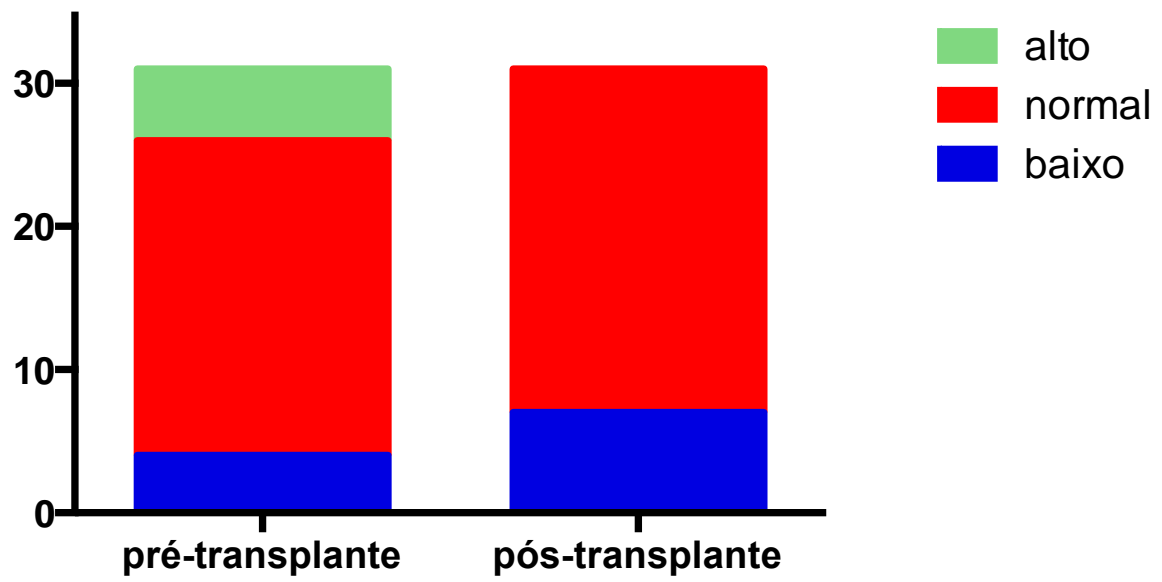

$$
P=0,0522
$$

Figura 9 - Distribuição da classificação das biópsias ósseas do pré e 1 ano após o transplante renal de acordo com o sistema TMV (remodelação, mineralização e volume). 
Tabela 10 - Parâmetros estáticos e dinâmicos da histomorfometria pré e 1 ano após o transplante renal.

\begin{tabular}{|c|c|c|c|}
\hline Parâmetro & Pré-transplante & Pós-transplante & $p$ \\
\hline BV/TV (\%) & $23,1(20,9-27,6)$ & $21,2(16,1-28,9)$ & 0,439 \\
\hline Tb.Sp $(\mu \mathrm{m})$ & $362(291-474)$ & $434(359-605)$ & 0,006 \\
\hline Tb.N (/mm) & $2,03(1,65-2,37)$ & $1,77(1,37-2,04)$ & 0,001 \\
\hline Tb.Th $(\mu \mathrm{m})$ & $121,2(110-138,8)$ & $130(109-145)$ & 0,112 \\
\hline OV/BV $(\%)$ & $6,59(2,2-11,27)$ & $2,5(1,53-5,02)$ & 0,015 \\
\hline OS/BS (\%) & $40,3(20,3-49,5)$ & $19,2(15,1-34,6)$ & 0,005 \\
\hline O.Th $(\mu \mathrm{m})$ & $9,65(5,98-12,64)$ & $8,39(5,1-12,17)$ & 0,623 \\
\hline Ob.S/BS (\%) & $7,22(4,98-15,69)$ & $5,38(2,35-7,27)$ & 0,016 \\
\hline ES/BS (\%) & $10,8(7,5-15,6)$ & $4,54(2,65-6,17)$ & $<0,0001$ \\
\hline Oc.S/BS (\%) & $1,33(0,56-2,89)$ & $0,38(0,11-0,69)$ & $<0,0001$ \\
\hline $\mathrm{Fb} . \mathrm{V} / \mathrm{TV}(\%)$ & $0,22(0,01-1,60)$ & $0,0025(0-0,0341)$ & $<0,0001$ \\
\hline Ct.Po $(\%)$ & $7,1(5,6-8,8)$ & $5,3(2,5-7,1)$ & 0,001 \\
\hline Ct.Th $(\mu \mathrm{m})$ & $756(572-904)$ & $1084(820-1423)$ & $<0,0001$ \\
\hline MS/BS (\%) & $6,4(3,9-9,9)$ & $2,9(1,9-4,8)$ & $<0,0001$ \\
\hline $\operatorname{MAR}(\mu \mathrm{m} / \mathrm{dia})$ & $1,03(0,76-1,35)$ & $1,03(0,74-1,41)$ & 0,664 \\
\hline $\mathrm{BFR} / \mathrm{BS}\left(\mu \mathrm{m}^{3} / \mu \mathrm{m}^{2} / \mathrm{dia}\right)$ & $0,037(0,007-0,102)$ & $0,029(0,009-0,066)$ & 0,187 \\
\hline Mlt (dias) & $71,6(40-415,8)$ & $56,1(28,1-181,2)$ & 0,157 \\
\hline
\end{tabular}

BV/TV volume trabecular; Tb.Sp separação trabecular; Tb.N número trabecular; Tb.Th espessura trabecular; OV/BV volume osteóide; OS/BS superfície osteóide; O.Th espessura osteóide; Ob.S/BS superfície osteoblástica; ES/BS superfície de reabsorção; Oc.S/BS superfície osteoclástica; $\mathrm{Fb} . \mathrm{V} / \mathrm{TV}$ fibrose medular; $\mathrm{Ct}$.Po porosidade cortical; Ct.Th espessura cortical; MS/BS superfície mineralizante; MAR taxa de aposição mineral; BFR/BS taxa de formação óssea; Mlt tempo de mineralização.

Os dados estão expressos em forma de mediana e intervalo $25-75 \%$. 


\subsection{Expressão proteica pela imunohistoquimica e conteúdo proteico pelo multiplex}

O padrão de distribuição das proteínas pela imunohistoquimica não sofreu alteração em relação às biopsias basais. Houve diminuição do número total de osteócitos quando comparado com o basal, de 656 para 326 ( $\mathrm{p}<0,0001$ ). Numericamente, houve aumento da expressão óssea da esclerostina e da beta-catenina total e fosforilada após o transplante, confirmando a inibição da via Wnt pela diminuição da porção ativa da beta-catenina. Estes achados foram acompanhados do aumento de RANKL (Figuras 9-11). Houve aumento da relação RANKL/OPG. Não houve alteração significativa da expressão de OPG e FGF-23 pela imunohistoquimica, conforme descrito na Tabela 11.

O conteúdo proteico ósseo da esclerostina e do RANKL, medidos por multiplex, aumentaram após 1 ano de transplante, em conformidade com os dados da imunohistoquimica. Já o conteúdo proteico de OPG e FGF-23 diminuiu. Houve aumento da relação RANKL/OPG, compatível com a imunohistoquimica. Não houve alteração em relação ao DKK1 (Tabela 12). 


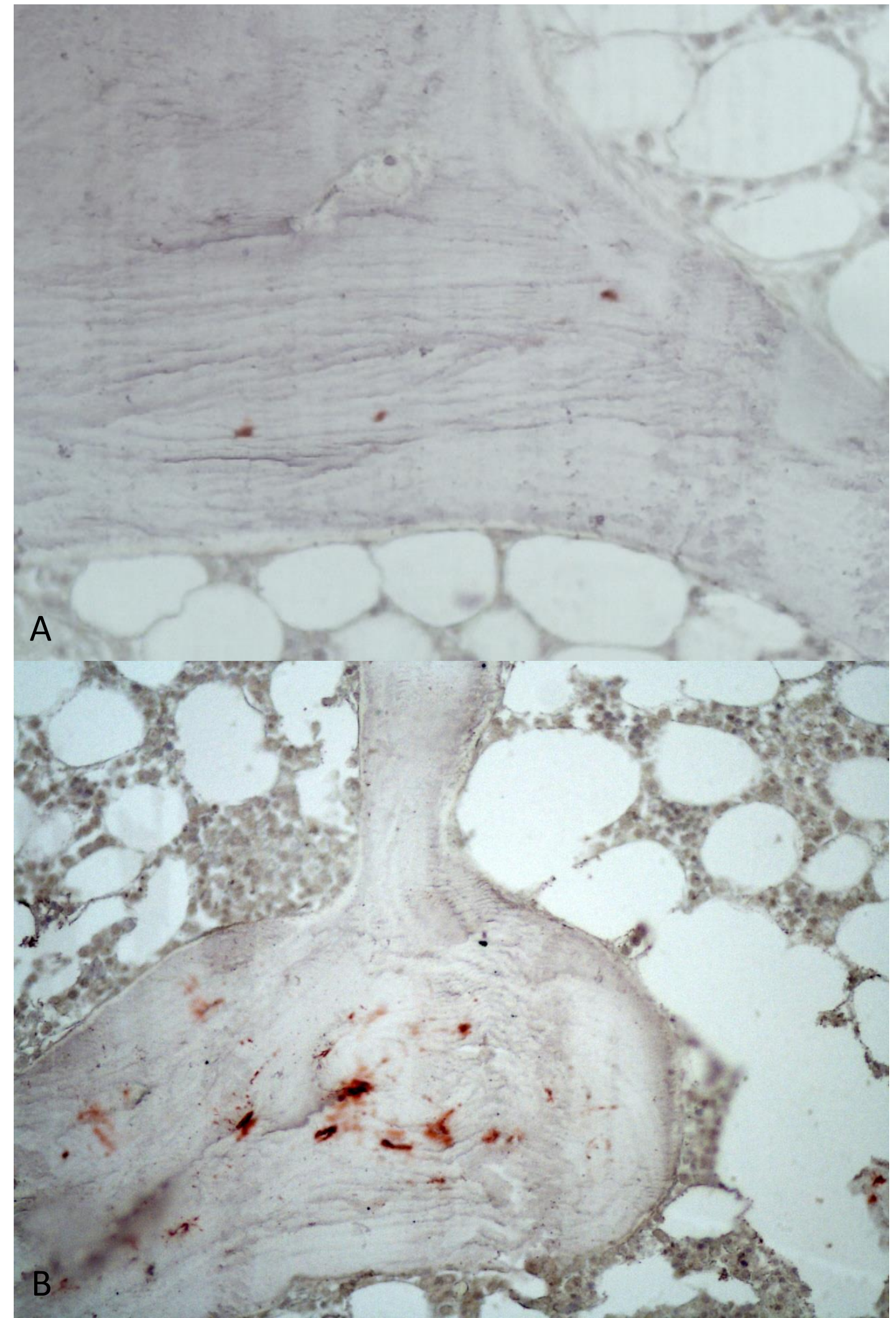

Figura 10 - Expressão de esclerostina óssea através da imunohistoquimica pré (A) e 1 ano (B) após transplante renal, aumento de 200x. 


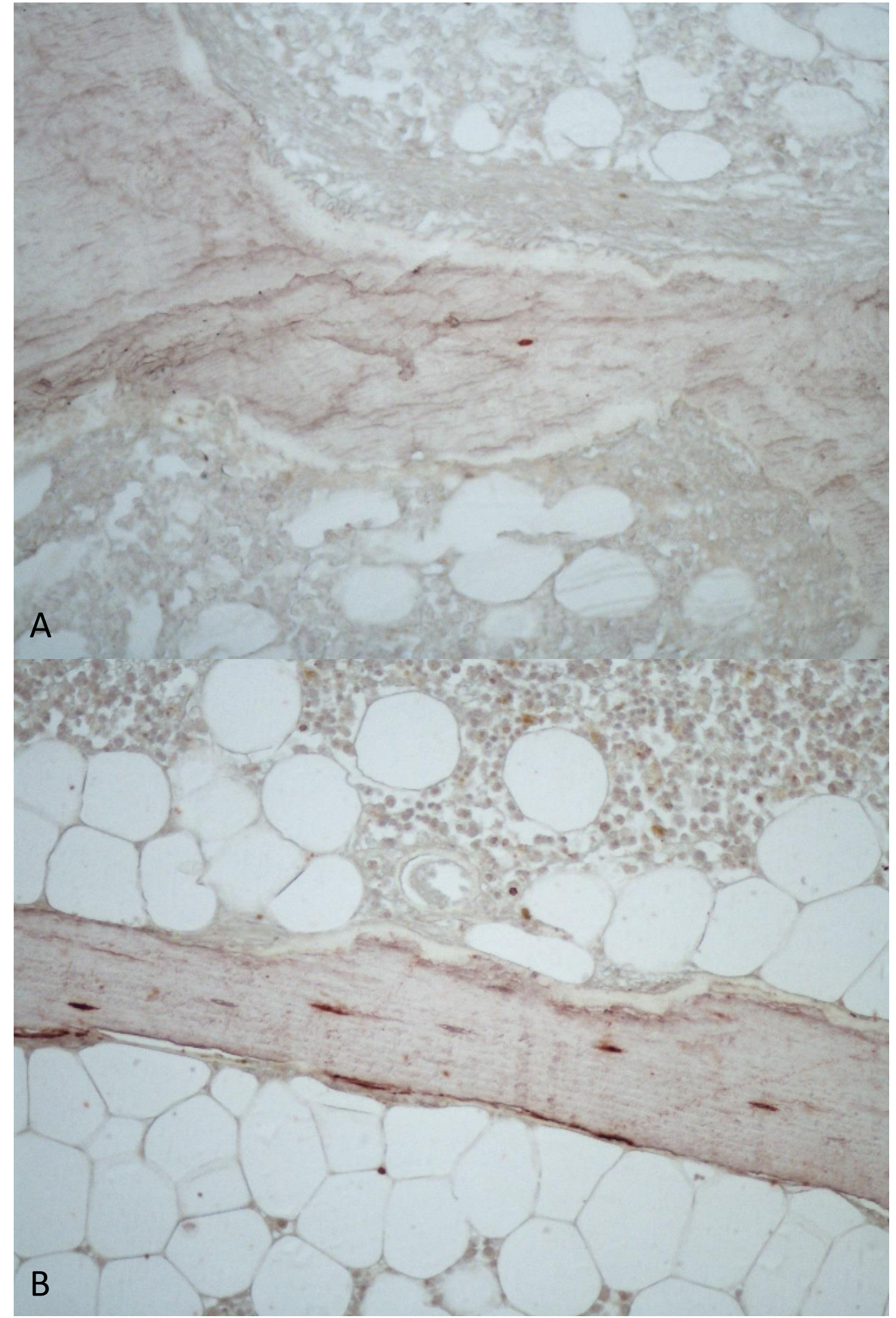

Figura 11 - Expressão de beta-catenina total através da imunohistoquimica pré (A) e 1 ano (B) após transplante renal, aumento de 200x. 


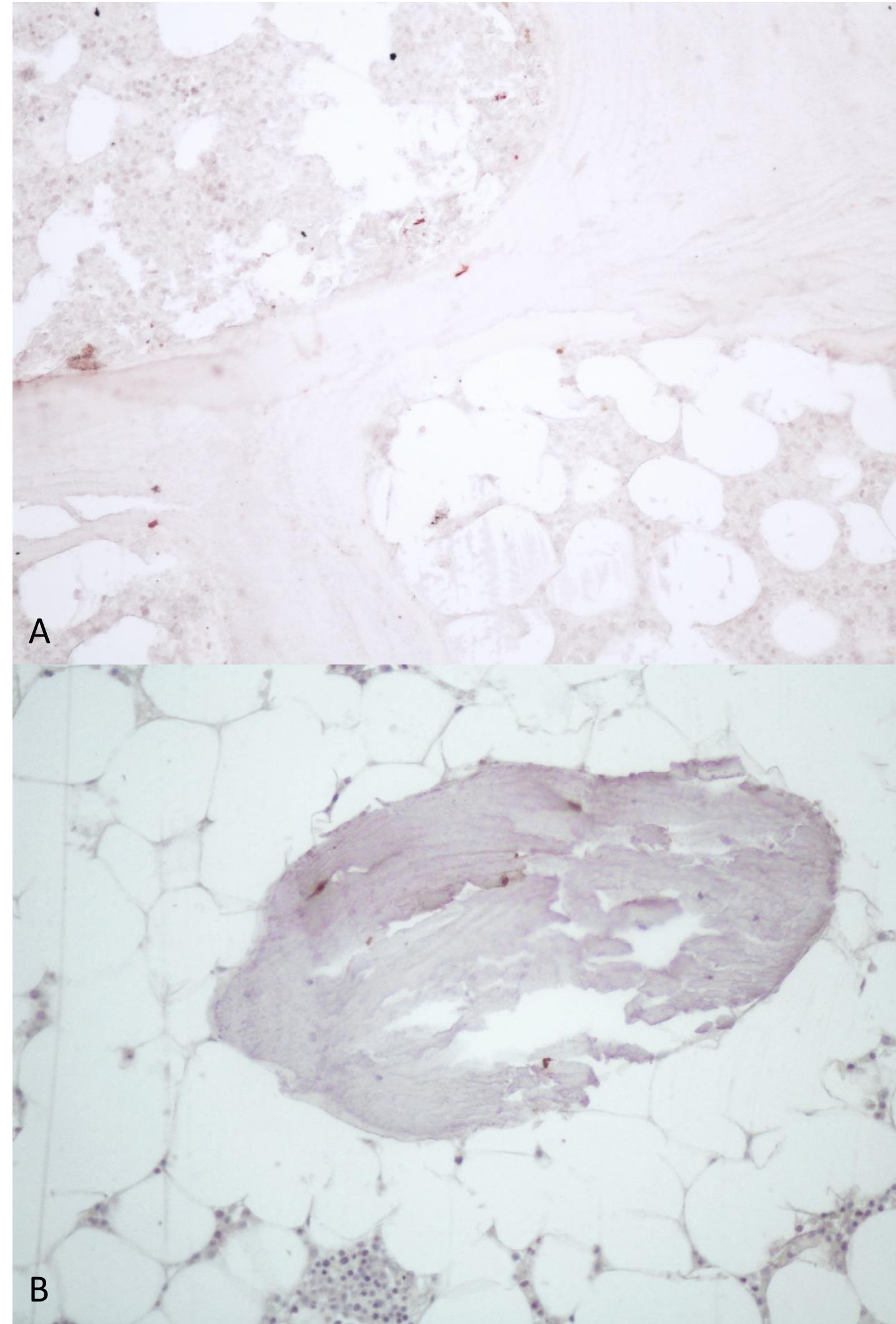

Figura 12 - Expressão de RANKL através da imunohistoquimica pré (A) e 1 ano (B) após transplante renal, aumento de 200x. 
Tabela 11 - Expressão protéica óssea através de imunohistoquimica pré e 1 ano após o transplante renal.

\begin{tabular}{ccccccr}
\hline & \multicolumn{2}{c}{ Pré-transplante } & \multicolumn{2}{c}{ Pós-transplante } & p & p \\
\hline Proteína & $\begin{array}{c}\text { Osteócitos } \\
\text { marcados }\end{array}$ & $\begin{array}{c}\text { \% Osteócitos } \\
\text { marcados/totais }\end{array}$ & $\begin{array}{c}\text { Osteócitos } \\
\text { marcados }\end{array}$ & $\begin{array}{c}\text { \% Osteócitos } \\
\text { marcados/totais }\end{array}$ & Osteócitos & $\%$ \\
\hline Esclerostina & $27(11-56)$ & $5,6(1,8-14,2)$ & $57(28-120)$ & $20,9(6,7-44)$ & 0,010 & 0,003 \\
$\begin{array}{c}\text { Beta-catenina } \\
\text { total }\end{array}$ & $61(17-97)$ & $9,1(2,5-17,3)$ & $69(32-116)$ & $18,5(7,7-33,9)$ & 0,222 & 0,007 \\
$\begin{array}{c}\text { Beta-catenina } \\
\text { fosforilada }\end{array}$ & $23(6-40)$ & $3,6(1,3-6,5)$ & $32(15-67)$ & $10,4(3,0-20,3)$ & 0,052 & 0,001 \\
RANKL & $4(1-12)$ & $0,76(0,21-1,42)$ & $7(3-13)$ & $2,24(0,84-3,37)$ & 0,115 & 0,001 \\
OPG & $6(4-8)$ & $1,33(0,64-1,89)$ & $4(3-6)$ & $1,12(0,72-2,08)$ & 0,029 & 0,746 \\
RANKL/OPG* & & $0,67(0,17-2,0)$ & & $1,71(0,60-4,33)$ & 0,016 \\
FGF-23 & $37(7-125)$ & $7,8(1,8-24)$ & $44(12-119)$ & $8,2(4,0-40,4)$ & 0,516 & 0,315 \\
\hline
\end{tabular}

RANKL ligante do receptor ativador do fator nuclear Kappa-B; OPG osteoprotegerina; FGF-

23 Fator de crescimento do Fibroblasto 23.

* sem unidade

Os dados estão expressos em mediana e intervalo $25-75 \%$.

Tabela 12 - Conteúdo proteico (multiplex) pré e 1 ano após o transplante renal.

\begin{tabular}{cccc}
\hline & Pré-transplante & Pós-transplante & $\boldsymbol{p}$ \\
\hline pg/mg proteína & & & \\
Esclerostina & $544(382-945)$ & $811(496-1.372)$ & 0,042 \\
DKK1 & $2,94(2,23-3,81)$ & $2,87(2,13-4,29)$ & 0,946 \\
RANKL & $4,55(3,41-7,29)$ & $6,11(3,54-8,62)$ & 0,051 \\
OPG & $0,62(0,44-0,76)$ & $0,38(0,29-0,65)$ & 0,025 \\
RANKL/OPG* & $6,65(3,16-13,82)$ & $16,05(8,72-21,67)$ & 0,001 \\
FGF-23 & $6,32(4,29-12,96)$ & $5,11(3,76-6,81)$ & 0,005
\end{tabular}

DKK1 dickkopf-related protein 1; RANKL ligante do receptor ativador do fator nuclear Kappa-B; OPG osteoprotegerina; FGF-23 Fator de crescimento do Fibroblasto 23.

* sem unidade

Os dados estão expressos em mediana e intervalo $25-75 \%$. 


\subsection{Expressão gênica}

Conforme descrito na Tabela 13, observamos um aumento de expressão gênica de esclerostina e de beta-catenina após o transplante. Houve diminuição da expressão gênica de RANKL. Não encontramos diferenças significativas para OPG e FGF-23.

Tabela 13 - Comparação da expressão gênica entre o pré e 1 ano após o transplante renal.

\begin{tabular}{ccccccc}
\hline Gene & Tipo & Expressão & Erro-padrão & IC 95\% & $\boldsymbol{p}$ & Resultado \\
\hline $\begin{array}{c}\text { GAPDH } \\
\text { pós/basal }\end{array}$ & Referência & 1 & & & & \\
$\begin{array}{c}\text { Esclerostina } \\
\text { pós/basal }\end{array}$ & Alvo & 1,876 & $0,43-8$ & $0,13-29,86$ & 0,001 & elevado \\
$\begin{array}{c}\text { Beta-catenina } \\
\text { pós-/basal }\end{array}$ & Alvo & 1,318 & $0,57-2,64$ & $0,29-6,96$ & 0,011 & elevado \\
$\begin{array}{c}\text { RANKL } \\
\text { pós/basal }\end{array}$ & Alvo & 0,088 & $0,03-0,23$ & $0,02-0,51$ & 0,0001 & reduzido \\
$\begin{array}{c}\text { OPG pós/basal } \\
\text { FGF-23 }\end{array}$ & Alvo & 1,171 & $0,2-6,5$ & $0,05-25,99$ & 0,486 & - \\
pós/basal & Alvo & 0,815 & $0,27-2,46$ & $0,10-8,00$ & 0,205 & - \\
\hline
\end{tabular}

IC intervalo de confiança; GAPDH Proteína gliceraldeído-3-fosfato desidrogenase; RANKL ligante do receptor ativador do fator nuclear Kappa-B; OPG osteoprotegerina; FGF-23 Fator de crescimento do Fibroblasto 23.

\subsection{Resumo do comportamento das proteínas ósseas antes e após o transplante renal}

Conforme descrito na Tabela 14, colocamos o padrão de nível sérico, conteúdo proteico (por imunohistoquímica e multiplex) e expressão gênica das proteínas avaliadas, antes e após o transplante renal. 
Tabela 14 - Comportamento das proteínas ósseas pré e 1 ano após o transplante renal.

\begin{tabular}{|c|c|c|c|c|c|c|c|c|c|c|}
\hline & \multicolumn{2}{|c|}{ Esclerostina } & \multicolumn{2}{c|}{ Beta-catenina } & \multicolumn{2}{c|}{ RANKL } & \multicolumn{2}{c|}{ OPG } & \multicolumn{2}{c|}{ FGF-23 } \\
\hline & Pré & Pós & Pré & Pós & Pré & Pós & Pré & Pós & Pré & Pós \\
\hline Soro & $\uparrow$ & $\downarrow$ & ND & ND & ND & $\uparrow$ & $\uparrow$ & $\downarrow$ & $\uparrow$ & $\downarrow$ \\
\hline IH & ND & $\uparrow$ & ND & $\begin{array}{c}\text { Total } \\
\text { fosforilada }\end{array}$ & ND & $\uparrow$ & ND & $=$ & ND & $=$ \\
\hline Multiplex & $\uparrow$ & $\uparrow$ & ND & ND & $\uparrow$ & $\uparrow$ & $=$ & $\downarrow$ & $\uparrow$ & $\downarrow$ \\
\hline $\begin{array}{c}\text { Expressão } \\
\text { gênica }\end{array}$ & $\uparrow$ & $\uparrow$ & $=$ & $\uparrow$ & $\uparrow$ & $\downarrow$ & $\uparrow$ & $=$ & $\uparrow$ & $=$ \\
\hline
\end{tabular}

Pré: comparação em relação aos valores de referência ou ao grupo controle; pós: comparação em relação aos valores anteriores ao transplante.

DKK1 dickkopf-related protein 1; RANKL ligante do receptor ativador do fator nuclear Kappa-B; OPG osteoprotegerina; FGF-23 Fator de crescimento do Fibroblasto 23; IH imunohistoquimica; ND não disponível.

\subsection{Efeito do ácido zoledrônico}

Finalmente, realizamos a análise de GLM, com medidas independentes, para avaliar o efeito do tratamento com ácido zoledrônico sobre as variáveis bioquímicas, histomorfométricas e de conteúdo proteico ósseo. Pudemos observar que o transplante foi responsável, isoladamente, pela maior parte das alterações encontradas.

\subsubsection{Parâmetros laboratoriais, imunossupressão e DXA}

O transplante renal aumentou cálcio, e diminuiu fósforo, fosfatase alcalina, PTH, esclerostina, fosfatase alcalina óssea, TRAP5b, OPG e FGF-23. Observamos aumento numérico do RANKL nos grupos, mas não houve significância estatística. Por sua vez, o ácido zoledrônico diminui a fosfatase alcalina e mostrou tendência a diminuir a TRAP5b (esta não atingiu significância estatística). Não houve interação entre o zoledrônico e o transplante em nenhum desses fatores, conforme descrito na tabela 15.

Não houve diferença na dose média de corticóide utilizada pelos pacientes dos dois grupos $(3.983,8 \times 3.570,5 \mathrm{~g} ; \mathrm{p}=0,208)$. 
Houve ganho de DMO pela DXA ocasionada pelo transplante na coluna lombar e no fêmur total, sem efeito direto do ácido zoledrônico. O efeito na coluna lombar teve interferência do ácido zolendrônico. 
Tabela 15 - Avaliação do efeito do ácido zoledrônico e do transplante nos parâmetros laboratoriais e DXA pré e 1 ano após o transplante renal.

\begin{tabular}{|c|c|c|c|c|c|c|c|}
\hline Parâmetros & $\begin{array}{c}\text { Pré-transplante } \\
\text { placebo }\end{array}$ & $\begin{array}{c}\text { Pós-transplante } \\
\text { placebo }\end{array}$ & $\begin{array}{c}\text { Pré-transplante } \\
\text { zoledrônico }\end{array}$ & $\begin{array}{c}\text { Pós-transplante } \\
\text { zoledrônico }\end{array}$ & $\begin{array}{c}\text { Transplante } \\
\text { renal }\end{array}$ & $\begin{array}{c}\text { GLM } \\
\text { Zoledrônico }\end{array}$ & Interação \\
\hline Cálcio (mg/dl) & $9,2(8,3-9,6)$ & $9,7(9,1-9,9)$ & $9,1(8,7-9,6)$ & $9,5(9,1-9,9)$ & 0,008 & 0,600 & 0,809 \\
\hline Fósforo (mg/dl) & $6,7(5,9-7,4)$ & $2,8(2,5-3,8)$ & $7,7(6,4-9,4)$ & $3,0(2,5-3,7)$ & 0,0001 & 0,147 & 0,143 \\
\hline Fosfatase alcalina (UI/L) & $173(111-241)$ & $119(89-128)$ & $138(69-144)$ & $71(48-88)$ & 0,002 & 0,043 & 0,727 \\
\hline PTH $(\mathrm{pg} / \mathrm{ml})$ & $400(188-846)$ & $77(56-114)$ & $364(211-431)$ & $74(45-100)$ & 0,0001 & 0,293 & 0,392 \\
\hline Esclerostina $(\mathrm{ng} / \mathrm{ml})$ & $0,95(0,56-1,75)$ & $0,53(0,41-0,58)$ & $1,19(0,65-1,94)$ & $0,53(0,46-0,70)$ & 0,0001 & 0,217 & 0,230 \\
\hline Fosfatase alcalina óssea(UI/L) & $120(52-131)$ & $36(32-65)$ & $66(32-98)$ & $19(17-28)$ & 0,0001 & 0,159 & 0,667 \\
\hline TRAP5b (UI/L) & $10,01(7,27-12,93)$ & $5,19(2,80-6,43)$ & $8,09(5,91-12,47)$ & $1,80(1,23-2,58)$ & 0,0001 & 0,082 & 0,172 \\
\hline RANKL (pg/ml) & $4,98(2,96-7,28)$ & $7,79(4,73-11,20)$ & $7,15(2,96-9,80)$ & $10,86(6,84-14,11)$ & 0,185 & 0,928 & 0,107 \\
\hline OPG (pg/mol) & 1499 (1305-2294) & $1164(976-1615)$ & $1882(1281-2613)$ & 1103 (976-1277) & 0,0001 & 0,725 & 0,255 \\
\hline RANKL/OPG & $0,004(0,002-0,005)$ & $0,007(0,003-0,011)$ & $0,003(0,002-0,008)$ & $0,010(0,005-0,014)$ & 0,065 & 0,713 & 0,260 \\
\hline FGF-23 (pg/ml) & 917 (186-2318) & $25(15-45)$ & 899 (247-10858) & $21(14-29)$ & 0,005 & 0,216 & 0,212 \\
\hline DMO femur total $\left(\mathrm{g} / \mathrm{cm}^{2}\right)$ & $0,89 \pm 0,14$ & $0,93 \pm 0,13$ & $0,79 \pm 0,14$ & $0,85 \pm 0,13$ & 0,0001 & 0,080 & 0,057 \\
\hline
\end{tabular}

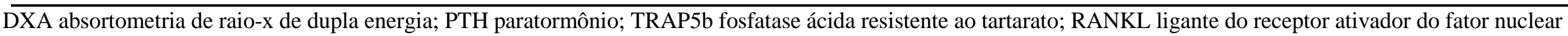
Kappa-B; OPG osteoprotegerina; FGF-23 Fator de crescimento do Fibroblasto 23; DMO densidade mineral e óssea.

Os dados estão expressos em média e desvio-padrão ou mediana e intervalo $25-75 \%$. 


\subsubsection{Histomorfometria}

Conforme descrito na tabela 16, o transplante aumentou a separação e diminuiu o número de traves, sem alterar o volume ósseo trabecular. Houve também diminuição de superfície osteóide, além das superfícies osteoblástica, superfície osteoclástica, superfície de reabsorção e fibrose medular. No compartimento cortical, encontramos diminuição da porosidade com aumento da espessura. A superfície mineralizante diminuiu e houve uma tendência à diminuição da taxa de formação óssea, esta última sem significância estatística. $\mathrm{O}$ uso do ácido zoledrônico não alterou nenhum dos parâmetros da histomorfometria. Porém, foi observada interação entre o transplante renal e o ácido zoledrônico para superfície osteóide e superfície osteoblástica, sugerindo que a queda dos valores destes parâmetros tenha sido mais significativa com o uso da medicação. 
Tabela 16 - Avaliação do efeito do ácido zoledrônico e do transplante na histomorfometria pré e 1 ano após o transplante renal.

\begin{tabular}{|c|c|c|c|c|c|c|c|}
\hline Parâmetros & $\begin{array}{c}\text { Pré- } \\
\text { transplante } \\
\text { placebo }\end{array}$ & $\begin{array}{c}\text { Pós- } \\
\text { transplante } \\
\text { placebo }\end{array}$ & $\begin{array}{c}\text { Pré-transplante } \\
\text { zoledrônico }\end{array}$ & $\begin{array}{c}\text { Pós- } \\
\text { transplante } \\
\text { zoledrônico }\end{array}$ & $\begin{array}{c}\text { transplante } \\
\text { renal }\end{array}$ & Zoledrônico & Interação \\
\hline $\mathrm{BV} / \mathrm{TV}(\%)$ & $24,77(20,11-28,54)$ & $27,0(18,95-29,87)$ & $22,92(21,01-26,47)$ & $19,74(15,18-26,17)$ & 0,459 & 0,064 & 0,213 \\
\hline Tb.Sp $(\mu \mathrm{m})$ & 355 (264-514) & $362(321-443)$ & $392(322-469)$ & $518(407-679)$ & 0,006 & 0,174 & 0,078 \\
\hline Tb.N (/mm) & $2,07(1,65-2,56)$ & $1,93(1,75-2,21)$ & $1,97(1,62-2,25)$ & $1,54(1,26-1,77)$ & 0,001 & 0,103 & 0,225 \\
\hline Tb.Th $(\mu \mathrm{m})$ & $126,2(111,4-140,3)$ & $131,4(106,4-153,8)$ & $118(99-136)$ & $125(110-144)$ & 0,119 & 0,466 & 0,947 \\
\hline OV/BV (\%) & $7,19(1,12-10,56)$ & $3,28(2,41-7,62)$ & $5,58(3,22-11,46)$ & $1,73(0,59-3,81)$ & 0,093 & 0,698 & 0,098 \\
\hline OS/BS (\%) & $37,44(19,71-48,75)$ & $21,72(19,19-37,15)$ & $44,36(26,39-55,61)$ & $16,42(8,56-25,80)$ & 0,003 & 0,533 & 0,041 \\
\hline O.Th $(\mu \mathrm{m})$ & $10,65(5,62-13,36)$ & $10,44(6,18-14,13)$ & $8,56(6,42-12,11)$ & $7,16(4,94-11,38)$ & 0,648 & 0,158 & 0,249 \\
\hline Ob.S/BS (\%) & $7,03(2,48-13,59)$ & $6,08(5,06-7,91)$ & $9,79(5,13-18,23)$ & $3,57(1,98-6,18)$ & 0,007 & 0,831 & 0,025 \\
\hline ES/BS (\%) & $10,72(7,51-14,95)$ & $4,77(3,03-6,89)$ & $10,99(7,70-16,77)$ & $3,92(1,49-6,02)$ & 0,0001 & 0,891 & 0,419 \\
\hline Oc.S/BS (\%) & $1,71(0,34-2,51)$ & $0,39(0,19-0,75)$ & $1,29(0,92-3,97)$ & $0,21(0,06-0,56)$ & 0,0001 & 0,360 & 0,108 \\
\hline $\mathrm{Fb} . \mathrm{V} / \mathrm{TV}(\%)$ & $0,164(0,003-1,601)$ & $0(0-0,056)$ & $0,299(0,027-1,862)$ & $0,003(0-0,025)$ & 0,015 & 0,549 & 0,644 \\
\hline Ct.Po (\%) & $7,22(6,08-10,09)$ & $5,28(2,41-6,97)$ & $7,07(5,06-8,66)$ & $5,01(3,15-7,98)$ & 0,001 & 0,841 & 0,318 \\
\hline Ct.Th $(\mu \mathrm{m})$ & $691(572-915)$ & $1084(785-1422)$ & $771(559-879)$ & $1166(876-1431)$ & 0,0001 & 0,498 & 0,304 \\
\hline MS/BS (\%) & $7,55(3,88-11,05)$ & $4,32(2,40-5,03)$ & $4,65(2,48-6,90)$ & $2,91(1,69-4,46)$ & 0,0001 & 0,278 & 0,505 \\
\hline $\operatorname{MAR}(\mu \mathrm{m} / \mathrm{dia})$ & $1,03(0,96-1,35)$ & $1,03(0,74-1,47)$ & $0,92(0,75-1,54)$ & $1,03(0,64-1,51)$ & 0,999 & 0,924 & 0,881 \\
\hline $\mathrm{BFR} / \mathrm{BS}\left(\mu \mathrm{m}^{3} / \mu \mathrm{m}^{2} / \mathrm{dia}\right)$ & $0,062(0,014-0,136)$ & $0,036(0,018-0,068)$ & $0,027(0,002-0,081)$ & $0,023(0,004-0,061)$ & 0,084 & 0,407 & 0,876 \\
\hline Mlt (dias) & $64,4(41,5-396,6)$ & $83,7(30,1-181,2)$ & $74,5(38,6-538,6)$ & $46,7(15,1-231,5)$ & 0,640 & 0,724 & 0,969 \\
\hline
\end{tabular}

BV/TV volume trabecular; Tb.Sp separação trabecular; Tb.N número trabecular; Tb.Th espessura trabecular; OV/BV volume osteóide; OS/BS superfície osteóide; O.Th espessura osteóide; Ob.S/BS superfície osteoblástica; ES/BS superfície de reabsorção; Oc.S/BS superfície osteoclástica; $\mathrm{Fb}$.V/TV fibrose medular; Ct.Po porosidade cortical; Ct.Th espessura cortical; MS/BS superfície mineralizante; MAR taxa de aposição mineral; BFR/BS taxa de formação óssea; Mlt tempo de mineralização.

Os dados estão expressos em mediana e intervalo $25-75 \%$. 


\subsubsection{Proteínas ósseas}

O transplante isoladamente ocasionou aumento da esclerostina, beta-catenina total, beta-catenina fosforilada e RANKL pela imunohistoquimica, assim como o aumento da esclerostina e RANKL pelo multiplex. Observamos um aumento da relação RANKL/OPG ocasionada pelo transplante na imunohistoquimica e no multiplex. Houve tendência a diminuição da FGF-23 ocasionada pelo transplante, no multiplex, mas sem significância estatística. O uso do ácido zoledrônico não interferiu no comportamento das proteínas ósseas (Tabela 17). 
Tabela 17 - Avaliação do efeito do ácido zoledrônico e do transplante nas proteínas ósseas avaliadas por imunohistoquimica e multiplex pré e 1 ano após o transplante renal.

\section{Parâmetros}

\begin{tabular}{l} 
Parâmetros \\
\hline Imunohistoquimica \\
\% osteócitos positivos/totais
\end{tabular}

\section{Pré-transplante \\ placebo}

\section{Pós-transplante \\ placebo}

\section{Pré-transplante zoledrônico}

\section{GLM \\ GLM}

Pós-transplante
zoledrônico

Transplante renal

Zoledrônico Interação

\section{0,007 \\ 0,042 \\ 0,003 \\ 0,008 \\ 0,891 \\ 0,034 \\ 0,213}

\section{Esclerostina}

Beta-catenina total

Beta-catenina fosforilada

RANKL

OPG

RANKL/OPG*

FGF-23

Multiplex

pg/mg proteína

$\begin{array}{ll}\text { Esclerostina } & 628(370-1115) \\ \text { DKK1 } & 2,96(2,75-3,88) \\ \text { RANKL } & 5,18(3,70-8,49) \\ \text { OPG } & 0,62(0,46-1,31) \\ \text { RANKL/OPG* } & 7,05(2,8-14,59) \\ \text { FGF-23 } & 6,32(4,29-12,96)\end{array}$

$$
\begin{gathered}
5,67(3,98-13,5) \\
9,77(1,14-17,25) \\
3,98(1,28-7,13) \\
1,06(0,31-1,60) \\
1,33(0,63-2,32) \\
0,89(0,17-1,75) \\
11,1(3,03-31,29)
\end{gathered}
$$

$\begin{array}{ll}4,5(1,09-24,72) & 14,12(4,51-39,68) \\ 7,31(3,07-23,34) & 24,44(8,02-43,19) \\ 3,10(1,21-5,69) & 12,53(5,77-23,66) \\ 0,59(0,16-1,27) & 1,89(0,95-2,92) \\ 1,22(0,62-1,81) & 1,17(0,74-2,07) \\ 0,50(0,15-2,13) & 1,44(0,61-3,19) \\ 5,12(1,22-25,05) & 18,4(4,43-43,21)\end{array}$

$7,93(3,63-32,6)$

0,029
0,684
0,052
0,226
0,0001
0,067

$\begin{array}{cll}811(554-2055) & 531(371-722) & 827(443-1316) \\ 2,96(1,6-4,47) & 2,36(2,01-3,65) & 2,86(2,28-4,16) \\ 5,83(3,54-10,08) & 3,92(2,26-5,61) & 6,28(3,69-7,66) \\ 0,47(0,33-0,86) & 0,6(0,39-0,69) & 0,36(0,29-0,51) \\ 15,25(7,99-19,88) & 6,08(3,16-13,04) & 16,05(10,99-24,05) \\ 5,23(3,82-6,81) & 6,56(4,12-13,8) & 4,19(2,81-7,18)\end{array}$

0,195

0,165

0,551

0.187

0,763

0,701

0,237

0,662

0,756

0,999

0,517

0,666

0,764

0,471

0,257

0,575

0,230

RANKL ligante do receptor ativador do fator nuclear Kappa-B; OPG osteoprotegerina; FGF-23 Fator de crescimento do Fibroblasto 23; DKK1 dickkopf-related protein 1 .

* sem unidade

Os dados estão expressos em mediana e intervalo $25-75 \%$. 


\section{Discussão}

Pelo nosso conhecimento, este é o primeiro trabalho a avaliar prospectivamente as proteínas ósseas em pacientes transplantados renais adultos, tanto no conteúdo, por dois métodos (imunohistoquimica e multiplex), como através da expressão gênica. Pudemos observar que a diminuição da esclerostina sérica, previamente documentada por outros autores, não foi acompanhada de diminuição de seu conteúdo ósseo. Na realidade, houve aumento do conteúdo ósseo, tanto por imunohistoquimica, quanto pelo multiplex, acompanhados por um aumento da expressão gênica. Foi observado também aumento da beta-catenina total e fosforilada pela imunohistoquimica, confirmando a inibição da via Wnt. Em consonância com a inibição da Via Wnt, detectamos um aumento na relação RANKL/OPG, favorecendo a reabsorção, observado tanto através da dosagem sérica, como da expressão óssea por imunohistoquimica e conteúdo ósseo por multiplex. Desta forma, análise do conteúdo local destas proteínas mostrou um cenário um pouco diferente daquele estimado pela avaliação da concentração sérica, podendo ser um novo elemento na elucidação da fisiopatologia da doença óssea encontrada no pós-transplante.

A população analisada nesse trabalho difere do perfil da população geral em diálise, por se tratar de uma população mais jovem, com baixa prevalência de diabéticos, e pouco tempo de terapia renal substitutiva. Nossos pacientes, por estarem em estudo para realização de transplante renal com doador vivo, diferiram do padrão da população em diálise no nosso país. De acordo com o último inquérito brasileiro de diálise, a etiologia mais prevalente de DRC é hipertensão arterial, seguida de diabetes mellitus, e mais de $30 \%$ dos pacientes atualmente em diálise tem mais de 65 anos ${ }^{71}$. Consequentemente, nosso grupo de pacientes se apresentou com um perfil de PTH não tão elevado, e mediana dentro do recomendado pelo KDIGO, o que pode ser considerado como um ponto 
positivo, pois diminui o viés de pacientes com hiperparatiroidismo avançado, histórico de fraturas e histórico de uso de drogas que interfiram no metabolismo ósseo.

Mesmo se tratando de uma população com menor tempo de diálise e doença óssea menos avançada, foi possível observar níveis não adequados de 25-hidroxi-vitamina D em mais de $70 \%$ dos pacientes, e valores elevados de FGF-23 (marcador precoce de doença óssea e metabólica), fosfatase alcalina óssea (marcador de formação), TRAP5b (marcador de reabsorção), e níveis elevados de OPG e RANKL. Considerando o compartimento ósseo, no pré-transplante o conteúdo ósseo de esclerostina e FGF-23, através do multiplex, estava elevado. Uma maior expressão óssea do FGF-23 e esclerostina em pacientes com DRC já foi demonstrada anteriormente ${ }^{72}$. Além de todas essas alterações, a expressão gênica de quase todas as proteínas estudadas acima, com exceção da beta-catenina, estava aumentada em relação aos controles. Mesmo em um grupo de pacientes com um perfil ósseo clínico mais brando, as alterações a nível molecular e genético já estão ocorrendo, corroborando as últimas publicações, que argumentam que a doença óssea começa de forma precoce em conjunto com as primeiras alterações da DRC. Há relato do aumento da expressão óssea do FGF-23, através da imunohistoquimica, em pacientes pediátricos com DRC ${ }^{72}$. Publicação recente do nosso grupo já tinha demonstrado elevação da expressão de esclerostina óssea, beta-catenina total e fosforilada e FGF-23, através da imunohistoquimica, em estágios iniciais de DRC quando comparados a controles normais. $\mathrm{O}$ aumento da expressão da esclerostina, em adultos, ocorre de forma mais precoce que o FGF-23 ${ }^{62,70}$. Pelo nosso conhecimento, este é o primeiro estudo que avalia o metabolismo ósseo, através de vários biomarcadores, em sua dosagem sérica, no conteúdo ósseo e pela expressão gênica no mesmo momento.

Utilizamos dois métodos para avaliar as proteínas ósseas: expressão óssea através da imunohistoquimica e conteúdo proteico através do multiplex. Houve boa correlação 
entre os dois métodos, quando comparamos as medidas do pré-transplante da esclerostina e do FGF-23. No caso do RANKL e da OPG essa correlação não foi encontrada; porém, esse achado não é inesperado, visto que essas proteínas são expressas em outras linhagens celulares, além dos osteócitos e osteoblastos, especialmente células mesenquimais e linfócitos ${ }^{53,73}$. Não é de nosso conhecimento que essa comparação tenha sido feita antes, e estes resultados sugerem que ambos os métodos possam ser usados para estimar o conteúdo ósseo de esclerostina e FGF-23, mesmo sendo a imunohistoquimica um método mais dependente do observador. Por outro lado, a imunohistoquimica pode ser realizada no mesmo fragmento utilizado para a histomorfometria, enquanto o multiplex necessita de outro fragmento, um processamento específico e com maior custo.

Como esperado, após um transplante renal bem sucedido e função renal estável, observamos um aumento dos níveis séricos de cálcio, acompanhado de queda do PTH e dos marcadores de formação e reabsorção óssea, fosfatase alcalina óssea e TRAP5B respectivamente. No entanto, as mudanças nos níveis séricos de RANKL, OPG e esclerostina, marcadores não avaliados habitualmente na prática clínica, chamam atenção. Como dito anteriormente, os níveis séricos de OPG e RANKL são resultado não apenas de sua síntese por osteócitos e osteoblastos, mas também de células do sistema imune. Portanto, não podemos afirmar com certeza, baseados apenas nos níveis séricos, que estes valores reflitam mudança local no tecido ósseo.

A diminuição da esclerostina sérica após o transplante renal é compatível com resultados de estudos anteriores, mas não conseguimos visualizar o comportamento bimodal descrito nos mesmos devido a uma única dosagem após um ano ${ }^{60,61}$. Porém, nós não realizamos dosagem de esclerostina no pós transplante imediato, e, portanto, não podemos descartar que nossos pacientes também tenham tido níveis mais baixos nos primeiros dias após o transplante, voltando a subir após alguns meses. Mais importante, 
vimos que a queda nos níveis séricos de esclerostina é fruto da recuperação da função renal e não da diminuição de sua síntese pelos osteócitos.

Pereira et al ${ }^{63}$ demonstraram que pacientes pediátricos transplantados de órgãos sólidos tinham maior expressão proteica de esclerostina e FGF-23, através da imunohistoquimica, do que pacientes com DRC pré-diálise. Porém, estes autores não puderam afirmar que a expressão óssea daqueles pacientes específicos aumentou após o transplante, já que eles não foram avaliados antes da cirurgia. No nosso caso, além de estudarmos indivíduos adultos, fizemos análise prospectiva, de forma que vimos a evolução nos próprios pacientes, ao invés de compará-los com controles. Além disto, a expressão de esclerostina em crianças é predominantemente cortical e é praticamente inexistente no pré-transplante, diferente de adultos, onde se expressa em ambos os compartimentos: cortical e trabecular.

Portanto, nossos dados nos permitem afirmar que, embora haja diminuição dos níveis séricos de esclerostina, há aumento de sua transcrição e síntese localmente pelos osteócitos. A queda dos níveis séricos deve estar relacionada à recuperação da função renal, como já sugeridos pelos resultados de Bonani et al ${ }^{61}$ e Evenepoel et al ${ }^{60}$. Outro fator é a queda das toxinas urêmicas e citocinas inflamatórias que acompanham a melhora da função renal e que podem exercer influência na regulação da esclerostina ${ }^{74}$. Na realidade, o aumento da síntese de esclerostina não é um achado inesperado, uma vez que há queda importante dos níveis de PTH após o transplante, e as evidências atuais demonstram uma correlação inversa entre PTH e esclerostina. Em estudos iniciais com modelos roedores, a infusão contínua de PTH ocasionou supressão da expressão gênica e do nível em osteócitos da esclerostina ${ }^{75}$, e em outro estudo o tratamento com infusão intermitente de PTH também suprimiu a expressão gênica e o nível proteico ósseo de esclerostina ${ }^{76}$. A infusão do PTH em humanos também demonstrou resultados 
semelhantes, sendo observada a diminuição dos níveis séricos de esclerostina em homens adultos saudáveis ${ }^{77}$ e mulheres menopausadas com osteoporose ${ }^{78}$. Estudos em pacientes com hiperparatiroidismo primário demonstram níveis séricos mais baixos de esclerostina quando comparados a controles ${ }^{79}$ ou a pacientes que foram submetidos a paratireoidectomia $^{80}$.

Outro potencial modulador da esclerostina é o corticoesteróide, os dados ainda são discrepantes. Porém, estudo com humanos em uso exógeno de corticoide evidenciou aumento discreto dos níveis séricos de esclerostina após 12 meses quando comparados ao basal ${ }^{81}$. Outro estudo com camundongos também demonstrou aumento da expressão da esclerostina e do número de osteócitos positivos para esclerostina com o uso de corticóides $^{82}$.

Os estudos com os efeitos da reposição de vitamina D sobre a esclerostina são controversos. Estudo in vitro evidenciou aumento da expressão gênica e dos níveis proteicos de esclerostina após reposição com 1,25 dihidroxi-vitamina $\mathrm{D}{ }^{83}$. Suplementação com vitamina D e cálcio por 2 anos aumentou os níveis séricos de esclerostina em homens, mas não em mulheres ${ }^{84}$. Apesar de não haver mudança significativa dos níveis séricos de vitamina $\mathrm{D}$, nossos pacientes receberam essa suplementação e a maioria tinha níveis adequados após 1 ano.

Não evidenciamos ação do ácido zoledrônico sobre os níveis séricos, conteúdo ósseo ou expressão gênica da esclerostina em nossa população. Estudos com mulheres menopausadas com osteoporose apresentam resultados conflitantes. Em um grupo de 40 mulheres foi observado aumento inicial do nível sérico de esclerostina com 30 dias, mas retorno ao basal após 1 ano ${ }^{85}$, enquanto outro estudo com 46 mulheres foi evidenciado diminuição do nível sérico de esclerostina quando comparado ao basal ${ }^{86}$. 
Como a esclerostina inibe a via Wnt, seria esperado aumento da fosforilação do fator de transcrição beta catenina, o que foi encontrado. ${ }^{50}$. O aumento da transcrição da beta catenina, que poderia ser interpretado como um evento contraditório, não se traduziu em ativação da via Wnt, já que houve aumento da fosforilação. Podemos aventar que este aumento da expressão gênica pode ser resultado de um mecanismo compensatório, causado pela maior degradação.

Da mesma forma que demonstrado por outros estudos anteriores ${ }^{87,88}$, o transplante renal diminuiu o nível sérico de OPG. Porém, na nossa população ainda permaneceu mais elevado que o valor de referência do método, acompanhado do aumento dos níveis séricos de RANKL, efeito ainda não demonstrado na literatura. Com a queda do PTH, poderíamos esperar um aumento do OPG com diminuição do RANKL, o que é o oposto do nosso resultado. Pode ser que, com o PTH baixo, a esclerostina alta esteja estimulando a síntese de RANKL. Estudo com deleção da beta-catenina, levou a diminuição do OPG e aumento do RANKL, com consequente diminuição da relação RANKL/OPG ${ }^{89}$, compatível com nosso resultado que também demonstrou aumento dessa relação. O envolvimento do sistema OPG/RANKL na patogênese dos distúrbios de remodelação nos receptores de transplante renal já havia sido sugerido anteriormente, onde houve correlação entre os níveis elevados de OPG antes do transplante com o sistema IGF-1 ${ }^{90}$.

O balanço da via RANKL/OPG no osso parece apontar na mesma direção dos achados do soro. Houve aumento do RANKL, na imunohistoquimica e no multiplex, com diminuição do OPG, na imunohistoquimica (apenas de forma numérica, sem significância estatística) e no multiplex, o que leva a aumento da produção e atividade dos osteoclastos, favorecendo a reabsorção. Da mesma forma que, na comparação sérica, a relação RANKL/OPG no osso também aumentou, tanto na imunohistoquimica quanto no 
multiplex. Podemos interpretar que no osso há uma dinâmica que favorece a diminuição da formação com aumento da reabsorção. Apesar de não termos encontrado diminuição importante de massa óssea após um ano, não sabemos as consequências desse balanço negativo a longo prazo, tanto para o osso em si, como para a sobrevida do enxerto e do paciente, pois alguns desses marcadores, pela dosagem sérica, já são sabidamente conhecidos e relacionados a aumento de risco cardiovascular em pacientes transplantados renais ${ }^{91}$. Entretanto, não há na literatura, relato do comportamento desses biomarcadores em pacientes transplantados renais, muito menos correlação com desfechos a longo prazo.

Houve queda dramática dos níveis plasmáticos de FGF-23, com retorno a níveis próximos da normalidade, conforme esperado pelo relato de estudos anteriores ${ }^{48,61,92}$. Neste caso, este resultado pode ser decorrente tanto do aumento da excreção renal, como da diminuição da síntese desta proteína. Também observamos queda importante do fósforo plasmático, provavelmente devido a intensa fosfatúria observada nos primeiros meses pós-transplante. $\mathrm{O}$ fósforo é fundamental para mineralização óssea, e não está bem estabelecido se essa queda inicial poderá interferir na mineralização óssea a longo prazo. Nos nossos pacientes, não houve mudança em relação a mineralização após o transplante, nem de melhora e nem de piora. Com relação ao FGF-23, encontramos diminuição do nível sérico e do conteúdo pelo multiplex, sem mudanças significativas na imunohistoquímica e na expressão gênica. No estudo pediátrico anteriormente citado, os autores afirmam que há um aumento da expressão óssea de FGF-23 pela imunohistoquímica, o que seria um achado oposto ao nosso. Porém, é necessário lembrar que eles não fizeram um estudo prospectivo e, portanto, não podem assegurar que houve de fato este aumento. ${ }^{63}$. Além disto, crianças parecem ter elevação dos níveis séricos mais precoce e expressão óssea de FGF-23 mais abundante do que adultos ${ }^{62}$. 
Houve tratamento com ácido zoledrônico em um subgrupo dos pacientes do estudo, e para avaliar a interferência da medicação nas alterações descritas realizamos a análise de ANOVA de duas vias, com medidas independentes, que tem o poder de avaliar o efeito das duas variáveis (transplante renal e ácido zoledrônico) ao mesmo tempo. Pudemos observar que o transplante foi responsável, isoladamente, pela maior parte das alterações encontradas. $\mathrm{O}$ ácido zoledrônico diminuiu a fosfatase alcalina e teve tendência a diminuir a TRAP5b, um efeito já esperado devido ao seu mecanismo de ação antirreabsortivo. Todas as outras alterações testadas (bioquímica, histomorfometria e nas proteínas ósseas) foram efeito exclusivo do transplante renal. Os estudos que avaliaram o efeito de bifosfonados sobre a massa óssea após o transplante renal não avaliaram o conteúdo ósseo das proteínas, não tendo como realizarmos essa comparação. Tampouco pudemos observar o efeito isolado do ácido zoledrônico na massa óssea. Observamos, quando considerado o grupo todo, ganho de DMO, tanto da coluna lombar como do fêmur total, medida por DXA e nenhuma diferença em relação ao BV/TV na histomorfometria. Entretanto, quando comparamos o efeito combinado do transplante renal e do ácido zoledrônico, notamos que este último parece intensificar o ganho de DMO na DXA ocasionado pelo transplante. Na histomorfometria, o transplante isolado não alterou o $\mathrm{BV} / \mathrm{TV}$, enquanto o ácido zoledrônico teve uma tendência estatística, porém não significativa, $(\mathrm{p}=0,06)$ a diminuir esse parâmetro. Esses achados da nossa população estão em consonância com os estudos mais recentes que também encontraram uma menor perda de massa óssea no primeiro ano após transplante, possivelmente pelo uso de doses menores de corticóide e aumento da suplementação de cálcio e vitamina $\mathrm{D}^{32,35,93}$. Se olharmos para o osso cortical, houve inclusive diminuição da porosidade e aumento da espessura como efeito do transplante renal. Estudo com biópsia óssea antes e após o transplante renal em 7 pacientes, relatou efeitos opostos no compartimento cortical e 
trabecular, sem perda na cortical, talvez pelo fato do osso cortical ser metabolicamente menos ativo e menos sensível a medicações imunossupressoras ${ }^{94}$. Entretanto, dois estudos que avaliaram o compartimento cortical pela tomografia computadorizada periférica quantitativa de alta resolução observaram aumento de porosidade cortical após o transplante renal ${ }^{95,96}$, relacionando esse efeito aos níveis de PTH. Os dois tinham mais diabéticos e níveis de PTH discretamente mais elevados. Além disso, embora estudo recente de nosso grupo tenha mostrado concordância entre achados de HR-pQCT e histomorfometria óssea ${ }^{97}$, ainda não podemos afirmar com certeza que estes métodos são de fato comparáveis.

Nosso estudo apresenta algumas limitações, como o número relativamente pequeno de participantes. Para algumas variáveis, observamos algumas tendências que poderiam ser significativas com um número maior de pacientes em cada grupo. Além disto, por ser um grupo de pacientes específico, candidatos a transplante doador vivo, com menos tempo diálise, não representa a maior parte da população em diálise no Brasil. Porém, podemos observar vários pontos positivos nesse estudo. Primeiro foi realizado de maneira prospectiva, e os pacientes foram seus próprios controles evolutivos, tirando o viés de comparar com outra população. Segundo, avaliamos a dinâmica das diversas proteínas relacionadas ao metabolismo ósseo em um único ensaio. Pelo nosso conhecimento não há até agora estudo que tenha avaliado todas simultaneamente. Terceiro, além da dosagem sérica, as proteínas também foram analisadas no compartimento ósseo, e por três métodos diferentes: imunohistoquimica, multiplex e expressão gênica.

Portanto, acreditamos que as informações trazidas por este estudo podem nos ajudar no melhor entendimento da fisiopatologia da doença óssea após o transplante e no seu tratamento. 
6. Conclusões 


\section{Conclusão}

A recuperação da função renal após o transplante é acompanhada de mudanças nas proteínas séricas e ósseas. A esclerostina óssea aumentou, apesar da diminuição do nível sérico, acompanhada de mudanças em outras proteínas que confirmam a inibição da via Wnt. Houve também um balanço que favorece a reabsorção óssea da via RANKL/OPG. Embora não tenhamos encontrado alterações histomorfométricas compatíveis com perda de massa óssea após 1 ano, estas alterações detectadas podem justificar a doença óssea encontrada no transplante renal a longo prazo. Acreditamos que nossos achados podem ajudar a desvendar a fisiopatologia da doença óssea pós transplante e guiar a busca por novas terapias. 
7. ANEXOS 
Anexo A - Comprovante de aprovação do Comitê de Ética do HCFMUSP.

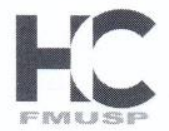

\author{
Hospital das Clínicas da FMUSP \\ Comissão de Ética para Análise de Projetos de Pesquisa \\ CAPPesq
}

No Protocolo: 0776/11

Título: Ácido Zoledrônico para Prevenir a Perda Óssea no Primeiro Ano após o Transplante Renal: Um Estudo Prospectivo e Randomizado

Pesquisador Responsável: Elias David Neto

Pesquisador Executante: Igor Denizarde Bacelar Marques

Disciplina: Nefrologia

Departamento: CLÍNICA MÉDICA

A Comissão de Ética para Análise de Projetos de Pesquisa CAPPesq da Diretoria Clínica do Hospital das Clínicas da Faculdade de Medicina da Universidade de São Paulo, APROVOU / TOMOU CIÊNCIA na sessão datada de 04/05/2016, do(s) documento(s) abaixo mencionado(s):

- Carta datada de 28.03.16 - Inclusão da aluna de pós-graduação Maria Júlia C. L. Nepomuceno Araújo na pesquisa; Relatório parcial do estudo

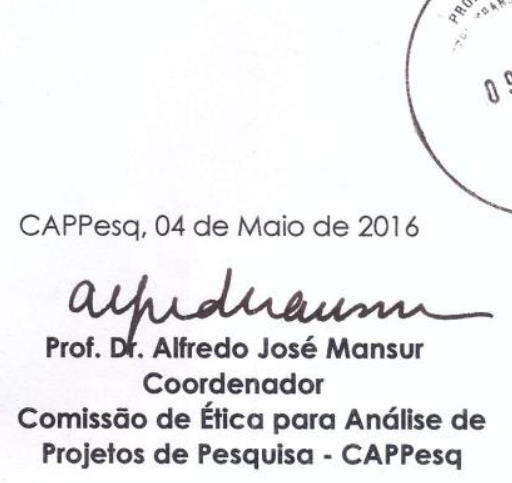

Rua Dr. Ovídio Pires de Campos, 225 - Prédio da Administração - $5^{\circ}$ andar - CEP 05403-010 - São Paulo - SP. $55112661-7585$ - $55112661-6442$ | cappesq.adm@hc.fm.usp.br 
8. REFERÊNCIAS 


\section{REFERÊNCIAS}

1. Wolfe RA, Ashby VB, Milford EL, et al. Comparison of mortality in all patients on dialysis, patients on dialysis awaiting transplantation, and recipients of a first cadaveric transplant. N Engl J Med. 1999;341(23):1725-1730.

2. Ojo AO, Hanson JA, Meier-Kriesche H, et al. Survival in recipients of marginal cadaveric donor kidneys compared with other recipients and wait-listed transplant candidates. J Am Soc Nephrol. 2001;12(3):589-597.

3. Neves CL, dos Reis LM, Batista DG, et al. Persistence of bone and mineral disorders 2 years after successful kidney transplantation. Transplantation. 2013;96(3):290-296.

4. Julian BA, Laskow DA, Dubovsky J, Dubovsky EV, Curtis JJ, Quarles LD. Rapid loss of vertebral mineral density after renal transplantation. $N$ Engl $\mathrm{J}$ Med. 1991;325(8):544-550.

5. Brandenburg VM, Westenfeld R, Ketteler M. The fate of bone after renal transplantation. J Nephrol. 2004;17(2):190-204.

6. Durieux S, Mercadal L, Orcel $\mathrm{P}$, et al. Bone mineral density and fracture prevalence in long-term kidney graft recipients. Transplantation. 2002;74(4):496500.

7. Kalantar-Zadeh K, Molnar MZ, Kovesdy CP, Mucsi I, Bunnapradist S. Management of mineral and bone disorder after kidney transplantation. Curr Opin Nephrol Hypertens. 2012;21(4):389-403.

8. Ball AM, Gillen DL, Sherrard D, et al. Risk of hip fracture among dialysis and renal transplant recipients. JAMA. 2002;288(23):3014-3018.

9. Vautour LM, Melton LJ, Clarke BL, Achenbach SJ, Oberg AL, McCarthy JT. Long-term fracture risk following renal transplantation: a population-based study. Osteoporos Int. 2004;15(2):160-167.

10. Alshayeb HM, Josephson MA, Sprague SM. CKD-mineral and bone disorder management in kidney transplant recipients. Am J Kidney Dis. 2013;61(2):310325.

11. Nam JH, Moon JI, Chung SS, et al. Prevalence and risk factors for vertebral fractures in renal transplants. Transplant Proc. 2000;32(7):1877.

12. Haas M, Leko-Mohr Z, Roschger P, et al. Zoledronic acid to prevent bone loss in the first 6 months after renal transplantation. Kidney Int. 2003;63(3):1130-1136.

13. Malluche $\mathrm{HH}$, Monier-Faugere MC, Herberth J. Bone disease after renal transplantation. Nat Rev Nephrol. 2010;6(1):32-40.

14. Monier-Faugere MC, Mawad H, Qi Q, Friedler RM, Malluche HH. High prevalence of low bone turnover and occurrence of osteomalacia after kidney transplantation. J Am Soc Nephrol. 2000;11(6):1093-1099.

15. Cruz EA, Lugon JR, Jorgetti V, Draibe SA, Carvalho AB. Histologic evolution of bone disease 6 months after successful kidney transplantation. Am J Kidney Dis. 2004;44(4):747-756.

16. Rojas E, Carlini RG, Clesca P, et al. The pathogenesis of osteodystrophy after renal transplantation as detected by early alterations in bone remodeling. Kidney Int. 2003;63(5):1915-1923.

17. Gupta AK, Huang M, Prasad GV. Determinants of bone mineral density in stable kidney transplant recipients. J Nephrol. 2012;25(3):373-383. 
18. Weisinger JR, Carlini RG, Rojas E, Bellorin-Font E. Bone disease after renal transplantation. Clin J Am Soc Nephrol. 2006;1(6):1300-1313.

19. Naylor KL, Jamal SA, Zou G, et al. Fracture Incidence in Adult Kidney Transplant Recipients. Transplantation. 2015.

20. Evenepoel P. Recovery versus persistence of disordered mineral metabolism in kidney transplant recipients. Semin Nephrol. 2013;33(2):191-203.

21. Wolf M, Weir MR, Kopyt N, et al. A Prospective Cohort Study of Mineral Metabolism After Kidney Transplantation. Transplantation. 2015.

22. Perrin P, Caillard S, Javier RM, et al. Persistent hyperparathyroidism is a major risk factor for fractures in the five years after kidney transplantation. Am J Transplant. 2013;13(10):2653-2663.

23. Pihlstrøm H, Dahle DO, Mjøen G, et al. Increased risk of all-cause mortality and renal graft loss in stable renal transplant recipients with hyperparathyroidism. Transplantation. 2015;99(2):351-359.

24. Blaslov K, Katalinic L, Kes P, Spasovski G, Smalcelj R, Basic-Jukic N. What is the impact of immunosuppressive treatment on the post-transplant renal osteopathy? Int Urol Nephrol. 2014;46(5):1019-1024.

25. Guañabens N, Gifre L, Peris P. The role of Wnt signaling and sclerostin in the pathogenesis of glucocorticoid-induced osteoporosis. Curr Osteoporos Rep. 2014;12(1):90-97.

26. Sun L, Blair HC, Peng Y, et al. Calcineurin regulates bone formation by the osteoblast. Proc Natl Acad Sci U S A. 2005;102(47):17130-17135.

27. Moreira RO, Thiago LS, Oliveira FL, et al. Cyclosporine A, but not tacrolimus, is associated with impaired proliferation and differentiation of human osteoblastlike cells in vitro. Med Sci Monit. 2009;15(3):BR65-70.

28. Westenfeld R, Schlieper G, Wöltje M, et al. Impact of sirolimus, tacrolimus and mycophenolate mofetil on osteoclastogenesis--implications for posttransplantation bone disease. Nephrol Dial Transplant. 2011;26(12):4115-4123.

29. Group KDIGOKC-MW. KDIGO clinical practice guideline for the diagnosis, evaluation, prevention, and treatment of Chronic Kidney Disease-Mineral and Bone Disorder (CKD-MBD). Kidney Int Suppl. 2009(113):S1-130.

30. Chapman JR. The KDIGO clinical practice guidelines for the care of kidney transplant recipients. Transplantation. 2010;89(6):644-645.

31. Palmer SC, McGregor DO, Strippoli GF. Interventions for preventing bone disease in kidney transplant recipients. Cochrane Database Syst Rev. 2007(3):CD005015.

32. Stein EM, Ortiz D, Jin Z, McMahon DJ, Shane E. Prevention of fractures after solid organ transplantation: a meta-analysis. J Clin Endocrinol Metab. 2011;96(11):3457-3465.

33. Coco M, Glicklich D, Faugere MC, et al. Prevention of bone loss in renal transplant recipients: a prospective, randomized trial of intravenous pamidronate. J Am Soc Nephrol. 2003;14(10):2669-2676.

34. Schwarz C, Mitterbauer C, Heinze G, Woloszczuk W, Haas M, Oberbauer R. Nonsustained effect of short-term bisphosphonate therapy on bone turnover three years after renal transplantation. Kidney Int. 2004;65(1):304-309.

35. Bonani M, Frey D, Brockmann J, et al. Effect of Twice-Yearly Denosumab on Prevention of Bone Mineral Density Loss in De Novo Kidney Transplant Recipients: A Randomized Controlled Trial. Am J Transplant. 2016;16(6):18821891. 
36. Cohen JB, Gordon CE, Balk EM, Francis JM. Cinacalcet for the treatment of hyperparathyroidism in kidney transplant recipients: a systematic review and meta-analysis. Transplantation. 2012;94(10):1041-1048.

37. Cannata-Andia JB, Roman-Garcia P, Hruska K. The connections between vascular calcification and bone health. Nephrol Dial Transplant. 2011;26(11):3429-3436.

38. Hu MC, Shiizaki K, Kuro-o M, Moe OW. Fibroblast growth factor 23 and Klotho: physiology and pathophysiology of an endocrine network of mineral metabolism. Annu Rev Physiol. 2013;75:503-533.

39. Quarles LD. A systems biology preview of the relationships between mineral and metabolic complications in chronic kidney disease. Semin Nephrol. 2013;33(2):130-142.

40. Bonucci E, Gherardi G. Osteocyte ultrastructure in renal osteodystrophy. Virchows Arch A Pathol Anat Histol. 1977;373(3):213-231.

41. Dallas SL, Prideaux M, Bonewald LF. The osteocyte: an endocrine cell ... and more. Endocr Rev. 2013;34(5):658-690.

42. Bellido T. Osteocyte-driven bone remodeling. Calcif Tissue Int. 2014;94(1):2534.

43. Plotkin LI, Bellido T. Osteocytic signalling pathways as therapeutic targets for bone fragility. Nat Rev Endocrinol. 2016;12(10):593-605.

44. Shimada T, Mizutani S, Muto T, et al. Cloning and characterization of FGF23 as a causative factor of tumor-induced osteomalacia. Proc Natl Acad Sci U S A. 2001;98(11):6500-6505.

45. Ben-Dov IZ, Galitzer H, Lavi-Moshayoff V, et al. The parathyroid is a target organ for FGF23 in rats. J Clin Invest. 2007;117(12):4003-4008.

46. Moysés RM, Schiavi SC. Sclerostin, Osteocytes, and Chronic Kidney Disease Mineral Bone Disorder. Semin Dial. 2015;28(6):578-586.

47. Han SY, Hwang EA, Park SB, Kim HC, Kim HT. Elevated fibroblast growth factor 23 levels as a cause of early post-renal transplantation hypophosphatemia. Transplant Proc. 2012;44(3):657-660.

48. Kawarazaki H, Shibagaki Y, Fukumoto S, et al. Natural history of mineral and bone disorders after living-donor kidney transplantation: a one-year prospective observational study. Ther Apher Dial. 2011;15(5):481-487.

49. Wolf M, Molnar MZ, Amaral AP, et al. Elevated fibroblast growth factor 23 is a risk factor for kidney transplant loss and mortality. J Am Soc Nephrol. 2011;22(5):956-966.

50. Baron R, Kneissel M. WNT signaling in bone homeostasis and disease: from human mutations to treatments. Nat Med. 2013;19(2):179-192.

51. Krishnan V, Bryant HU, Macdougald OA. Regulation of bone mass by Wnt signaling. J Clin Invest. 2006;116(5):1202-1209.

52. Teti A. Mechanisms of osteoclast-dependent bone formation. Bonekey Rep. 2013;2:449.

53. Nakashima T, Hayashi M, Fukunaga T, et al. Evidence for osteocyte regulation of bone homeostasis through RANKL expression. Nat Med. 2011;17(10):12311234.

54. Evenepoel P, D'Haese P, Brandenburg V. Sclerostin and DKK1: new players in renal bone and vascular disease. Kidney Int. 2015;88(2):235-240. 
55. Sabbagh Y, Graciolli FG, O'Brien S, et al. Repression of osteocyte Wnt/ $\beta$-catenin signaling is an early event in the progression of renal osteodystrophy. $J$ Bone Miner Res. 2012;27(8):1757-1772.

56. Ryan ZC, Ketha H, McNulty MS, et al. Sclerostin alters serum vitamin D metabolite and fibroblast growth factor 23 concentrations and the urinary excretion of calcium. Proc Natl Acad Sci U S A. 2013;110(15):6199-6204.

57. Cejka D, Marculescu R, Kozakowski N, et al. Renal elimination of sclerostin increases with declining kidney function. $J$ Clin Endocrinol Metab. 2014;99(1):248-255.

58. Gonçalves FL, Elias RM, dos Reis LM, et al. Serum sclerostin is an independent predictor of mortality in hemodialysis patients. BMC Nephrol. 2014;15:190.

59. Tomei P, Zaza G, Granata S, et al. Sclerostin and Dickkopf-1 in post-menopausal renal allograft recipients. Transplant Proc. 2014;46(7):2241-2246.

60. Evenepoel P, Claes K, Viaene L, et al. Decreased Circulating Sclerostin Levels in Renal Transplant Recipients With Persistent Hyperparathyroidism. Transplantation. 2016;100(10):2188-2193.

61. Bonani M, Rodriguez D, Fehr T, et al. Sclerostin blood levels before and after kidney transplantation. Kidney Blood Press Res. 2014;39(4):230-239.

62. Graciolli FG, Neves KR, Barreto F, et al. The complexity of chronic kidney disease-mineral and bone disorder across stages of chronic kidney disease. Kidney Int. 2017;91(6):1436-1446.

63. Pereira RC, Valta H, Tumber N, et al. Altered Osteocyte-Specific Protein Expression in Bone after Childhood Solid Organ Transplantation. PLoS One. 2015;10(9):e0138156.

64. Dos Reis LM, Batalha JR, Muñoz DR, et al. Brazilian normal static bone histomorphometry: effects of age, sex, and race. J Bone Miner Metab. 2007;25(6):400-406.

65. Dempster DW, Compston JE, Drezner MK, et al. Standardized nomenclature, symbols, and units for bone histomorphometry: a 2012 update of the report of the ASBMR Histomorphometry Nomenclature Committee. J Bone Miner Res. 2013;28(1):2-17.

66. Melsen F, Mosekilde L. Tetracycline double-labeling of iliac trabecular bone in 41 normal adults. Calcif Tissue Res. 1978;26(2):99-102.

67. Moe S, Drüeke T, Cunningham J, et al. Definition, evaluation, and classification of renal osteodystrophy: a position statement from Kidney Disease: Improving Global Outcomes (KDIGO). Kidney Int. 2006;69(11):1945-1953.

68. Malluche HH, Mawad HW, Monier-Faugere MC. Renal osteodystrophy in the first decade of the new millennium: analysis of 630 bone biopsies in black and white patients. J Bone Miner Res. 2011;26(6):1368-1376.

69. Gomes SA, dos Reis LM, de Oliveira IB, Noronha IL, Jorgetti V, Heilberg IP. Usefulness of a quick decalcification of bone sections embedded in methyl methacrylate[corrected]: an improved method for immunohistochemistry. $J$ Bone Miner Metab. 2008;26(1):110-113.

70. Graciolli FG NK, Barreto F, Barreto DV, dos Reis LM, Canziani ME, Sabbagh Y, Carvalho AB, JOrgetti V, Elias RM, Schiavi S, Moysés RMA. CKD-MBD across CKD stages: a study of biochemical markers, bone, histomorphometry and immunohistochemistry. Kidney International. 2017.

71. Sesso RC, Lopes AA, Thomé FS, Lugon JR, Martins CT. Brazilian Chronic Dialysis Census 2014. J Bras Nefrol. 2016;38(1):54-61. 
72. Pereira RC, Juppner H, Azucena-Serrano CE, Yadin O, Salusky IB, WesselingPerry K. Patterns of FGF-23, DMP1, and MEPE expression in patients with chronic kidney disease. Bone. 2009;45(6):1161-1168.

73. Xiong J, Onal M, Jilka RL, Weinstein RS, Manolagas SC, O'Brien CA. Matrixembedded cells control osteoclast formation. Nat Med. 2011;17(10):1235-1241.

74. Drake MT, Khosla S. Hormonal and systemic regulation of sclerostin. Bone. 2017;96:8-17.

75. Bellido T, Ali AA, Gubrij I, et al. Chronic elevation of parathyroid hormone in mice reduces expression of sclerostin by osteocytes: a novel mechanism for hormonal control of osteoblastogenesis. Endocrinology. 2005;146(11):45774583.

76. Silvestrini G, Ballanti P, Leopizzi M, et al. Effects of intermittent parathyroid hormone $(\mathrm{PTH})$ administration on SOST mRNA and protein in rat bone. $J$ Mol Histol. 2007;38(4):261-269.

77. Yu EW, Kumbhani R, Siwila-Sackman E, Leder BZ. Acute decline in serum sclerostin in response to PTH infusion in healthy men. J Clin Endocrinol Metab. 2011;96(11):E1848-1851.

78. Piemonte S, Romagnoli E, Bratengeier C, et al. Serum sclerostin levels decline in post-menopausal women with osteoporosis following treatment with intermittent parathyroid hormone. J Endocrinol Invest. 2012;35(9):866-868.

79. van Lierop AH, Witteveen JE, Hamdy NA, Papapoulos SE. Patients with primary hyperparathyroidism have lower circulating sclerostin levels than euparathyroid controls. Eur J Endocrinol. 2010;163(5):833-837.

80. Ardawi MS, Al-Sibiany AM, Bakhsh TM, Rouzi AA, Qari MH. Decreased serum sclerostin levels in patients with primary hyperparathyroidism: a cross-sectional and a longitudinal study. Osteoporos Int. 2012;23(6):1789-1797.

81. Gifre L, Ruiz-Gaspà S, Monegal A, et al. Effect of glucocorticoid treatment on Wnt signalling antagonists (sclerostin and Dkk-1) and their relationship with bone turnover. Bone. 2013;57(1):272-276.

82. Sato AY, Cregor M, Delgado-Calle J, et al. Protection From GlucocorticoidInduced Osteoporosis by Anti-Catabolic Signaling in the Absence of Sost/Sclerostin. J Bone Miner Res. 2016;31(10):1791-1802.

83. Dawson-Hughes B, Harris SS, Ceglia L, Palermo NJ. Effect of supplemental vitamin D and calcium on serum sclerostin levels. Eur $J$ Endocrinol. 2014;170(4):645-650.

84. Wijenayaka AR, Prideaux M, Yang D, et al. Early response of the human SOST gene to stimulation by 1 $\alpha, 25$-dihydroxyvitamin D3. J Steroid Biochem Mol Biol. 2016;164:369-373.

85. Catalano A, Morabito N, Basile G, Brancatelli S, Cucinotta D, Lasco A. Zoledronic acid acutely increases sclerostin serum levels in women with postmenopausal osteoporosis. J Clin Endocrinol Metab. 2013;98(5):1911-1915.

86. Anastasilakis AD, Polyzos SA, Gkiomisi A, Bisbinas I, Gerou S, Makras P. Comparative effect of zoledronic acid versus denosumab on serum sclerostin and dickkopf-1 levels of naive postmenopausal women with low bone mass: a randomized, head-to-head clinical trial. $J$ Clin Endocrinol Metab. 2013;98(8):3206-3212.

87. Bargnoux AS, Dupuy AM, Garrigue V, Deleuze S, Cristol JP, Mourad G. Renal transplantation decreases osteoprotegerin levels. Transplant Proc. 2006;38(7):2317-2318. 
88. Sato T, Tominaga Y, Iwasaki Y, et al. Osteoprotegerin levels before and after renal transplantation. Am J Kidney Dis. 2001;38(4 Suppl 1):S175-177.

89. Glass DA, Bialek P, Ahn JD, et al. Canonical Wnt signaling in differentiated osteoblasts controls osteoclast differentiation. Dev Cell. 2005;8(5):751-764.

90. Malyszko J, Malyszko JS, Wolczynski S, Mysliwiec M. Osteoprotegerin and its correlations with new markers of bone formation and bone resorption in kidney transplant recipients. Transplant Proc. 2003;35(6):2227-2229.

91. Svensson M, Dahle DO, Mjøen G, et al. Osteoprotegerin as a predictor of renal and cardiovascular outcomes in renal transplant recipients: follow-up data from the ALERT study. Nephrol Dial Transplant. 2012;27(6):2571-2575.

92. Amiri FS, Khatami MR. Fibroblast Growth Factor 23 in Postrenal Transplant: An Often Forgotten Hormone. Exp Clin Transplant. 2016;14(6):606-616.

93. Nikkel LE, Mohan S, Zhang A, et al. Reduced fracture risk with early corticosteroid withdrawal after kidney transplant. Am J Transplant. 2012;12(3):649-659.

94. Carvalho C, Magalhães J, Pereira L, Simões-Silva L, Castro-Ferreira I, Frazão JM. Evolution of bone disease after kidney transplantation: A prospective histomorphometric analysis of trabecular and cortical bone. Nephrology (Carlton). 2016;21(1):55-61.

95. Iyer SP, Nikkel LE, Nishiyama KK, et al. Kidney transplantation with early corticosteroid withdrawal: paradoxical effects at the central and peripheral skeleton. J Am Soc Nephrol. 2014;25(6):1331-1341.

96. Nishiyama KK, Pauchard Y, Nikkel LE, et al. Longitudinal HR-pQCT and image registration detects endocortical bone loss in kidney transplantation patients. $J$ Bone Miner Res. 2015;30(3):554-561.

97. Marques ID, Araújo MJ, Graciolli FG, et al. Biopsy vs. peripheral computed tomography to assess bone disease in CKD patients on dialysis: differences and similarities. Osteoporos Int. 2017;28(5):1675-1683. 
APÊNDICES 
Artigo submetido à revista BMC Nephrology

\section{Persistent hyperparathyroidism as a risk factor for long-term graft failure}

Maria Júlia C. L. N. Araujo M.D. ${ }^{1,2}$, Janaina A. M. Ramalho M.D. ${ }^{1,2}$, Rosilene M. Elias M.D., PhD ${ }^{2}$, Vanda Jorgetti M.D., $\mathrm{PhD}^{2}$, William Nahas M.D., PhD ${ }^{1}$, Melani Custodio M.D., $\mathrm{PhD}^{2}$, Rosa M.A. Moyses M.D., $\mathrm{PhD}^{2}$ and Elias David-Neto M.D., PhD ${ }^{1,2}$.

1 - Renal Transplantation Service and 2- Nephrology Division, São Paulo University School of Medicine, São Paulo, Brazil

Running Head: Hyperparathyroidism and graft failure

Key words: kidney transplant, graft failure, hyperparathyroidism

\section{Corresponding author:}

Maria Júlia Araújo, M.D.

Hospital das Clínicas - Instituto Central - sala 7036

Av. Dr. Enéas de Carvalho Aguiar, 255; São Paulo, SP - Brasil

ZIP code: 05403-000

Phone number +551126618089 FAX +55 1126617238

maju_araujo@yahoo.com.br 


\begin{abstract}
Background: Although a successful kidney transplant (KTx) improves most of the mineral disorders (MBD) produced by $\mathrm{CKD}$, hyperparathyroism (pHPT) may persist. Recent studies have pointed out the association between pHPT and poor graft outcomes. Methods: Retrospective analysis of 911 adult KTx between Jan/2005 and Dec/2014. Clinical and laboratory data were collected from electronic database. Graft failure was defined as return to dialysis. Results: Overall, $62 \%$ of the patients were classified as having pHPT one year after KTx. After a mean follow-up time of 47 months, there were 59 graft failures (49 in pHPT and 10 in non-pHPT group, $\mathrm{p}=0.003$ ). At last follow-up, death-censored graft survival was lower in the pHPT group $(\mathrm{p}=0.009)$, which remained after adjustment for age at transplantation, donor age, donor type, acute rejection, parathyroidectomy and eGFR at 1 year after transplantation (OR 1.99; 1.004-3.971; $\mathrm{p}=0.049)$. A PTH of $150 \mathrm{pg} / \mathrm{ml}$ at six months was the best cut-off to predict $\mathrm{pHPT}$ at one year $($ specificity $=92.1 \%)$. Conclusions: Individuals with pHPT, even those with slightly elevated PTH, have an increased risk of long-term death-censored graft failure. These results highlight the need for a better management of CKD-MBD before and during the first year after KTx.
\end{abstract}

Key words: kidney transplant, graft failure, hyperparathyroidism 


\section{Introduction}

A successful kidney transplantation (KTx) corrects the majority of the metabolic disturbances of chronic kidney disease (CKD). In addition, it has also the potential to improve quality of life, to restore a productive life and to prolong survival $[1,2]$. The development of novel immunosuppressive therapies led to even better outcomes compared to conventional dialysis therapy [3].

Mineral and bone disorder (MBD) is a very common CKD complication and is associated with vascular and soft tissues calcification, fractures, lower quality of life and increased mortality [4]. Successful KTx should also improve CKD-MBD [5, 6]. However, a high incidence of alterations in bone turnover, mineralization and volume has been demonstrated in these patients for years after transplantation [7].

Persistent hyperparathyroidism (pHTP) has been identified in up to $80 \%$ of patients throughout the first year after KTx [8], although the numbers may vary as the definition of pHPT changes among centers, and the ideal range of parathormone (PTH) plasma levels after transplantation is not well defined [9].

In the scenario of pHPT, PTH levels are inappropriately high and contribute to post-transplant complications such as hypercalcemia, hypophosphatemia, elevated fibroblast growth factor 23 (FGF-23) and nephrocalcinosis [10-13]. Some evidences are pointing to unfavourable renal outcomes $[14,15]$ associated with pHPT. The clinical and biochemical consequences of pHPT may persist for years if not appropriately treated [16, 17]. The KDIGO (Kidney Disease - Improving Global Outcomes) guidelines recommend pHPT treatment with active vitamin D or bisphosphonates in the first 12 months after KTx in those with estimated glomerular filtration rate (eGFR) greater than $30 \mathrm{ml} / \mathrm{min} / 1.73 \mathrm{~m}^{2}$ and low bone mineral density [18]. Recently, calcimimetics have been used with encouraging results [19], although, even with this effective drug, severe cases of pHPT still require parathyroidectomy (PTX) [15]. Nonetheless, there is no robust evidence on how to guide the treatment of pHPT after KTx.

There is still controversy in the literature regarding the impact of high pretransplant PTH levels, on both early [20] and one-year graft function [21], as well as in survival [22]. Wether pHPT may affect long-term graft function is not well elucidated. 
Few studies that address this issue failed in demonstrating the participation of MBD in this context and yet, the relationship is associative rather than causal [23].

In the current analysis, we evaluated the impact of pHPT one year after KTx, on the long-term graft outcome, in a single-center, large cohort of patients with pHPT. In addition, we examined possible factors that could be implicated in the risk of pHPT.

\section{Materials and methods}

Between January 2000 and December 2014, 1,708 isolated adult KTx were performed at our center. Standard immunosuppressive therapy consisted of tacrolimus, mycophenolic acid prodrug and prednisone. Steroids were started on the day of transplantation and were gradually tapered to $5 \mathrm{mg}$ at 1-2 months.

Data concerning recipients (age, gender, primary renal disease, dialysis vintage and modality before KTx, history of PTX, panel status), donors (age, gender and type cadaveric vs. alive, expanded vs. standard criteria among the cadaveric), and graft (immunosuppression, history of acute rejection episodes, cytomegalovirus infection, poliomavirus infection) were collected from the electronic charts. Patients were considered sensitized when panel was different from zero.

Biochemical data were evaluated pre KTx, at 6 months and then every year after KTx until the end of follow-up. Study variables included: serum creatinine, plasma PTH, serum 25-hydroxy-vitamin D, serum total alkaline phosphatase, serum ionized calcium (iCa) and serum phosphate. Pre-transplant PTH levels were defined as any measurement obtained 6 months before and up to one week after the KTx.

To minimize confounding factors that would be introduced by poor allograft function, we excluded patients with an eGFR (calculated by Modification of Diet in Renal Disease - MDRD4- equation) of less than $30 \mathrm{ml} / \mathrm{min} / 1.73 \mathrm{~m}^{2}$ at one year of KTx. We have also excluded patients with missing data on PTH or $\mathrm{iCa}$, and those who were lost from follow-up: died before one year, had early graft loss (before 1 year) or had been transferred to another transplant center. 
pHPT was defined as $\mathrm{iCa}>5.3 \mathrm{mg} / \mathrm{dl}$ and/or PTH $>100 \mathrm{pg} / \mathrm{ml}$ at one year after KTx. Patients were followed until graft loss, death or end of study period (June, $31^{\text {st }}, 2015$ ). Graft loss was defined as return to dialysis.

All laboratory analyses were performed by standard techniques, specifically: iCa [reference range $(R R)=4.6$ to $5.3 \mathrm{mg} / \mathrm{dl}$; selective ion method]; serum phosphate $(\mathrm{RR}=$ 2.7 to $4.5 \mathrm{mg} / \mathrm{dl}$; enzymatic colorimetric method); alkaline phosphatase ( $\mathrm{RR}=32$ to 122 $\mathrm{U} / \mathrm{L}$ ); PTH (RR = 15 to $65 \mathrm{pg} / \mathrm{ml}$, eletroquimioluminescense assay); 25-hydroxy-vitamin $\mathrm{D}(\mathrm{RR}=30$ to $100 \mathrm{ng} / \mathrm{ml}$; quimioluminescence method); and serum creatinine $(\mathrm{RR}=0.7$ to $1.2 \mathrm{mg} / \mathrm{dl}$; kinetic colorimetric method).

\section{Statistical analysis}

Continuous data are presented as means \pm standard deviation unless indicated otherwise, and categorical data are presented as percentage. Student's t-test or Mann Whitney test was used to compare groups, according to normal or abnormally distributed variables, respectively. Qui-square test was used to compare categorical variables between groups. Logistic regression models were used to estimate the odds ratio (OR) and $95 \%$ confidence interval of pHPT.

Graft survival was censored by death. Kaplan-Meyer and Cox proportional hazards regression models analyzed potential associations with survival. The graft survival analysis was adjusted for donor and recipient age, type of donor, including expanded $v s$. standard, eGFR at one year, dialysis vintage and modality, and PTX before and after transplantation.

Discrimination abilities of different levels of PTH in classify pHPT post KTx were investigated using a receiver operator characteristic (ROC) curve. All p values were twosided and values $<0.05$ were considered significant. Analyses were performed with the use of SPSS 20.0.1 (SPSS Inc, Chicago, Ill). 


\section{Results}

From the total of 1,708 KTx performed between January 2005 and December 2014, 210 were excluded because of an eGFR $<30 \mathrm{ml} / \mathrm{min}$ one year after KTx, 348 due to missing data on PTH or iCa on one-year evaluation, and 239 for loss of follow up. Therefore, 911 patients were enrolled in 1 of 2 strata, according to pHPT, as described on methods (Figure 1).

One year after KTx, 568 (62\%) of the patients were classified as having pHPT and $343(38 \%)$ were not.

As described in Table 1, patients with pHPT were longer on dialysis, were more frequently treated by hemodialysis than peritoneal dialysis, and received less preemptive KTx, had lower percentage of diabetes and a lower proportion of them had been submitted to PTX previous to KTx. In addition, they had received kidney from older donors. Patients with pHPT also had higher levels of serum iCa, phosphorus, PTH and alkaline phosphatase before KTx when compared to those without pHPT.

As shown in Table 2, although renal function was not different between the two groups at six months after KTx, pHPT patients presented slightly lower eGFR at one year. Alkaline phosphatase was persistently higher in these patients, whereas levels of phosphorus and 25-hydroxy-vitamin D were lower at one-year evaluation. As expected, the percentage of PTX post KTx was higher in patients with pHPT.

In the multivariate logistic regression analysis, shown in Table 3, the variables that increased the risk of pHPT at one year were: longer dialysis vintage, high levels of $\mathrm{iCa}$, phosphate and PTH pre KTx, and receiving a kidney from a female donor, whereas history of previous PTX and high levels of eGFR one year after transplantation protected against pHPT. Although donor gender was not significant in the univariate analysis, it was entered in the multivariable analysis, as patients who received a KTx from female gender presented low eGFR at 1 year as compared to a male gender donor (57 \pm 17 vs. $60 \pm 18 \mathrm{ml} / \mathrm{min}, \mathrm{p}=0.002$ ). Of note, the analysis without donor gender did not change the results (data not shown). Also, expanded criteria donor had no significant impact on the above-mentioned results (data not shown). 


\section{Patient and graft survival analysis}

The mean follow-up time was 47 months, ranging from 4 to 126 months. Patient survival was similar between those with and without pHPT (median of 3,498 vs. 3,331 days, respectively, $\mathrm{p}=0.387$ ).

Death-censored graft failure was observed in 59 patients (49 in pHPT and 10 in non-pHPT group, $p=0.009)$. The death-censored graft survival was lower in the pHPT group (Figure 2A). Cox-regression analysis confirmed this result (OR 1.99; 1.004-3.971; $\mathrm{p}=0.049$ ) after adjustment for age at transplantation, donor age, donor type, acute rejection, PTX and eGFR at 1 year after transplantation, as shown in Figure 2B.

\section{PTH levels cut-offs to predict $\mathbf{p H P T}$}

As we found that pHPT can affect graft survival, a ROC curve for the detection of PTH cut-off value that can predict pHPT post KTx at different time points was performed. The suggested time and value for PTH levels are shown in Figure 3 and Table 4. At the 6-month after KTx the ROC curve of PTH values gave the higher AUC and a PTH cut-off value of $150 \mathrm{pg} / \mathrm{ml}$ had the highest specificity for $\mathrm{pHPT}$ at one year.

\section{Discussion}

In this retrospective study, the prevalence of pHPT at one year after KTx, as evaluated by PTH higher than $100 \mathrm{pg} / \mathrm{ml}$ and $\mathrm{iCa}>5.3$ is substantial. These patients are more likely to have high levels of $\mathrm{PTH}, \mathrm{iCa}$ and phosphorus before transplantation. Moreover, we have demonstrated that having a pHPT is an independent risk factor for graft loss. Indeed, PTH levels at 6 months after KTx can predict this outcome.

The optimal PTH value before transplantation is not well established, but a prospective observational study suggested that a PTH level of $300 \mathrm{pg} / \mathrm{ml}$, the upper limit recommended by the KDOQI (Kidney Disease Outcomes Quality Initiative) guideline, might be an appropriate target to prevent MBD after KTx [10]. We found that pre KTx PTH was a good predictor of pHPT. Our findings are not corroborated by a recent 
prospective study showing there was no difference when comparing PTH $<65$ and between $65-300 \mathrm{pg} / \mathrm{ml}$ on the risk of pHPT [8].This divergence can be explained, at least partially, by the severity of HPT in our patients. Besides PTH, we found that iCa and phosphorus before transplantation are predictors of $\mathrm{pHPT}$.

Likewise the pre-KTx period, an ideal level of PTH after transplantation is not known. KDIGO recommends that patients submitted to KTx should have the management of the CKD-MBD abnormalities, including PTH, similarly to patients with CKD 3-5. In this case, the PTH level should be within the reference range defined by each assay [18]. For this reason, some studies have considered pHPT when PTH is higher than $65 \mathrm{pg} / \mathrm{ml}$ after KTx, as this is the upper limit of PTH value obtained from most assays. By using this cut-off, one study has failed to demonstrate the association between pHPT and graft loss at 6 months after KTx [24]. In the current study, we have considered a PTH threshold of 1.5 times the upper limit of the assay $(100 \mathrm{pg} / \mathrm{ml})$ to define pHPT after KTx, founding a prevalence of $62 \%$. This is similar to recently demonstrated [8]. If we have considered a PTH level of $65 \mathrm{pg} / \mathrm{ml}$, the prevalence of pHPT would be even higher (77\% of patients). This finding raises the fact that even those patients considered on target by KDOQI or KDIGO before transplant, might have an abnormal PTH level afterwards.

Graft failure was already associated with CKD-MBD markers: PTH levels pre KTx [21, 25], iCa [26], phosphorus and alkaline phosphatase [22, 27]. In addition, high levels of pre KTx FGF-23 were also associated with increased risk of the composite outcome of all-cause mortality and graft loss [28], although these results are not unanimous [29]. To be classified as having a successful KTx, recipients are supposed to have an eGFR around $60-70 \mathrm{ml} / \mathrm{min} / 1.73 \mathrm{~m}^{2}$ [9]. Indeed, in this study, at 6 months the mean eGFR from both groups was similar and fitted the expected average eGFR for this time of transplantation. [30]. However, at one year the pHPT group had a slightly statistically significant lower eGFR, without substantial clinical difference. It is possible that, in a long term, these differences may become more evident. In order to avoid this bias on the outcomes, the graft failure was controlled to eGFR at one year in the Coxregression analysis. In fact, we have demonstrated that $\mathrm{pHPT}$ was associated with higher rate of graft loss, even after adjustments for many factors including but not limit to oneyear renal function, age, donor age and type and acute rejection, reducing the chance of 
confounding factors in our results. Of note, the same outcomes were observed using a PTH threshold of $65 \mathrm{pg} / \mathrm{ml}$ (data not shown).

The exact mechanism that leads pHPT to cause graft dysfunction is not well known. It can be due to vasoconstriction and tubulointerstitial calcification [15, 31], and the later was also associated with high levels of PTH and calcium pre KTx, which in turn was responsible for nephrocalcinosis and graft loss [32]. Interestingly, those patients submitted to PTX before transplantation were protected from this outcome [33], similarly to our findings. If this is due to the above-mentioned mechanism deserves further investigation.

Although the mechanism is not known, there is growing evidence to sustain that pHPT can lead to graft dysfunction. Earlier recognition and treatment of pHPT may revert this unfavorable outcome. To guide our efforts in identify patients at higher risk, values of PTH associated with higher specificity should be chosen to guide the recognition of these patients. However, it must be stressed that as current guidelines advocate to await spontaneous resolution of hyperparathyroidism for one year [34], our results should be taken into account to consider treatment in advance.

The ROC curve value for PTH level above $150 \mathrm{pg} / \mathrm{ml}$ at 6 months was predictive of one-year pHPT with $92 \%$ specificity. This cut-off should drive earlier therapy, avoiding the inevitable harm that will occur at one year, when renal structural changes might be already established.

Our study has some limitations due to its observational and retrospective design. We did not evaluate the potential mechanism by which pHPT might lead to graft loss. As the ideal PTH after KTx is not known, our results were based on a PTH cut-off of 100 $\mathrm{pg} / \mathrm{ml}$, while other studies have chosen $65 \mathrm{pg} / \mathrm{ml}$. All in all, any cut-off we have tested ended with the same outcome. Major strengths of our study are the large number of patients included, the long-term follow-up, several measurements of PTH and the adjustment for several aspects that could also contribute to the graft failure.

In conclusion, our study has shown that individuals with pHPT one year after KTx, even those with slightly elevated calcium or PTH, have an increased risk of longterm graft failure. pHPT can be predicted at 6 months using PTH values with a high 
specificity what can drive early intervention to improve graft outcome. Further studies are needed to prove that the proposed early intervention has an impact on graft outcomes.

M.J.C.L.N.A. designed, collected data, analyzed the data, prepared and reviewed the manuscript; J.A.M. collected data and reviewed the manuscript; R.M.E. analyzed the data and prepared the manuscript; V.J. reviewed the manuscript; W.N. reviewed the manuscript; M.C. designed, collected data and reviewed the manuscript; R.M.A.M. designed, analyzed the data, prepared and reviewed the manuscript; E.D.N. designed, reviewed the manuscript.

\section{References}

1 Wolfe RA, Ashby VB, Milford EL, Ojo AO, Ettenger RE, Agodoa LY, Held PJ, Port FK: Comparison of mortality in all patients on dialysis, patients on dialysis awaiting transplantation, and recipients of a first cadaveric transplant. $\mathrm{N}$ Engl $\mathrm{J}$ Med 1999;341:1725-1730.

2 Ojo AO, Hanson JA, Meier-Kriesche H, Okechukwu CN, Wolfe RA, Leichtman AB, Agodoa LY, Kaplan B, Port FK: Survival in recipients of marginal cadaveric donor kidneys compared with other recipients and wait-listed transplant candidates. J Am Soc Nephrol 2001;12:589-597.

3 Sayegh MH, Carpenter CB: Transplantation 50 years later--progress, challenges, and promises. N Engl J Med 2004;351:2761-2766.

4 Group KDIGOKC-MW: KDIGO clinical practice guideline for the diagnosis, evaluation, prevention, and treatment of Chronic Kidney Disease-Mineral and Bone Disorder (CKD-MBD). Kidney international Supplement 2009:S1-130.

5 Abdallah KA, Jorgetti V, Pereira RC, Reis LM, Pereira LM, Corrêa PH, Borelli A, Ianhez LE, Moysés RM, David-Neto E: Improvement of adynamic bone disease after renal transplantation. Braz J Med Biol Res 2006;39:31-41.

6 David-Neto E, Jorgetti V, Soeiro NM, Pereira RC, Borelli A, Ianhez LE, Sabbaga E, Wajchemberg BL, Arap S: Reversal of aluminum-related bone disease after renal transplantation. Am J Nephrol 1993;13:12-17.

7 Neves CL, dos Reis LM, Batista DG, Custodio MR, Graciolli FG, Martin ReC, Neves KR, Dominguez WV, Moyses RM, Jorgetti V: Persistence of bone and mineral disorders 2 years after successful kidney transplantation. Transplantation 2013;96:290296. 
8 Wolf M, Weir MR, Kopyt N, Mannon RB, Von Visger J, Deng H, Yue S, Vincenti F: A Prospective Cohort Study of Mineral Metabolism After Kidney Transplantation. Transplantation 2015

9 Srinivas TR, Flechner SM, Poggio ED, Askar M, Goldfarb DA, Navaneethan SD, Schold JD: Glomerular filtration rate slopes have significantly improved among renal transplants in the United States. Transplantation 2010;90:1499-1505.

10 Kawarazaki H, Shibagaki Y, Fukumoto S, Kido R, Ando K, Nakajima I, Fuchinoue S, Fujita T, Fukagawa M, Teraoka S: Natural history of mineral and bone disorders after living-donor kidney transplantation: a one-year prospective observational study. Ther Apher Dial 2011;15:481-487.

11 Evenepoel P: Recovery versus persistence of disordered mineral metabolism in kidney transplant recipients. Semin Nephrol 2013;33:191-203.

12 Han SY, Hwang EA, Park SB, Kim HC, Kim HT: Elevated fibroblast growth factor 23 levels as a cause of early post-renal transplantation hypophosphatemia. Transplant Proc 2012;44:657-660.

13 Bhan I, Shah A, Holmes J, Isakova T, Gutierrez O, Burnett SM, Jüppner H, Wolf M: Post-transplant hypophosphatemia: Tertiary 'Hyper-Phosphatoninism'? Kidney Int 2006;70:1486-1494.

14 Messa P, Cafforio C, Alfieri C: Clinical impact of hypercalcemia in kidney transplant. Int J Nephrol 2011;2011:906832.

15 Torregrosa JV, Barros X: Management of hypercalcemia after renal transplantation. Nefrologia 2013;33:751-757.

16 Goldsmith D, Owen WJ: Persistent post-transplant autonomous hyperparathyroidism despite 23 years of excellent renal allograft function. Nephron 2001;89:105-107.

17 Muirhead N, Zaltman JS, Gill JS, Churchill DN, Poulin-Costello M, Mann V, Cole EH: Hypercalcemia in renal transplant patients: prevalence and management in Canadian transplant practice. Clin Transplant 2014;28:161-165.

18 Chapman JR: The KDIGO clinical practice guidelines for the care of kidney transplant recipients. Transplantation 2010;89:644-645.

19 Alshayeb HM, Josephson MA, Sprague SM: CKD-mineral and bone disorder management in kidney transplant recipients. Am J Kidney Dis 2013;61:310-325.

20 Ahmadi F, Ali-Madadi A, Lessan-Pezeshki M, Khatami M, Mahdavi-Mazdeh M, Razeghi E, Maziar S, Seifi S, Abbasi M: Pre-transplant calcium-phosphate-parathormone homeostasis as a risk factor for early graft dysfunction. Saudi J Kidney Dis Transpl 2008; 19:54-58.

21 Roodnat JI, van Gurp EA, Mulder PG, van Gelder T, de Rijke YB, de Herder WW, Kal-van Gestel JA, Pols HA, Ijzermans JN, Weimar W: High pretransplant parathyroid hormone levels increase the risk for graft failure after renal transplantation. Transplantation 2006;82:362-367. 
22 Molnar MZ, Kovesdy CP, Mucsi I, Salusky IB, Kalantar-Zadeh K: Association of pre-kidney transplant markers of mineral and bone disorder with post-transplant outcomes. Clinical journal of the American Society of Nephrology : CJASN 2012;7:1859-1871.

23 Bouquegneau A, Salam S, Delanaye P, Eastell R, Khwaja A: Bone Disease after Kidney Transplantation. Clin J Am Soc Nephrol 2016

24 Pihlstrøm H, Dahle DO, Mjøen G, Pilz S, März W, Abedini S, Holme I, Fellström $\mathrm{B}$, Jardine AG, Holdaas H: Increased risk of all-cause mortality and renal graft loss in stable renal transplant recipients with hyperparathyroidism. Transplantation 2015;99:351-359.

25 Bleskestad IH, Bergrem H, Leivestad T, Hartmann A, Gøransson LG: Parathyroid hormone and clinical outcome in kidney transplant patients with optimal transplant function. Clin Transplant 2014;28:479-486.

26 Egbuna OI, Taylor JG, Bushinsky DA, Zand MS: Elevated calcium phosphate product after renal transplantation is a risk factor for graft failure. Clin Transplant 2007;21:558-566.

27 Sampaio MS, Molnar MZ, Kovesdy CP, Mehrotra R, Mucsi I, Sim JJ, Krishnan M, Nissenson AR, Kalantar-Zadeh K: Association of pretransplant serum phosphorus with posttransplant outcomes. Clin J Am Soc Nephrol 2011;6:2712-2721.

28 Seeherunvong W, Wolf M: Tertiary excess of fibroblast growth factor 23 and hypophosphatemia following kidney transplantation. Pediatr Transplant 2011;15:37-46.

29 Marcén R, Jimenez S, Fernández A, Galeano C, Villafruela JJ, Burgos FJ, Quereda C: The effects of mineral metabolism markers on renal transplant outcomes. Transplant Proc 2012;44:2567-2569.

30 Kasiske BL, Israni AK, Snyder JJ, Skeans MA, Patient Outcomes in Renal Transplantation I: The relationship between kidney function and long-term graft survival after kidney transplant. American journal of kidney diseases : the official journal of the National Kidney Foundation 2011;57:466-475.

31 Levi M, Ellis MA, Berl T: Control of renal hemodynamics and glomerular filtration rate in chronic hypercalcemia. Role of prostaglandins, renin-angiotensin system, and calcium. J Clin Invest 1983;71:1624-1632.

32 Gwinner W, Suppa S, Mengel M, Hoy L, Kreipe HH, Haller H, Schwarz A: Early calcification of renal allografts detected by protocol biopsies: causes and clinical implications. Am J Transplant 2005;5:1934-1941.

33 Schwarz A, Mengel M, Gwinner W, Radermacher J, Hiss M, Kreipe H, Haller H: Risk factors for chronic allograft nephropathy after renal transplantation: a protocol biopsy study. Kidney international 2005;67:341-348.

34 Transplantation EEGoR: European best practice guidelines for renal transplantation. Section IV: Long-term management of the transplant recipient. IV.8. Bone disease. Nephrol Dial Transplant 2002;17 Suppl 4:43-48. 
Table 1 - Baseline demographic, clinical and biochemical data regarding the presence of persistent hyperparathyroidism (pHPT).

\begin{tabular}{|c|c|c|c|c|}
\hline & $\begin{array}{c}\text { Total } \\
\mathrm{N}=911\end{array}$ & $\begin{array}{l}\text { Non pHPT } \\
\mathbf{N}=343\end{array}$ & $\begin{array}{c}\text { pHPT } \\
\mathrm{N}=568\end{array}$ & $\mathbf{p}$ \\
\hline Age, years & $51(39 ; 60)$ & $52(39 ; 61)$ & $51(39 ; 60)$ & 0.407 \\
\hline Male sex, n (\%) & $476(52.3)$ & $170(49.6)$ & $306(53.9)$ & 0.207 \\
\hline Race, n (\%) & & & & 0.159 \\
\hline White & $619(67.9)$ & $243(70.8)$ & $376(66.2)$ & \\
\hline Black & $278(30,5)$ & $93(27.1)$ & $185(32.6)$ & \\
\hline Asian & $14(1.5)$ & $7(1.2)$ & $7(1.2)$ & \\
\hline Dialysis vintage, months & $29(14 ; 56)$ & $24(11 ; 41)$ & $35(16 ; 64)$ & 0.001 \\
\hline $\begin{array}{l}\text { Renal replacement modality, } \\
\text { n }(\%)\end{array}$ & & & & 0.001 \\
\hline Preemptive KTx & $65(7.2)$ & $33(9.6)$ & $32(5.6)$ & \\
\hline HD & $791(86.9)$ & $279(81.6)$ & $511(90.1)$ & \\
\hline PD & $53(5.9)$ & $30(8.8)$ & $24(4.2)$ & \\
\hline Cause of ESRD, $n(\%)$ & & & & 0.286 \\
\hline Hypertension & $136(14.9)$ & $46(13.4)$ & $90(15.8)$ & \\
\hline Diabetes & $123(13.5)$ & $57(16.6)$ & $66(11.6)$ & \\
\hline Glomerular & $291(31.9)$ & $103(30)$ & $188(33.1)$ & \\
\hline Others & $152(16.6)$ & $58(17)$ & $94(16.6)$ & \\
\hline Not-known & $209(22.9)$ & $79(23)$ & $130(22.9)$ & \\
\hline Diabetes, n (\%) & $150(16.5)$ & $69(20.1)$ & $81(14.3)$ & 0.021 \\
\hline PTX pre-KTx, n (\%) & $36(4)$ & $25(7.3)$ & $11(1.2)$ & 0.001 \\
\hline Donor type, n (\%) & $497(54.6)$ & $176(51.3)$ & $321(56.5)$ & 0.127 \\
\hline Deceased & $414(45.4)$ & $167(48.7)$ & $247(43.5)$ & \\
\hline Living & & & & \\
\hline Donor age, years & $43(32 ; 51)$ & $42(32 ; 50)$ & $44(33 ; 52)$ & 0.037 \\
\hline Male Donor, n (\%) & $466(51.2)$ & $164(48)$ & $302(53.2)$ & 0.127 \\
\hline $\begin{array}{l}\text { Expanded criteria donor, } \mathbf{n} \\
(\%)\end{array}$ & $80(18.2)$ & $28(17.8)$ & $52(18.4)$ & 0.498 \\
\hline Sensitized, $\mathbf{n}(\%)$ & $201(24.4)$ & $74(22.4)$ & $127(25.8)$ & 0.151 \\
\hline Induction drug, n (\%) & & & & 0.573 \\
\hline None & $32(3.5 \%)$ & $10(2.9 \%)$ & $22(3.9 \%)$ & \\
\hline Basiliximab & $534(58.7 \%)$ & $200(58.5 \%)$ & $334(58.9 \%)$ & \\
\hline ATG & $321(35.3 \%)$ & $121(35.4 \%)$ & $200(35.3 \%)$ & \\
\hline Others & $22(2.4 \%)$ & $11(3.2 \%)$ & $11(1.9 \%)$ & \\
\hline Ionized Calcium, mg/dl & $4.9(4.6 ; 5.2)$ & $4.9(4.6 ; 5.1)$ & $5.0(4.7 ; 5.3)$ & 0.005 \\
\hline Alkaline phosphatase, U/L & $101(73 ; 148)$ & $92(67 ; 122)$ & $107(76 ; 159)$ & 0.001 \\
\hline PTH, pg/ml & $320(148 ; 640)$ & $232(104 ; 391)$ & $430(210 ; 860)$ & 0.001 \\
\hline Phosphorus, mg/dl & $5.1(4.2 ; 6.3)$ & $4.8(3.8 ; 6.0)$ & $5.2(4.3 ; 6.5)$ & 0.001 \\
\hline 25-OH-vitamin D, ng/ml & $23(17 ; 31)$ & $23(16 ; 30)$ & $24(17 ; 31)$ & 0.300 \\
\hline
\end{tabular}

Values are mean SD or median $(25,75)$, unless indicated otherwise. KTx, kidney transplantation; HD, hemodialysis; PD, peritoneal dialysis; ESRD, end-stage renal disease; PTX, parathyroidectomy; ATG, thymoglobulin; PTH, parathormone. 
Table 2 - Clinical and biochemical outcomes post kidney transplantation according to the presence of persistent hyperparathyroidism (pHPT).

\begin{tabular}{|c|c|c|c|c|}
\hline & $\begin{array}{c}\text { Total } \\
\mathbf{N}=911\end{array}$ & $\begin{array}{c}\text { Non pHPT } \\
\mathbf{N}=343\end{array}$ & $\begin{array}{c}\text { pHPT } \\
N=568\end{array}$ & $\mathbf{p}$ \\
\hline \multicolumn{5}{|l|}{ Outcomes at any time after $\mathrm{KTx}$} \\
\hline PTX post-KTx, n (\%) & $38(4.2)$ & $5(1.5)$ & $33(3.6)$ & 0.001 \\
\hline CMV infection, n (\%) & $169(18.6)$ & $55(16)$ & $114(20.1)$ & 0.076 \\
\hline Poliomavirus infection, $\mathrm{n}(\%)$ & $13(1.4)$ & $3(0.9)$ & $10(1.8)$ & 0.214 \\
\hline Acute rejection, $\mathbf{n}(\%)$ & $197(21.6)$ & $67(19.5)$ & $130(22.9)$ & 0.234 \\
\hline \multicolumn{5}{|l|}{ eGFR after KTx } \\
\hline eGFR at six months, $\mathrm{ml} / \mathrm{min}$ & $55(42-64)$ & $53(45-65)$ & $52(40-63)$ & 0.237 \\
\hline eGFR at one year, $\mathrm{ml} / \mathrm{min}$ & $56(44-67)$ & $58(48-69)$ & $54(43-67)$ & 0.002 \\
\hline \multicolumn{5}{|l|}{ Biochemical variables one year after } \\
\hline KTx & $5.2(5.0-5.5)$ & $5.0(4.8-5.2)$ & $5.4(5.1-5.6)$ & 0.001 \\
\hline iCa, mg/dl & & & & \\
\hline $\mathbf{A P}, \mathbf{U} / \mathbf{L}$ & $84(64-113)$ & $73(58-94)$ & $91(70-124)$ & 0.001 \\
\hline PTH, pg/ml & $92(59-145)$ & $60(46-79)$ & $132(101-193)$ & 0.001 \\
\hline Phosphorus, mg/dl & $3.2(2.8-3.7)$ & $3.4(2.9-3.8)$ & $3.1(2.7-3.5)$ & 0.001 \\
\hline 25-OH-vitamin D, ng/ml & $23(17-29)$ & $24(19-31)$ & $22(16-28)$ & 0.001 \\
\hline
\end{tabular}

Values are mean \pm SD or median (25-75), unless indicated otherwise. KTx, kidney transplantation; PTX, Parathyroidectomy; CMV, cytomegalovirus; eGFR, estimated glomerular filtration rate; iCa, ionized calcium; AP, alkaline phosphatase; PTH, parathormone. 
Table 3 - Multiple Logistic regression of the association between persistent hyperparathyroidism (pHPT) and covariates obtained from univariate analysis.

\begin{tabular}{lcccccccc}
\hline & Univariate & \multicolumn{4}{c}{ Multivariate } \\
\hline Covariates & $\mathbf{p}$ & $\begin{array}{c}\text { Odds } \\
\text { Ratio }\end{array}$ & $\mathbf{9 5 \%} \mathbf{C I}$ & $\mathbf{p}$ & $\begin{array}{c}\text { Odds } \\
\text { Ratio }\end{array}$ & $\mathbf{9 5 \%}$ CI \\
\hline Dialysis vintage & 0.0001 & 1.008 & 1.004 & 1.012 & $\mathbf{0 . 0 0 1}$ & 1.009 & 1.004 & 1.014 \\
Ionized Ca pre-KTx & 0.0001 & 1.674 & 1.258 & 2.228 & $\mathbf{0 . 0 0 0 1}$ & 2.233 & 1.470 & 3.393 \\
P pre-KTx & 0.024 & 1.397 & 1.045 & 1.868 & $\mathbf{0 . 0 1 7}$ & 1.156 & 1.027 & 1.301 \\
Diabetes pre-KTx & 0.021 & 1.517 & 1.065 & 2.161 & 0.899 & 1.031 & 0.064 & 1.653 \\
PTX pre-KTx & 0.0001 & 0.251 & 0.122 & 0.516 & $\mathbf{0 . 0 2 5}$ & 2.935 & 1.145 & 7.525 \\
AP pre-KTx & 0.0001 & 1.005 & 1.003 & 1.007 & 0.400 & 1.001 & 0.999 & 1.004 \\
PTH pre-KTx & 0.0001 & 1.002 & 1.001 & 1.002 & $\mathbf{0 . 0 0 0 1}$ & 1.002 & 0.478 & 1.002 \\
Female donor & 0.117 & 1.240 & 0.948 & 1.624 & $\mathbf{0 . 0 5 2}$ & 0.692 & 1.030 & 2.138 \\
Donor age & 0.211 & 1.011 & 1.000 & 1.023 & 0.301 & 1.009 & 0.992 & 1.026 \\
eGFR 1 year after & 0.004 & 0.989 & 0.982 & 0.997 & $\mathbf{0 . 0 2 0}$ & 0.986 & 0.975 & 0.998 \\
KTx & & & & & & & & \\
\hline
\end{tabular}

CI, confidence interval; Ca, calcium; KTX, kidney transplantation; $\mathrm{P}$, phosphorus, PTX, parathyroidectomy; AP, alkaline phosphatase; PTH, parathormone; eGFR, estimated glomerular filtration rate.

-2 Log likelihood 704.422. 
Table 4 - Suggested PTH levels cut-offs and their corresponding area under the ROC curve

\section{AUC Sensitivity Specificity p $\quad 95 \%$ CI}

\begin{tabular}{lllllll}
$\begin{array}{l}\text { Pre transplant } \\
\text { Best cut-off: } \mathbf{3 9 5} \mathbf{~ p g / m l}\end{array}$ & 0.717 & 62.3 & 81.6 & 0.001 & 0.616 & 0.818 \\
$\quad \begin{array}{l}\text { Suggested value: } \mathbf{4 5 0} \mathbf{~ p g} / \mathbf{m l} \\
\text { One month after transplant }\end{array}$ & 0.676 & 50.7 & 84.2 & 0.001 & 0.581 & 0.770 \\
$\quad$ Best cut-off: $\mathbf{1 6 3} \mathbf{~ p g / m l}$ & 0.704 & 66.7 & 68.4 & 0.001 & 0.601 & 0.808 \\
$\quad \begin{array}{l}\text { Suggested value: } \mathbf{2 2 0} \mathbf{~ p g} / \mathbf{m l} \\
\text { Six months after transplant }\end{array}$ & 0.667 & 46.4 & 81.6 & 0.0001 & 0.572 & 0.762 \\
$\quad$ Best cut-off: $\mathbf{8 7 . 5} \mathbf{~ p g / m l ~}$ & 0.822 & 88.4 & 68.4 & 0.001 & 0.740 & 0.904 \\
$\quad$ Suggested value: $\mathbf{1 5 0} \mathbf{~ p g / m l}$ & 0.688 & 43.5 & 92.1 & 0.0001 & 0.596 & 0.781 \\
\hline
\end{tabular}

PTH, parathyroid hormone; ROC, receiver operator characteristic; AUC, area under curve; CI, confidence interval. 


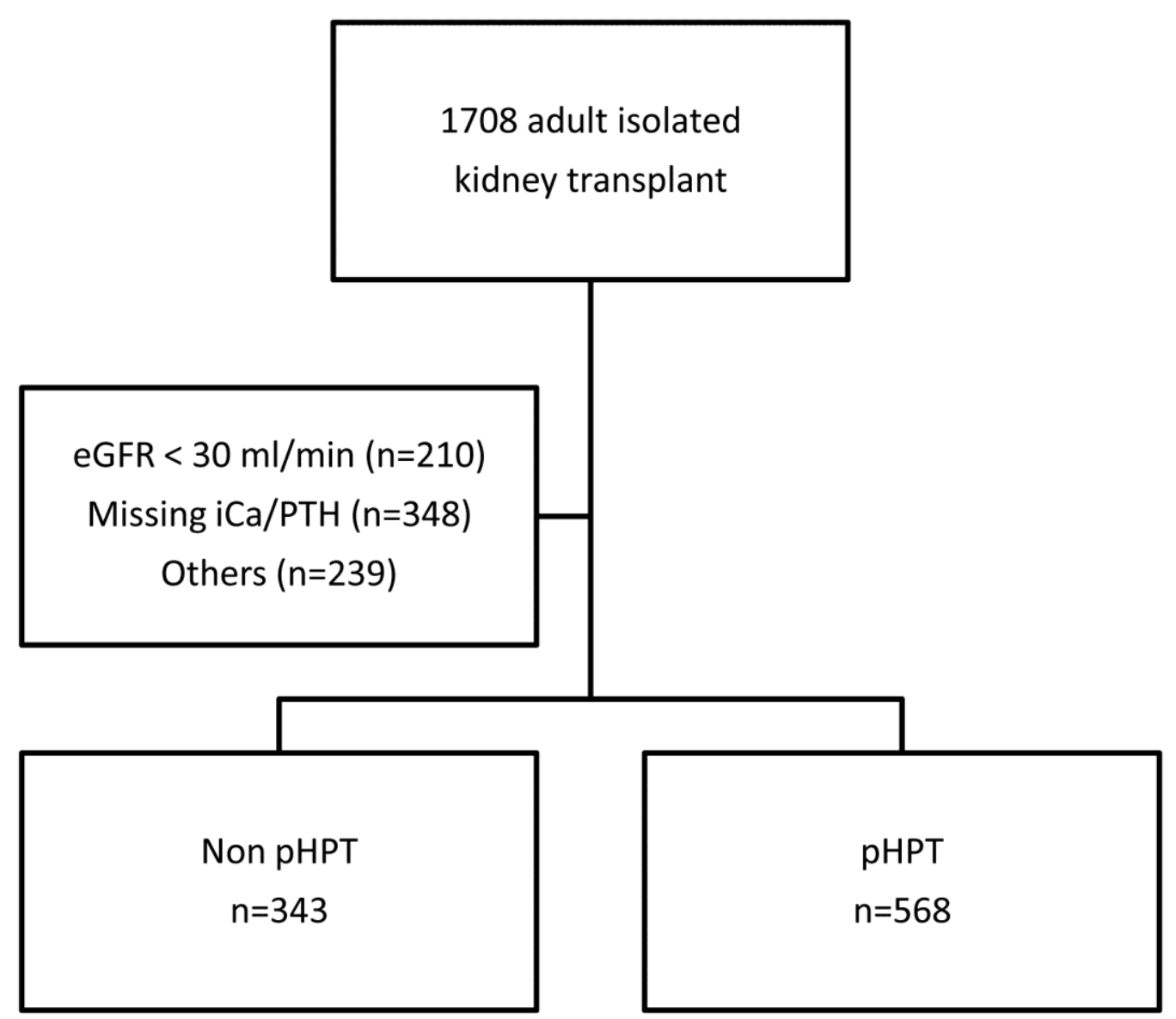

Figure 1. Flow chart of patient enrolment and follow-up after kidney transplant.

eGFR, estimated glomerular filtration rate; $\mathrm{iCa}$, ionized calcium; $\mathrm{PTH}$, parathormone; pHPT, persistent hyperparathyroidism. 
(A)

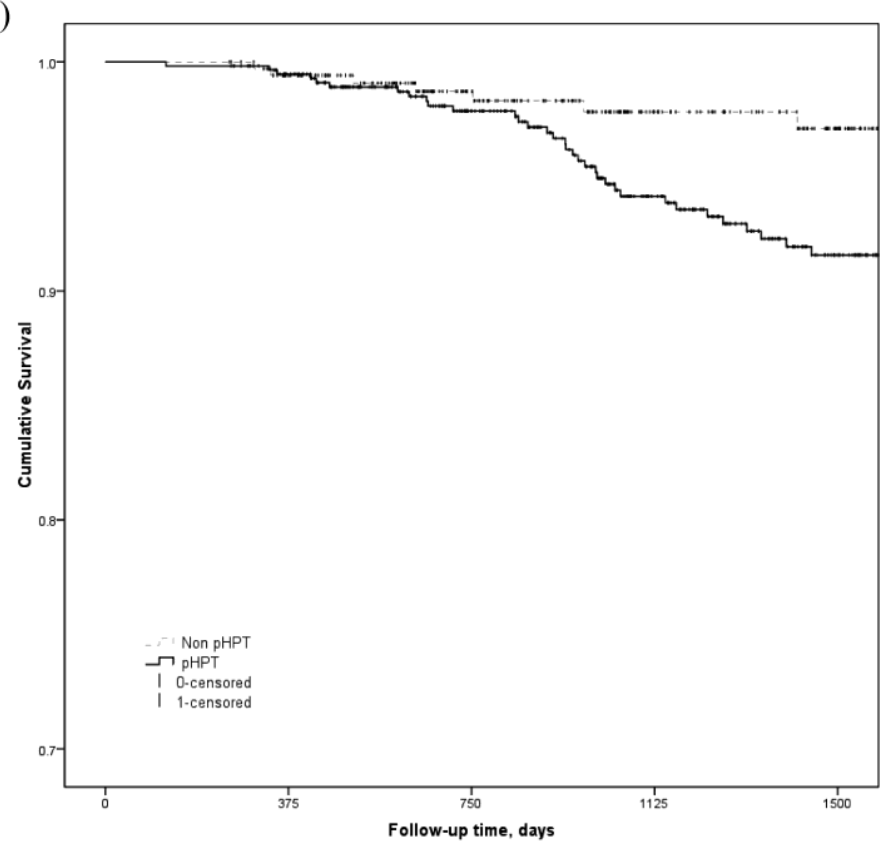

(B)

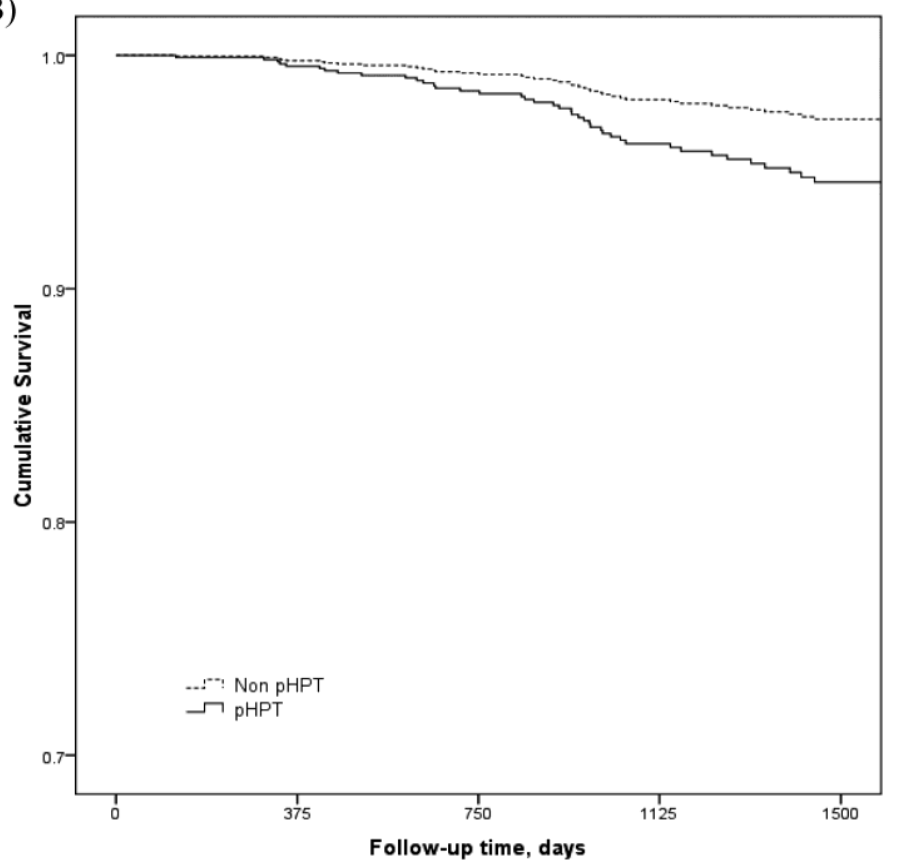

Figure 2. (A) Unadjusted death-censored graft survival curves according to persistent hyperparathyroidism (pHPT). A lower median graft survival time was observed among patients with pHPT (3366 days) [inferior continuous line] than non-pHPT group (3515 days) [superior dashed line] (log-rank $\mathrm{p}=0.009$ ). (B) Adjusted death-censored survival curve for age at transplantation, donor age, donor type, acute rejection, PTX and eGFR at 1 year after transplantation $(\mathrm{P}<0.001)$. 


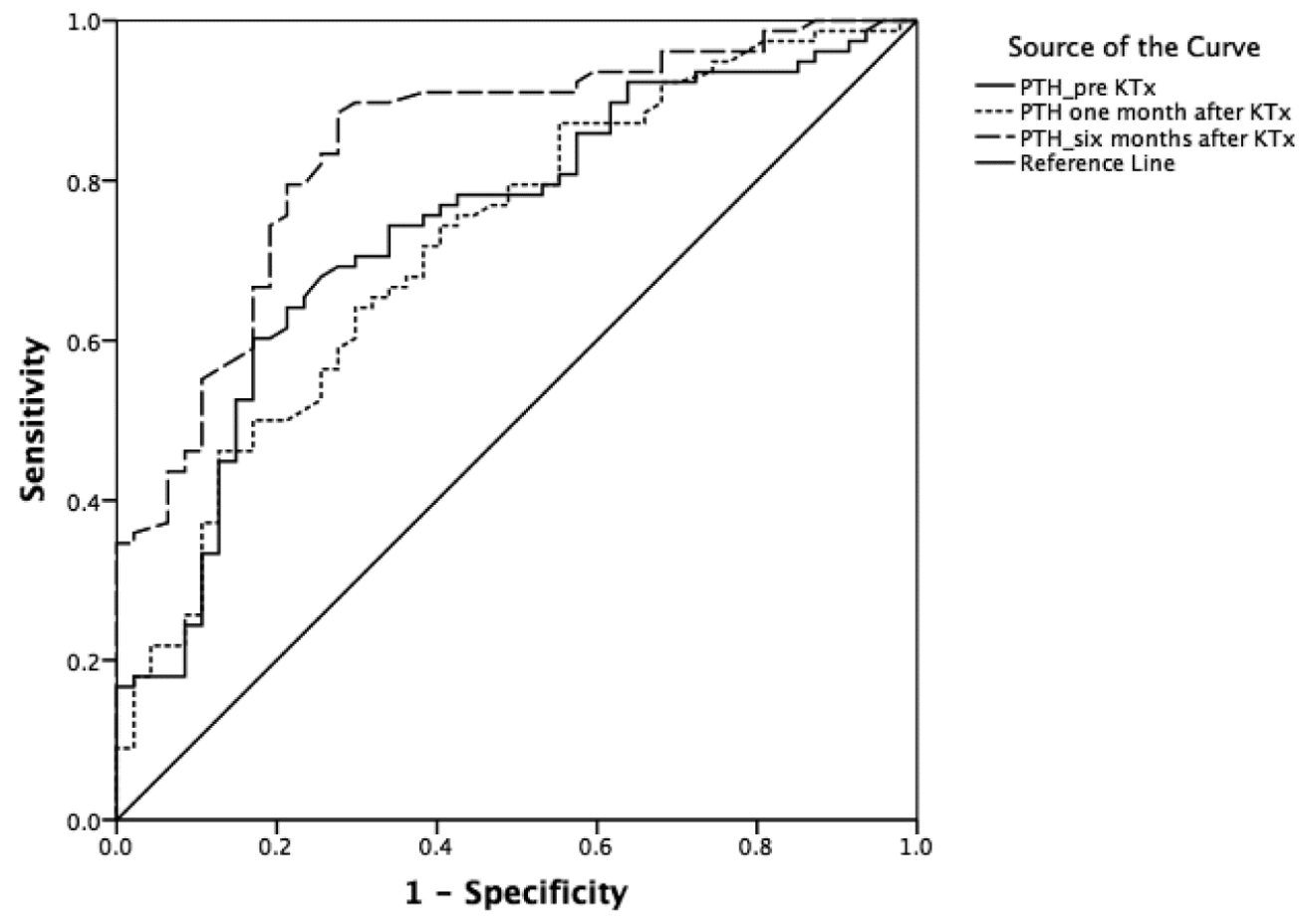

Figure 3. ROC curves for the persistent hyperparathyroidism (pHPT) prediction based on parathyroid hormone (iPTH) collected at various time-points. The 6-month period produced the ROC curve with the higher AUC. 